\title{
O CONSUMO ALIMENTAR EM REGIÕES METROPOLITANAS BRASILEIRAS ANÁLISE DA PESQUISA DE ORÇAMENTOS FAMILIARES/IBGE 1995/96
}

\section{BEATRIZ FREIRE BERTASSO \\ Economista}

Orientador: Prof. Rodolfo Hoffmann

\begin{abstract}
Dissertação apresentada à Escola Superior de Agricultura "Luiz de Queiroz", Universidade de São Paulo, para a obtenção do título de Mestre em Ciências. Área de concentração: Economia Aplicada.
\end{abstract}

PIR A C I C A B A

Estado de São Paulo - Brasil

Dezembro - 2000 


\section{Errata}

\begin{tabular}{ccccc}
$\mathrm{p}$ & Item & linha & \multicolumn{1}{c}{ onde se lê } & leia-se \\
23 & 2.1 .1 .1 & décima quinta & Esforços têm se concentrando ... & Esforços têm se concentrado $\ldots$ \\
25 & 2.1 .1 .2 & décima segunda & $y=\sum_{i=1}^{n} \phi_{i}(y)=\sum_{i=1}^{n} p_{i} q_{i}$ & $y=\sum_{i=1}^{n} \phi_{i}(y)+\sum_{i=1}^{n} a_{i}=\sum_{i=1}^{n} p_{i} q_{i}$
\end{tabular}

$26 \quad 2.1 .2 \quad$ vigésima terceira ...designadas nas eq. (6) e (8).

4133 sétima

... Ambos utilizam todos os dados individuais ...

$46 \quad 3.2 .1 .1 \quad$ décima terceira

..., como seria esperado em uma regressão simples ...

$46 \quad 3.2 .1 .1 \quad$ décima sexta

...e o modelo será tendencioso $\mathrm{e}$ inconsistente.

$50 \quad 3.2 .1 .1 .2$ segunda

... valor esperado da variável consumo, ...

53 3.2.2. décima terceira

... e o consumo alimentar médio per capita serão estimados ...

53 3.2.2.1 vigésima quarta $\ldots$, utilizando o número de famílias por classe de renda...

...designadas nas eq. (5) e (8).

... Ambos utilizam os dados individuais ...

(eliminar o período)

... e o estimador de mínimos quadrados de $\beta$ será tendencioso e inconsistente.

... valor do consumo, ...

... e o consumo médio per capita será estimada ...

..., utilizando o número de pessoas por classe de renda...

$\begin{array}{lll}65 & 4.2 \quad \text { quarta }\end{array}$

... para as 'famílias tradicionais'.

... para as 'novas familias'.

$\begin{array}{lll}66 & 4.3 \quad \text { primeira }\end{array}$

4.3. Os modelos e seu resultados

4.3. Os modelos e seus resultados

$\begin{array}{lll}72 & 4.3 .1 \quad \text { terceira }\end{array}$

... para os alimentos cuja a proporção de aquisições ...

$\begin{array}{lll}83 & 4.3 .1 .5 & \text { décima } \\ 88 & 4.32 & \text { Oitava }\end{array}$
..., observando-se a tabela $7, \ldots$ ... para os alimentos cuja proporção de aquisições ... ..., os 'enlatados' e a 'alimentação fora do domicílio', ... ..., observando-se a tabela $6, \ldots$ ..., os 'enlatados' e as 'refeições fora dos domicilios', ...

$88 \quad 4.3 .2 \quad$ Nona
... para os 'refrigerantes' e os. 'outros alimentos fora do domicílio'. ... para os 'cereais', 'refrigerantes', a 'alimentação fora do domicílio' e os 'outros alimentos fora do domicílio'.

$90 \quad 4.3 .2 \quad$ Quarta ... nas seções 3.2.3 e 4.3.1.2 ... ...nas seções 3.2.1.1.2 e 4.3.1.2 ...

108 Inserir nas Referências Bibliográficas: HOFFMANN, R. Elasticidades de Engel para dispêndios familiares na cidade do Rio de Janeiro - outro método de estimação. Pesquisa e Planejamento Econômico. Abril/1983, p.267 a 274

109 Inserir nas Referências Bibliográficas: SILBERBERG, E.The Structure of Economics: A mathematical Analysis. Second edition. USA: McGraw Hill, Inc., 1990. 686 p. 
Dados Internacionais de Catalogação na Publicação (CIP) DIVISÃO DE BIBLIOTECA E DOCUMENTAÇÃO - Campus "Luiz de QueirOz"/USP

Bertasso, Beatriz Freire

O consumo alimentar em regiões metropolitanas brasileiras análise da pesquisa de orçamentos familiares/IBGE. - - Piracicaba, 2000.

109 p. : il

Dissertação (mestrado) - - Escola Superior de Agricultura Luiz de Queiroz, 2000. . Bibliografia.

1. Área metropolitana 2. Consumo alimentar 3. Habito alimentar 4. Orçamento doméstico l. Título

CDD 339.4863

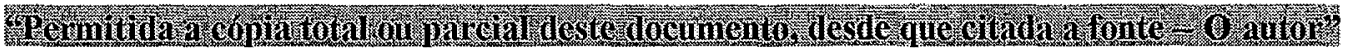


Para Dado, Cida e Nelson, com carinho e gratidão. 


\section{Agradecimentos}

Agradeço ao meu orientador, professor Rodolfo Hoffmann, pelas infindáveis e pacientes horas de trabalho. Mais do que técnicas de pesquisa, aprendi um pouco mais de o que significa 'ser um profissional'.

Às professoras Ana Lúcia Kassouf, Mirian Bacchi e Ângela Corrêa pela fundamental contribuição à consecução desse trabalho.

Agradeço a Carol Souza, a orientadora cuidadosa na graduação e a Mônica Baer, a 'chefe' de conhecimentos inesgotáveis, que são amigas, incentivadoras e exemplos permanentes; ao professor Paulo Cidade, um educador que ensina a paixão pelo conhecer, que não teme ser humano nos relacionamentos, alguém que conquistou o meu respeito e carinho.

Aos professores do Departamento de Economia, Administração e Sociologia, pela formação acadêmica de notável qualidade e incentivo constante. Aos colegas de curso, pelo companheirismo. Aos funcionários, pelos preciosos e precisos serviços que prestaram, e pelo carinho de novos amigos.

À Capes, provedora de recursos para esse projeto. 


\section{SUMÁRIO}

SUMÁRIO

Página

Lista de figuras v

Lista de tabelas. vii

Lista de quadros viii

RESUMO $\mathrm{x}$

SUMMARY xi

1. INTRODUÇÃO xiii

1.1. O problema e sua importância 15

1.2. $\mathrm{O}$ enfoque proposto 15

1.3. Organização do estudo 17

2. REVISÃO DE LITERATURA 18

2.1. A Teoria do Comportamento do Consumidor e as Avaliações Empíricas 19

2.1.1. A Teoria do Comportamento do Consumidor - uma breve leitura 19

2.1.1.1. A função de demanda 22

2.1.1.2. A função consumo ou curva de Engel 22

2.1.1.3. A introdução de variáveis 'qualitativas' nos estudos de demanda

2.1.2. Avaliações empíricas e suas limitações 26

2.1.2.1. A análise da demanda com dados de corte seccional 27

2.2. Variáveis que condicionam o padrão alimentar 35

\section{MATERIAL E MÉTODOS} 41

3.1. A pesquisa de Orçamentos Familiares $95 / 96$ 41

3.2. Os métodos de estimação propostos 43

3.2.1. O modelo de seleção amostral ou procedimento de Heckman 43

3.2.1.1. O problema formal 44

3.2.1.1.1. A identificação do modelo 47

3.2.1.1.2. Os efeitos Marginais 48

3.2.1.2. A estimação 51

3.2.1.3. As formas funcionais

3.2.2. O ajustamento 'nas médias' 53

3.2.2.1. A forma funcional e sua estimação 
3.3. Recursos Computacionais ................................................................................ 54

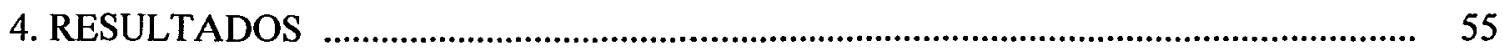

4.1. A amostra e as variáveis socioeconômicas ………………………..................... 55

4.2. Os produtos alimentares ...................................................................................... 61

4.3. Os modelos e seu resultados .............................................................................. 66

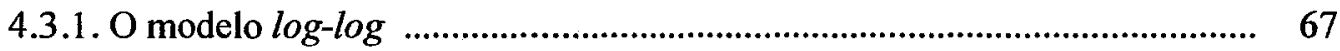

4.3.1.1. O efeito da variável 'nível de instrução' sobre a probabilidade de aquisição alimentar ...................................................................................... 73

4.3.1.2. O efeito da variável 'renda' .............................................................. 73

4.3.1.3. O efeito do 'tamanho' das famílias ................................................ 76

4.3.1.4. O efeito da composição etária da familia .......................................... 79

4.3.1.5. O efeito da inserção da mulher no mercado de trabalho ................... 83

4.3.1.6. O efeito da organização familiar .................................................... $\quad 84$

4.3.2. A elasticidade-despesa global do dispêndio alimentar ................................ 88

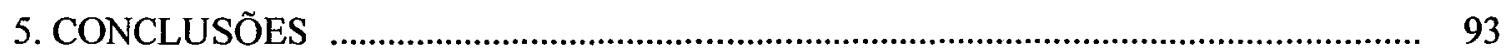

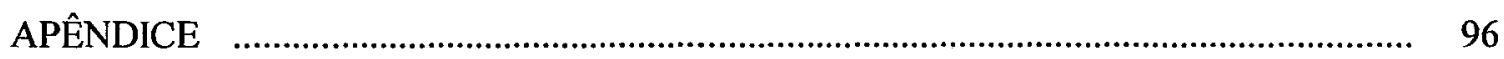

REFERÊNCIAS BIBLIOGRÁFICAS _.................................................................... 106 


\section{LISTA DE FIGURAS}

Página

1. Distribuição Normal Censurada ...................................................................... 34

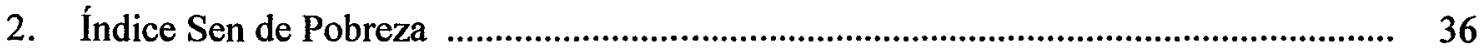

3. Desigualdade da distribuição de renda entre os brasileiros economicamente ativos com rendimento: Índice de Gini ........................................................................ 36

4. População brasileira residente, em milhares de pessoas, segundo grupos de idade. IBGE (1997)

5. Distribuição da variável normal reduzida $z[\phi(z)]$, a respectiva função de distribuição $[\Phi(z)]$ e o comportamento da variável lambda $(\lambda)$

6. Distribuição de freqüência da variável despesa global per capita ( $\mathrm{R}$ set/96)

7. Distribuição de frequiência da variável logaritmo da despesa global per capita $(\mathrm{R} \$$ set/96)

8. O dispêndio per capita e a freqüência de aquisição, dos alimentos em geral, segundo as classes de 'renda' (delimitadas pelos decis da 'renda' per capita).

9. O dispêndio per capita e a freqüência de aquisição, dos alimentos preparados, segundo as classes de 'renda' (delimitadas pelos decis da 'renda' per capita) ...

10. Frequiência de aquisição (observada) e dispêndio médio per capita com a alimentação fora do domicílio, segundo as pessoas de determinados tamanhos de família 


\section{LISTA DE TABELAS}

Página

1. Distribuição da organização familiar e não familiar nos domicílios brasileiros 1960 84 , em \%

2. Composição etária familiar média nas 11 áreas investigadas pela POF/IBGE

3. O tamanho e a composição etária familiar média segundo classes de 'despesa global' per capita (em \%)

4. POF $95 / 96$ - Número de famílias e pessoas por região

5. Dispêndio médio e mediano per capita com agregados alimentares ( $\mathrm{R} \$$ set/96)

6. Recebimento e dispêndios per capita médios, segundo a inserção feminina no mercado de trabalho

7. Recebimento e dispêndios per capita médios, segundo as regiões geográficas

8. Recebimento e dispêndios per capita médios, segundo os tipos familiares

9. Participação das pessoas nos 'tipos familiares', segundo as classes de despesa global per capita $(\mathrm{em} \%)$

10. Os efeitos marginais da regressão de próbites

11. A Função Consumo log-log

12. Número de famílias com aquisições: número observado e número previsto, considerando a previsão para cada família

13. Elasticidade-'renda' do dispêndio alimentar - efeitos direto e total/ Função $\log$ - $\log$, e sinais dos efeitos marginais indiretos

14. Probabilidade média de aquisição dos agregados alimentares e elasticidade-'renda' ampliada do dispêndio alimentar

15. 'Elasticidade-escala' do dispêndio alimentar - efeitos direto e total, e sinais dos efeitos marginais indiretos

16. Elasticidade-escala ampliada do consumo alimentar

17. Efeito marginal total da composição etária das famílias sobre o consumo alimentar e os sinais dos efeitos indiretos

18. O efeito marginal ampliado das faixas etárias e seus componentes

19. Efeito marginal total sobre o consumo alimentar per capita da existência de mulheres 'que trabalham' nas famílias, e os sinais dos efeitos indiretos

20. O efeito marginal ampliado das famílias com mulheres 'que trabalham' e seus componentes

21. Número de famílias segundo o 'tipo' e número de componentes

22. Efeitos Marginais totais dos 'tipos' familiares e sinais dos efeitos marginais indiretos 
23. O efeito marginal ampliado dos diferentes 'tipos' familiares e seus componentes

88

24. Regressão Poligonal $\log$-log

89

25. Elasticidade-despesa global do dispêndio alimentar - poligonal log-log

90

26. A elasticidade-renda do dispêndio alimentar 'ampliada' - modelo log-log

90

27. Elasticidade-despesa global do dispêndio alimentar, segundo os modelos log-log e poligonal $\log -\log$ 


\section{LISTA DE QUADROS}

1. Os agregados alimentares e seus principais componentes 


\section{O CONSUMO ALIMENTAR EM REGIÕES METROPOLITANAS BRASILEIRAS \\ ANÁLISE DA PESQUiSA DE ORÇAMENTOS FAMILIARES/IBGE - 1995/96}

Autor: BEATRIZ FREIRE BERTASSO

Orientador: PROF. RODOLFO HOFFMANN

\section{Resumo}

O objetivo deste estudo é analisar os efeitos de algumas variáveis socioeconômicas sobre o padrão de consumo alimentar dos brasileiros. Para tanto foram determinados grupos de alimentos associados a padrões 'modernos' e 'tradicionais' de alimentação e estimadas funções de consumo para cada um deles, com base nos dados da Pesquisa de Orçamentos Familiares de 1995/1996 (IBGE), por dois métodos: pelo procedimento de Heckman, e pelo ajuste às médias dos estratos.

A opção pela adoção de duas metodologias se deu pelos seguintes motivos: $i$. a avaliação do comportamento individual dos consumidores requer um tratamento especial das informações de consumo, uma vez que os dados fornecidos pela Pesquisa de Orçamentos Familiares são de despesas com alimentos, e não de ingestão - o que levou à escolha da estimação pelo procedimento de Heckman; ii. sendo a estimação às médias dos estratos um método mais robusto e mais usual na estimação de elasticidades-renda, optou-se por confrontar os resultados obtidos, para este coeficiente, com os dois métodos apontados.

Classificou-se como alimentos 'tradicionais' aqueles a serem consumidos no domicílio, que exigem uma certa 'elaboração' antes do consumo, enquanto os 'modernos', são aqueles de fácil preparo. A alimentação fora do domicílio também é tida como parte do padrão 'moderno' de alimentação. 
De acordo com os resultados obtidos, observou-se que existe uma tendência entre os brasileiros metropolitanos de 'mesclar' os padrões 'tradicional' e 'moderno' de alimentação sendo que as pessoas de famílias com mulheres inseridas no mercado de trabalho, que são referência ou cônjuge no lar, privilegiam a alimentação 'moderna'; e as de famílias onde preponderam pessoas de 51 anos ou mais, privilegiam um padrão 'tradicional' de alimentação.

O hábito de se alimentar fora do domicílio, por sua vez, é mais comum entre grupos sociais específicos: as pessoas de famílias com mulheres inseridas no mercado de trabalho (nas condições acima citadas), as de famílias onde o grupo etário de jovens de 21 a 30 anos se destaca (proporcionalmente), e de organizações familiares diferentes das 'famílias tradicionais' (estas compostas por casais com ou sem filhos, parentes e empregados, e sem não-parentes), consomem mais alimentos fora do domicílio. Essa constatação leva a alguma preocupação porque, em geral, esses grupos privilegiam o consumo de outros alimentos, que não as refeições (lanche, sucos, cafezinho, etc.) fora dos domicílios.

Constatou-se ainda que a renda continua sendo um fator de grande importância na determinação do consumo alimentar entre os brasileiros, principalmente para o consumo de alimentos 'modernos'. 


\section{FOOD CONSUMPTION IN BRAZILIAN METROPOLITAN AREAS \\ ANALYSIS OF HOUSEHOLD EXPENDITURE SURVEY /IBGE - 1995/96}

Author: BEATRIZ FREIRE BERTASSO

Adviser: PROF. RODOLFO HOFFMANN

\section{Summary}

The goal of this study is to analyze the effects of some social economic variables on the Brazilian food consumption pattern. For that, there were determined food groups associated to modern and traditional patterns of nutrition and estimated Engel curves for each of them, based on data from the 1995/1996 Household Expenditure Survey. Two methods were applied: Heckman's approach and estimation based on class average.

The choice for applying these two methodologies owing to: $i$. the evaluation of individual consumer behavior requires a special treatment of consumption data, once the information provided by the Household Expenditure Survey refers to expenditures with food, and not intake - what lead us to choose Heckman's approach; and ii. the fact that estimation based on class average is a more robust method and usually applied on estimation of income elasticities. Thus, we opted to confront the results obtained, for this factor, with both methods mentioned.

Traditional food was classified as the one consumed at home, requiring some kind of elaborated preparation before ingestion. On the other hand, modern food was classified as the one of easy preparation. Eating-out was also considered as part of a modern pattern of consumption. According to the results obtained, we noticed that it is a trend among metropolitan Brazilians to combine both patterns of consumption, traditional and modern - whereas families in which women (wife/mother) are inserted in the job market and participate on the home 
income, prefer modern patterns of consumption; in contrast, families with people with predominant age of 51 years old or more, favor the traditional pattern.

The custom to eat out, on its turn, is more common among specific social groups: families in which the woman is inserted in the job market (on the conditions explained above), in which the age group of 21 to 30 years old stands out (proportionally), and in which there are differences of the traditional family concept (couples with or without children, relatives and employees, and without non-relatives). This verification leads to worries, as, in general, these groups prefer the consumption of foodstuff other than meals (like snacks, juices, coffee, etc.) away from home.

It was also attested that income continues to be an important factor in order to determine Brazilian food consumption, mainly for the consumption of modern food. 


\section{INTRODUÇÃO}

\subsection{O problema e sua importância}

O alimento é um dos principais fatores determinantes da saúde do homem. Sendo assim, não é de se estranhar que, nos mais variados campos da ciência, busque-se estudar os alimentos e suas propriedades, assim como os hábitos alimentares das pessoas, procurando, de alguma forma, responder a perguntas como 'quais os tipos de alimentos mais saudáveis?', 'quais os hábitos alimentares da população?' e ‘como estabelecer um padrão alimentar mais saudável?’.

A proposta deste estudo, de caráter socioeconômico, é de contribuir para a solução da segunda daquelas questões, para o caso do brasileiro metropolitano - quais os hábitos alimentares dessa população? Para tanto propõe-se uma análise empírica do consumo alimentar dessas pessoas, com base na Pesquisa de Orçamentos Familiares realizada pelo IBGE, entre os anos de 1995 e 1996.

Tradicionalmente, na área econômica, a renda, dados os preços, é a principal variável condicionante do consumo das pessoas. Existem evidências, por outro lado, de que as decisões de consumo alimentar também são influenciadas por outras variáveis, de caráter sociocultural.

No Brasil os índices de pobreza vêm caindo lentamente ao longo das déaadas e, em paralelo, as taxas de subnutrição também têm assumido uma trajetória descendente. Por outro lado, enquanto a questão da 'fome' vai sendo equacionada, os problemas derivados da má e supernutrição vêm ganhando espaço, a passos largos, no cenário brasileiro. Provavelmente como reflexo dessa evolução, pode-se observar que o debate sobre a questão alimentar vêm mudando de foco: se os temas da fome e desnutrição eram recorrentes nos trabalhos acadêmicos brasileiros da área alimentar entre as décadas de setenta e oitenta, nos anos mais recentes, ainda 
que aquelas questões não tenham sido de todo ultrapassadas, a discussão sobre a crescente incidência da obesidade tem se tornado cada vez mais presente.

A convivência de fenômenos como a fome e a obesidade suscita a questão de se a acessibilidade alimentar ainda é o principal determinante do padrão de consumo dessas populações. Bleil (1998), num estudo sobre os hábitos alimentares dos brasileiros, diz que "Percebe-se que a fome hoje é resultante não só da pouca disponibilidade alimentar para grupos de baixa renda, mas também da redução da qualidade dos alimentos, excessivamente industrializados. Isto evidencia-se na anemia e na obesidade como grandes problemas de saúde pública, atingindo todos os estratos sociais".

Que fatores seriam esses que poderiam estar mudando os hábitos alimentares da população?

Aquela autora associa a perda de tempo com locomoção nos grandes centros, por exemplo, à necessidade de adoção de um padrão alimentar onde a facilidade de aquisição e tempo de preparo seriam fatores determinantes. Numa visão mais psicológica, sendo o alimento uma mercadoria como outra qualquer nas sociedades modernas, admite-se que as preferências dos consumidores poderiam estar sendo influenciadas pela mídia.

Assim, fatores como tempo de aquisição e preparo, 'tradição' ou 'modernidade', e mesmo o 'status' que alguns tipos de alimentos promovem aos seus consumidores, seriam algumas daquelas características que, além da restrição orçamentária, determinariam os hábitos alimentares da população.

A proposta deste estudo é de avaliar o padrão alimentar do brasileiro urbano segundo algumas características socioeconômicas - para o período assinalado. Pressupõe-se que grupos sociais relativamente homogêneos devam apresentar características próximas o suficiente para que suas preferências e necessidades sejam semelhantes - o que se refletiria em padrões alimentares também relativamente homogêneos.

Essa avaliação seria de grande mérito para qualquer tentativa de ingerência sobre os hábitos da população. Para qualquer proposta de alteração do padrão alimentar das pessoas seria interessante saber quais são as parcelas da população que deverão ser focadas para então determinar a estratégia de atuação. Se essa proposta for assumida pelo setor público, a necessidade de um quadro mais detalhado sobre o comportamento do consumidor se amplia. 
Tendo como exemplo a dinâmica do setor alimentício ${ }^{1}$ norte-americano, tem-se que, no ano de 1997, enquanto o volume de recursos daquele setor direcionado à propaganda chegou a 11 bilhões de dólares ${ }^{2}$, o Ministério da Agricultura do mesmo país executou um orçamento de cerca de US\$ 333 milhões em programas relacionados à educação nutricional (Gallo, 1999). Ainda que a mídia também possa disseminar informações sobre um tipo de 'vida saudável', sabe-se que boa parte dos recursos acima assinalados se destina à promoção de alimentos industrializados, redes de fast food, e outros, que acabam por promover um padrão de consumo alimentar baseado na 'facilidade' e 'modernidade', mas que em geral deixa muito a desejar em termos nutricionais - o que acaba por gerar problemas na área de saúde pública.

Desta forma, as autoridades brasileiras, que contam com recursos restritos, devem estar munidas para focar suas ações, principalmente quando se considera que tanto a indústria como as redes de serviços alimentares internacionais têm se enraizado cada vez mais no mercado brasileiro, elevando o nível de recursos para disseminar o tal padrão 'moderno' de alimentação.

Sem dúvida, medidas preventivas como a promoção de um padrão alimentar mais saudável e de incentivo ao hábito de fazer exercícios físicos entre a população levariam a um uso mais eficiente dos recursos públicos do que tratar de doenças já instaladas.

\subsection{O enfoque proposto}

O trabalho terá como base de dados a 'Pesquisa de Orçamentos Familiares', ou simplesmente 'POF', aplicada pelo Instituto Brasileiro de Geografia e Estatística (IBGE) em 9 regiões metropolitanas - Belém, Fortaleza, Recife, Salvador, Belo Horizonte, Rio de Janeiro, São Paulo, Curitiba e Porto Alegre - além do municípios de Goiânia e Distrito Federal, no período de outubro de 1995 a setembro de 1996.

Essa pesquisa reúne dados gerais e em especial de renda e consumo dos domicílios e seus moradores. Aqui, a unidade de referência para as características socioeconômicas avaliadas é a família.

\footnotetext{
${ }^{1}$ incluindo o mercado de bebidas alcoólicas.

${ }^{2}$ Esses gastos referem-se a anúncios em revistas, jornais locais e nacionais, outdoors e nos diversos tipos de rádio e televisão (rede, cabo, etc).
} 
Serão propostas duas metodologias para tratar os dados amostrais, de forma que os resultados obtidos reflitam, da melhor maneira possível, o comportamento dos consumidores e então será quantificada a influência das características socioeconômicas sobre o consumo de determinados tipos de alimentos - objetivo estrito do trabalho.

Segundo a classificação desses alimentos entre 'tradicionais' e 'modernos', pretende-se discriminar qual o atual padrão de alimentação privilegiado pelos diferentes grupos sociais.

Cabe ressaltar que a disponibilização, por parte do IBGE, dos dados individuais $\left(\right.$ microdados $^{3}$ ) da POF 95/96 foi um grande passo para a disseminação de pesquisas do tipo aqui apresentada.

\subsection{Organização do estudo}

Este trabalho está organizado em cinco capítulos: no primeiro introduziu-se o tema, ressaltando a sua importância e descrevendo o enfoque utilizado. No segundo, é feita uma breve revisão da teoria tradicional do comportamento do consumidor e das dificuldades com que os economistas vêm se deparando ao propor avaliações empíricas na área de consumo alimentar. No mesmo capítulo são apresentadas, ainda, as variáveis tidas como explicativas do consumo alimentar.

No terceiro capítulo a POF 95/96 é apresentada em maiores detalhes e são descritos os métodos adotados. No capítulo seguinte são apresentados e discutidos os resultados da pesquisa, sendo as conclusões mais gerais deixadas para o quinto e último capítulo.

\footnotetext{
${ }^{3}$ Dados no formato dos questionários aplicados.
} 


\section{REVISÃO DE LITERATURA}

A proposta de estudo do padrão de consumo alimentar, através da análise dos resultados de uma pesquisa domiciliar, remete a várias discussões de caráter teórico e econométrico.

Este capítulo trata destas questões e se propõe a apresentar, ainda, algumas das variáveis que condicionariam os hábitos alimentares das famílias à época da POF 95/96.

\subsection{A Teoria do Comportamento do Consumidor e as Avaliações Empíricas}

Uma das questões mais controversas ao se propor uma análise empírica, baseada em estatísticas, é a necessidade de adequação, ou não, a um arcabouço teórico específico.

Para alguns autores, a simples escolha de um modelo que apresente um bom ajustamento aos dados seria o suficiente para aquele intuito. Um exemplo clássico, lembrado na maior parte dos estudos de demanda, é o trabalho de Prais e Houthakker ${ }^{4}$, citado por Deaton (1986) como 'assumidamente pragmático'.

Mesmo para aqueles com linha teórica definida, essa questão não tem uma resposta única. Ao se propor a "mostrar como fazer a ponte entre o raciocínio teórico e um estudo empírico" na análise do consumo, Phlips (1983) cita Brown e Deaton, que deixam uma 'janela' para os que se propõem a fugir das 'amarras' teóricas:

\footnotetext{
${ }^{4}$ A referência é feita ao seguinte trabalho: Prais, S.J. and H.J. Houthakker. The Analysis of Family Budgets. Cambridge: Cambridge University Press, 1955. Neste estudo, são testados os modelos 'duplologaritmico', 'semi-logaritmico', 'hiperbólico' e 'log-recíproco', sem qualquer adequação ao corpo teórico 'neoclássico'. Mais tarde (1960), Houthakker procura adequar o modelo 'duplo-logaritmico' aos pressupostos teóricos, gerando as funções de utilidade 'aditivas-logaritmica', ou simplesmente 'addilog' (Phlips, 1983, p.113)
} 
"Strong a priori notions are built into the analysis by the choice of model and these will interact with the data to yield results which in some extent will be affected by the model chosen. At the same time such strong preconceptions are inevitable: some functional form must serve as a basis for estimation, and even then when it has been chosen it will in most circumstances be possible to estimate only a few parameters for each commodity. (...) Faced with all these considerations, and with the necessity of justifying the demand function chosen, it is perhaps natural that the investigators have turned to the theory of demand as a tool for deriving the necessary constraints and for organising their a priori assumptions. Because the theory is well worked out and well understood, demand equations which embody it will be guarded from some of the absurdities and inconsistences which may arise from pragmatic models if the latter are used without considerable care and expertise."(p.91-92)

Phlips (1983, p.91) compartilha com Silberberg (1990, p.10) e os demais autores comumente entitulados Neoclássicos ou Marginalistas a idéia de que 'fatos não falam por si próprios', ou seja, os dados estatísticos apenas revelam algum resultado 'significante' quando organizados e transformados no sentido de adaptar-se a hipóteses teóricas.

Para estudiosos dessa linha, o economista é um profissional que deve se ocupar das leis mais gerais de funcionamento do sistema econômico. Para ilustrar o que seria uma 'explicação econômica" de um determinado fato, neste contexto, Silberberg $(1990$, p.1) diz que "The term "explanation" means that there is some more general proposition that than the observed data for which these facts are especial cases. We interpret or understand these facts by applying some general laws or rules by which these events are supposedly guided". Postula-se, assim, que o comportamento humano é sistemático, permitindo que a mesma estrutura analítica seja aplicável a diferentes conjuntos de fatos.

Este 'generalismo' tem rendido severas críticas aos autores dessa vertente teórica ao longo do tempo. Talvez, de fato o comportamento humano seja relativamente homogêneo em ambientes semelhantes; entretanto, a diversidade de ambientes é uma realidade incontestável.

O caminho de evolução dessas teorias, entretanto, vem minimizando esse 'generalismo demasiado' ao adentrar cada vez mais nas especificidades dos campos de análise do comportamento humano. $\grave{A}$ medida em que se toma como realidade as especificidades dos 
diversos ambientes, ainda que se tenha que recorrer a 'minimalismos' impingidos pela formalidade matemática, as hipóteses subjacentes vão se tornando cada vez menos 'heróicas'.

Angus Deaton e John Muellbauer, além de teóricos, são estudiosos que têm dado grande contribuição ao debate de métodos de avaliação do comportamento do consumidor através de análises estatísticas. Estes autores preferem circunscrever os chamados 'Modelos Neoclássicos', dentro da Teoria do Comportamento do Consumidor de cunho quantitativo, àqueles que pressupõem restrições orçamentárias lineares; e ainda que admitam a sua limitação, ressaltam a sua utilidade como fundamento para modelos mais sofisticados ${ }^{5}$ :

"(...) We shall refer to these models as neoclassicals, a name we use to label the assumption of linear budget constraints with fixed, known prices. In the present context, none of the neoclassical models turns out to be very realistic and hence the substantial attention paid to their improvement in Part Four ${ }^{6}$. Nevertheless, it is extremely important to understand them. Firstly they play an important part in much contemporary economic analysis, and it is essential to understand exactly the assumptions on which their theoretical validity depends. Second, they yield important insights that we ignore at our peril and, in Part Four, they will be platform on which we attempt to build more realistic and relevant models." (Deaton \& Muellbauer, 1980, p.86).

Desta forma, acredita-se que seja relevante fazer uma breve apresentação da citada teoria como 'pano de fundo' para a discussão central deste estudo. Mais do que uma 'âncora' ao trabalho a ser realizado, acredita-se que ao lançar mão do debate sobre o tema 'Comportamento do Consumidor' serão encontradas as questões mais relevantes para a consecução do objetivo proposto.

\footnotetext{
${ }^{5}$ No prefácio de seu livro, 'Economics and Consumer Behaviour', Deaton \& Muellbauer (1980) exemplificam alguns dos modelos teóricos que recorrem a restrições não-lineares: "In recent years, important work has been done in many areas by applying consumer theory to nonstandard situations, for example, to discret choice, to rationing, to labor supply, to fertility, to quality choice, to choice with complex nonlinear budget constraints resulting from tax and benefit systems, liquidity constraints, uncertainty, and so on." (p.xii)

${ }^{6}$ Refere-se à continuação da obra citada.
} 


\subsubsection{A Teoria do Comportamento do Consumidor - uma breve leitura}

\subsubsection{A função de demanda}

Na tradicional apresentação da teoria do comportamento do consumidor, os indivíduos se depararão com a seguinte problemática:

$$
\begin{cases}\text { Maximizar } & U=v\left(q_{1}, q_{2}, \ldots, q_{n}\right) \\ \text { Sujeito a } & \sum_{\mathrm{i}=1}^{\mathrm{n}} p_{i} q_{i}=y\end{cases}
$$

onde $U$ é a função de utilidade a ser maximizada. O subscrito $i$ refere-se aos $n$ bens consumidos, $p_{i}$ e $q_{i}$ são seus respectivos preços e quantidades e $y$ é a renda - que na versão clássica do modelo corresponde ao dispêndio total do consumidor.

Da solução das condições de primeira ordem do problema - e satisfeitas as de segunda emergirá um sistema de funções de demanda do tipo:

$$
q_{i}=\phi_{\mathrm{i}}\left(p_{1}, p_{2}, \ldots, p_{n}, y\right) \quad \text { para } i=1,2, \ldots, n
$$

onde o consumo do bem $i$ depende do seu próprio preço, do preço dos demais bens e da renda do consumidor.

Julga-se desnecessária a apresentação dos axiomas que estão por trás da ordenação das preferências dos consumidores, que são a base de sustentação da existência de uma função utilidade genérica.

Entretanto, como sugerido na citação de Brown e Deaton por Phlips (1983), transcrita no início do item 2.1, a escolha das formas funcionais como traduções matemáticas do comportamento dos agentes é de suma importância pois, como em qualquer representação, impõem restrições a priori ao comportamento analisado.

Comum a todos os modelos de demanda estática tradicionais, a restrição orçamentária representa os 'limites à preferência' ou, de outra forma, as 'oportunidades para a escolha'. Por trás da imposição da linearidade, existe a pressuposição de que 'as oportunidades são limitadas por preços fixos conhecidos, de tal forma que o valor total dos objetos escolhidos não excede um 
predeterminado total', o. que remete ao arcabouço institucional de mercados eficientes com custos de transação insignificantes (Deaton \& Muellbauer, 1980, p.3 e 5).

Segundo Deaton e Muellbauer (1980), as principais características que as funções de demanda assumiriam, à partir dessa pressuposição, seriam:

i. Homogeneidade de grau zero: as funções demanda $\phi_{i}$ seriam homogêneas de grau zero em seus argumentos - renda e preços $\left(y\right.$ e $\left.p_{i}\right)$ - , ou seja, variações iguais nos preços e na renda não alterariam a quantidade demandada:

$$
\phi_{\mathrm{i}}\left(\theta p_{1}, \theta p_{2}, \ldots, \theta p_{n}, \theta y\right)=\phi_{\mathrm{i}}\left(p_{1}, p_{2}, \ldots, p_{n}, y\right)
$$

ii. Aditividade: o sistema de funções $\phi_{i}$ seria aditivo, ou seja, as equações de demanda devem ser tais que a soma dos gastos estimados (ou previstos) nos " $n$ " bens seja igual ao dispêndio total (aqui sugerido como a renda) em qualquer período:

$$
\sum_{i=1}^{n} p_{i} \phi_{i}=y
$$

A escolha de formas funcionais para as funções de utilidade, por sua vez, impõe outras restrições às funções de demanda.

Esforços têm se concentrando na procura de especificações menos restritivas possíveis para as funções de utilidade e dois instrumentais matemáticos têm sido largamente utilizados para alcançar esse intento.

O primeiro é o que ficou conhecido por 'relações duais'. Essas relações emergem da similitude entre o problema de maximização da utilidade do consumidor e o de minimização do seu dispêndio. Intuitivamente, se o consumidor conhece todos os preços da economia, sua renda (que é totalmente exaurida no consumo), e sua escala de preferências, um único ponto de equilíbrio será atingido - seja buscando a combinação de bens que lhe conferirá o maior nível de utilidade, dados sua renda e os preços; seja pela combinação que lhe proporcione o menor dispêndio, dados o nível de utilidade e os preços. 
O resultado do problema de minimização do dispêndio a um dado nível de utilidade também é um sistema de funções de demanda ${ }^{7}$ (de resultado numérico idêntico ao do problema anterior), e a função objetivo otimizada é denominada 'Função Custo'.

Uma vez conhecidos os pressupostos necessários para a construção de uma 'Função Custo' compatível com a teoria, ela tem sido utilizada pela relativa simplicidade que apresenta frente à dificuldade de se estabelecer diretamente uma função de utilidade 'bem comportada'.

O segundo instrumental matemático utilizado com o fim de estabelecer formas funcionais menos restritivas é a adoção das chamadas estruturas flexíveis - são formas funcionais que possuem a característica de se aproximar, localmente, de outras funções. Assim, ao invés de se determinar um comportamento explícito para a ordenação das preferências de um consumidor, busca-se uma forma arbitrária que a represente pontualmente.

Com o uso desses instrumentais, os teóricos vêm procurando determinar funções de demanda que possam retratar de forma mais próxima possível o comportamento humano, impondo cada vez menos condições comportamentais a priori.

\subsubsection{A função consumo ou curva de Engel}

Em geral a análise empírica da demanda do consumidor se dá pela exploração de dados de séries temporais. Uma segunda possibilidade é o estudo de dados de corte seccional. Em trabalhos dessa natureza, busca-se identificar as explicações para as diferenças de comportamento entre as unidades de consumo.

Nas palavras de Deaton \& Muellbauer (1980),

"Demand analysis is concerned not only with the analysis of time-series data but also with the explanation of behavioral differences between households in cross-section studies. In such studies, it is usually assumed that all households face identical prices, so that explanations of behavioral differences are sought in differences in total expenditure and in household characteristics, particularly those concerned with family composition" (p.18).

\footnotetext{
7 Neste caso são as chamadas funções de demanda 'Hicksianas' ou 'Compensadas'- que reagem a variações de preços, mantendo o nível de utilidade constante: $q_{i}=\varphi_{i}\left(u, p_{i}\right)$
} 
As formas funcionais que retratam essa situação são chamadas 'Curvas de Engel' ${ }^{8}$ e podem ser descritas, numa versão bastante simples, como 'uma relação entre a renda e o dispêndio com uma determinada mercadoria, tudo o mais permanecendo igual' (Phlips, 1983, p.103). A sua representação matemática pode assumir a seguinte forma genérica:

$$
p_{i} q_{i}=a_{i}+\phi_{i}(y) \quad \text { para } i=0,1, \ldots, n
$$

onde o subscrito ' $i$ ' refere-se aos $n$ bens, e ' $a_{i}$ ' é uma função dos preços, que aqui pode ser representada por uma constante.

Para que a função consumo, ou curva de Engel, seja compatível com a teoria do comportamento do consumidor, as restrições gerais da teoria da demanda devem ser satisfeitas. No caso, ao assumir a invariância dos preços, as restrições são bastante simplificadas - ficando como única a condição de aditividade (Phlips, 1983, p.103), ou seja,

$$
\begin{aligned}
& y=\sum_{i=1}^{n} \phi_{i}(y)=\sum_{i=1}^{n} p_{i} q_{i} \\
& \text { ou } \\
& \sum_{i=1}^{n} \frac{d\left(p_{i} q_{i}\right)}{d y}=1
\end{aligned}
$$

donde tem-se que a soma das propensões marginais a consumir (ou participação orçamentária marginal) é igual à unidade.

A restrição 'tudo o mais permanecendo igual' (ceteris paribus), por outro lado, refere-se à manutenção das condições gerais, ou seja, a dado nível de preços e escala de preferências.

\subsubsection{A introdução de variáveis 'qualitativas' nos estudos de demanda}

Caminhando no sentido de 'especializar' a teoria, os modelos de demanda também podem incorporar variáveis socioculturais em sua estrutura.

Como que numa continuação da citação acima [Deaton \& Muellbauer (1980, p.18)], Deaton (1986) afirma que em estudos de corte seccional as características dos domicílios variam muito,

\footnotetext{
${ }^{8}$ Trata-se de uma homenagem a Ernst Engel (1857), um dos primeiros estudiosos a registrar as leis que governam as relações entre a renda e o dispêndio com alguns produtos particulares (Phlips, 1983, p.103).
} 
em vários outros aspectos, além da renda, e essas variáveis podem ser incluídas nos modelos tradicionais:

"In cross-section studies, households typically vary in much more than total expenditure; age, and sex composition varies from household to household, as do the numbers and ages of children. These demographic characteristics have been the object of most attention and I shall concentrate the discussion around them, but other household characteristics can often be dealt with in the same way, (e.g. race, geographical region, religion, occupation, pattern of durable good ownership, and so on)' (p.1801-1802)

Sendo o sistema de demanda tradicional representado por

$$
q_{i}=\phi_{\mathrm{i}}\left(p_{1}, p_{2}, \ldots, p_{n}, y\right) \quad \text { para } i=1,2, \ldots, n
$$

O modelo assumindo tais características seria dado por:

$$
q_{i h}=\phi_{\mathrm{i}}\left(p_{1}, p_{2}, \ldots, p_{n}, y_{h}, \mathbf{a}_{h}\right) \quad \text { para } \mathbf{i}=1,2, \ldots, n
$$

onde o subscrito ' $i$ ' refere-se aos ' $n$ ' bens; ' $y_{h}$ ' e ' $\mathbf{a}_{h}$ ' são a renda e o vetor de características da $h$-ésima família, respectivamente.

Para os modelos que assumem a estabilidade de preços, ' $p_{i}$ ' é suprimido como argumento da função. A representação da função consumo seria, então:

$$
p_{i} q_{i h}=\phi_{\mathrm{i}}\left(y_{h}, \mathbf{a}_{h}\right) \quad \text { para } i=1,2, \ldots, n
$$

\subsubsection{Avaliações empíricas e suas limitações}

São inúmeras as questões que se colocam quando se pretende 'aplicar' os conhecimentos teóricos a investigações empíricas. A teoria diz que um consumidor 'típico', 'racional', apresentará funções de demanda do tipo explicitado na eq. (2), ou funções consumo como designadas nas eq. (6) e (8). A proposta estrita deste estudo, por outro lado, é de avaliar o efeito de diferentes variáveis socioeconômicas sobre o consumo alimentar, através dos dados obtidos em uma pesquisa de orçamentos familiares - dados de corte seccional. Assim, esta seção pretende cumprir o objetivo de levantar algumas das questões que têm sido apresentadas como principais lacunas a serem cobertas entre o mundo teórico e o empírico sobre o tema em questão. 


\subsubsection{A análise da demanda com dados de corte seccional}

\section{i. Demanda ou consumo?}

A primeira questão que se coloca é que tipo de análise deve ser aplicada quando os dados são de corte seccional: deve-se fazer um estudo da função demanda ou da função consumo (curva de Engel)?

Obviamente, a essa, como às demais questões aqui apresentadas, não existe uma resposta precisa. Assim, serão levantadas apenas algumas evidências para que se faça o corte necessário para a aplicação dos métodos quantitativos.

A diferença básica entre a análise da 'demanda' e do 'consumo' está no tratamento que se dá à variável 'preço'. No primeiro caso, considera-se a sua variabilidade e, no segundo, os preços são tratados como 'estáveis' para todas as unidades de consumo. Os dois tratamentos são admitidos, mas a sua escolha impõe diferentes resultados.

Sabe-se que a variável 'preço' é fortemente condicionada pelas condições de oferta dos produtos, situação que em geral identifica-se mais com análises de comportamento temporal do que com o tipo de dados que aqui se pretende explorar.

Em dados de pesquisas domiciliares - de curto tempo de duração ${ }^{9}$ - as variações de preços se dão por outras razões que não somente pelas condições de oferta. Para definir a melhor forma de explorar esses dados é importante compreender sua natureza.

Para iniciar a discussão recorre-se a Deaton (1997), que chama atenção para o fato de que em pesquisas domiciliares, em geral, são registradas apenas as informações do dispêndio total e da quantidade adquirida dos produtos em cada unidade de consumo - o que é verdadeiro para a pesquisa aqui explorada. Assim, o que se chama de 'preço' nesta situação é diferente da variável reconhecida pela teoria - trata-se do 'valor unitário' das mercadorias, calculado pelo quociente entre o dispêndio total e a quantidade adquirida. A esse respeito alerta: "Unit values are not the same thing as prices, and are affected by the choice of quality as well as by the actual prices that the consumer faces in the market."(p.284); e,

\footnotetext{
${ }^{9}$ Em geral essas pesquisas tem duração de um ano - como a POF 95/96 -, a fim de captar todos os efeitos sazonais quanto aos rendimentos e dispêndios das unidades de consumo.
} 
"One reason why unit values are not the same thing as prices is that unit values are affected by the choice of quality. A kilo of the best steak costs a great deal more than does a kilo of stewing beef, Roqueford costs more than cheddar, and even for relatively homogeneous commodities such as rice, there are many different grades and types. (...) As a consequence, and in contrast to a market price, over which the consumer has no control, a unit value is chosen, at least to some extent. ${ }^{\prime 10}$ (p.288).

Cox e Wohlgenant (1986) defendem a inclusão dos 'preços' e respectiva variabilidade na estimação do consumo alimentar em análises de corte seccional:

"The existence of cross-sectional price variation raises several important issues. Failure to adequately specify cross-sectional price effects could result in biased and misleading demand elasticities (Polinsky). Thus, traditional Engel analysis may be inappropriate if prices are not constant in the cross section. In addition, prices in cross-sectional data are generally assumed to reflect "quality" effects which should be corrected for prior to estimation (...)" (p.908).

O 'efeito qualidade', referido pelos autores, reflete algumas 'diferenciações' que os produtos apresentam que justificariam a variabilidade dos preços. A principal fonte deste efeito nos estudos empíricos seria a heterogeneidade das mercadorias compostas (agregadas) ${ }^{11}$. Quando um estudo é realizado sobre uma mercadoria singular, seu preço deveria ser homogêneo - tal qual apresentado pela teoria ${ }^{12}$. No entanto, ao conceber 'agregados', os estudos empíricos acabam por impor uma maior variabilidade aos preços observados.

Para avaliar suas hipóteses, Cox e Wohlgenant (1986) propõem um modelo que se contrapõe aos tradicionais. Esses, segundo os autores, quando tratam do assunto, o fazem através da inclusão de variáveis binárias que captariam os efeitos da variação dos preços derivadas das flutuações típicas de oferta, como diferenças regionais e sazonais; desprezando os tais 'efeitos qualidade'.

\footnotetext{
${ }^{10}$ Grifo da autora.

"Serviços 'vendidos' junto com a mercadoria, economias de tamanho auferidas pelas grandes familias tanto na aquisição como nas atividades domiciliares de produção e consumo, o custo da informação, etc, são alguns dos vários fatores considerados como determinantes da diferenciação de preços entre as mercadorias. Entretanto, ainda que esses fatores operem sobre mercadorias singulares, a variabilidade fatalmente se ampliará quando são analisadas as mercadorias compostas.

${ }^{12}$ Afirmação que se sabe nem sempre, ou raramente, corresponder à realidade.
} 
Inicialmente, depois de definir o modelo teórico, propõe-se uma metodologia para distinguir a parcela da variabilidade dos preços atribuída aos diferenciais de 'qualidade' dos produtos ${ }^{13}$, à qual são submetidos três agregados alimentícios: 'Vegetais frescos', 'Vegetais enlatados' e 'Vegetais congelados', originários de uma pesquisa de corte seccional aplicada na região Oeste dos Estados Unidos da América, entre os anos de 1977 e 1978.

A designação formal do modelo é:

$$
R D P M_{i}=p_{i}-\alpha_{i}=\sum_{j} \gamma_{i j} b_{i j}+e_{i}
$$

onde RDPM corresponde ao desvio do preço do i-ésimo produto em relação ao preço médio regional/trimestral;

$\alpha_{i}$ corresponde ao preço médio regional/trimestral do i-ésimo produto; e,

$b_{i j}$ corresponde às características do $j$-ésimo domicílio, consumidor do i-ésimo produto, que são usadas como proxies das preferências de qualidade - características não-observadas das mercadorias.

De posse desse resultado, três modelos de demanda foram estimados: um primeiro incluindo a variável 'preço', sem o seu ajuste com relação ao 'efeito qualidade'; um segundo incluindo a variável ajustada ao 'efeito qualidade' dos preços; e, finalmente um terceiro, sem a consideração da variável 'preço'.

Analisando os resultados obtidos, os autores admitem que ainda que tenham encontrado diferenças entre os modelos, essas não foram conclusivas. Os testes sugerem que o uso de variáveis binárias nas funções de Engel não é adequado para 'modelar' o efeito preço dos dados tipo cross-section; entretanto, as diferenças encontradas entre os resultados dos três modelos foram muito pequenas, mesmo quando agregou-se todos os 'Vegetais' em uma única mercadoria composta ('Vegetais' = 'Vegetais frescos' + 'Vegetais enlatados' + 'Vegetais congelados'). Com isso os autores concluem:

"Therefore, while the conceptual structure clearly indicates the potential difficulties of not correctly modeling cross-sectional price effects, these difficulties appear to be minor

${ }^{13} \mathrm{Na}$ avaliação do 'efeito qualidade' são envolvidas variáveis explicativas como as características socioeconômicas dos domicílios (situação dos domicílios - Urbano/rural, tamanho das família, renda, raça, idade dos componentes, emprego da 'mãe', etc); e questões mercadológicas, como os diferentes locais de compra (supermercados e não-supermercados). 
for the disaggregate and relatively homogenous commodities considered. Whether these results will hold for more aggregated and/or less homogenous commodities is an empirical issue worthy of further research." (p.918).

Alguns agregados alimentares apresentados na POF 95/96, por sua vez, apresentaram poucos registros de quantidade adquirida e qualquer tentativa de estimação da variabilidade dos preços seria comprometida por esse fato. Das 17.474 observações de aquisição de 'Cereais, leguminosas e oleaginosas', por exemplo, 15.679 apresentaram registro da quantidade adquirida (89,7\%, portanto), enquanto que para os 'Alimentos Preparados' apenas $18,1 \%$ das observações de dispêndio apresentavam as correspondentes quantidades (529 registros em 2.921 observações).

Isto posto, acredita-se não cometer uma grande arbitrariedade ao fazer uso da técnica tradicional de formulação da função de Engel, ou seja, considerar os preços 'estáveis', tomando o cuidado de discriminar variações regionais e sazonais do consumo.

Vale ressaltar que, com essa formulação será estimada a elasticidade-renda do dispêndio com determinados alimentos e não a elasticidade-renda da quantidade consumida.

\section{ii. Quais os itens e quem são os consumidores que se pretende avaliar?}

Na discussão acima, uma tradicional questão das avaliações empíricas foi colocada: a da agregação.

Como observado na seção 2.1., a teoria tradicional considera que o comportamento humano é sistemático, permitindo que a mesma estrutura analítica seja aplicável a diferentes conjuntos de fatos. Com isso, nos trabalhos empíricos permite-se que, segundo critérios razoavelmente lógicos, sejam estabelecidos 'grupos' de consumidores homogêneos, segundo determinadas características, para avaliar o seu comportamento. Assim, ao investigar unidades da mesma área geográfica, classe social, etc, a probabilidade de elas apresentarem uma mesma escala de preferências aumenta (Phlips, 1983).

É importante ressaltar, entretanto, que essa hipótese sempre apresentará um certo grau de arbitrariedade:

"We may add at once that perfect homogeneity can never be realized: age differences, differences in social or working habits, in religion, etc. The investigator has to decide for 
himself whether the data set is homogenous enough to subsume the remaining differences in an error term with known properties. Although it is probably impossible to achieve a perfect correspondence between the theory and the facts, much can be done to satisfy the hypothesis of a given utility function by a careful choice of the data and a careful analysis of the error term." (Phlips, 1983, p.105).

O mesmo vale para os produtos a serem investigados. Comumente os estudos realizados sobre o comportamento da demanda referem-se a agregados do tipo 'carnes', 'queijos', 'cereais', etc. Lembrando a discussão acima sobre a inclusão ou não da variável 'preço' no estudo, pode-se inferir o grau de dificuldade imposto à interpretação dos resultados quando as mercadorias são compostas.

Aqui, a simples especificação de variáveis socioeconômicas como explicativas do consumo já cumpre a tarefa de distinguir os diferentes tipos de consumidores, enquanto que a agregação dos produtos alimentares deve ser determinada de acordo com o objetivo do estudo.

\section{iii. Despesa total ou renda?}

De acordo com o modelo tradicional da curva de Engel - num estudo de dados de corte seccional, s $\sigma 6$ a hipótese de preços constantes - a pressuposição de 'aditividade' deve ser atendida. Na formulação tradicional a renda é igual à soma dos dispêndios; ou seja, o consumidor gasta tudo o que ganha.

Em um estudo como o proposto coloca-se, então, a questão de qual a variável explicativa a ser usada - os rendimentos declarados na pesquisa de campo ou a despesa global registrada pelos entrevistados?

A necessidade de realizar o estudo tomando em conta o dispêndio total, ao invés da renda propriamente dita, pode ser justificada com o argumento de Prais e Houthakker, citado por Phlips (1983):

"(...) By using budgets from different income classes, one tries to measure the long-run reactions of the representative family. The average expenses in an income class may be considered as typical for a family that has adapted itself to the social status associated 
with the income class. The $b^{14}$ coefficient therefore measures the reactions of a family to a variation in $y$, on the condition this family has had time to adapt its consumption pattern fully to the new values of $y$. For consistency, one should does try to measure the "normal' values of $y$, i.e. the values considered as normal given the corresponding social status. Total expenditures, which are the family's control, are probably a better proxy for this than the actual incomes, which may include all sorts of transitory (positive or negative) components. Furthermore, static demand theory defines $y$ as total expenditure, not as disposable income (which includes saving)(...)."(p.111-112)

De certa forma, esses autores sugerem que a 'despesa global' seria uma variável proxy para o que se conhece por 'renda permanente' na teoria, e as elasticidades obtidas para essa variável poderiam ser tidas como 'elasticidades de longo prazo'.

\section{iv. Medidas per capita}

Nas Pesquisas de Orçamentos Familiares, em geral, o consumo alimentar é associado aos registros de dispêndio com os diferentes alimentos por parte dos familiares. Para analisar o consumo pessoal a opção mais óbvia seria dividir tal dispêndio pelo número de componentes da família. Entretanto, indivíduos de diferentes faixas etárias apresentam necessidades de consumo tipicamente diferentes ${ }^{15}$, fazendo com que o dispêndio per capita seja uma medida inadequada para comparar o grau de 'bem estar' entre as famílias (famílias de mesmo tamanho e dispêndio total mas com composições etárias diferentes apresentariam distintos níveis de (bem estar'). Questões como esta devem ser levadas em consideração em estudos da demanda alimentar.

O método mais elaborado de considerar a questão é o uso de 'escalas de equivalência', que, grosso modo, são índices que uniformizam esse tipo de discrepância, fazendo com que a 'unidade per capita' se referencie a um indivíduo 'padrão'. Assim, a título de exemplo; uma família com um casal de adultos e uma criança de $x$ anos poderia representar ' 2,3 equivalentesadulto' no consumo alimentar, conforme a escala de referência.

\footnotetext{
14 ' $\mathrm{b}$ ' aqui representa o coeficiente que mede a relação entre a quantidade consumida $\left(q_{i}\right)$ e o dispêndio $(y)$ total nos modelos 'duplo-logaritico', 'semi-logaritmico', 'hiperbólico' e 'log-inversa' testados pelos referidos autores.

${ }^{15} \mathrm{O}$ consumo de cereais e carnes, por exemplo, diverge em quantidade consumida entre adultos e crianças de tenra idade.
} 
Segundo Deaton (1980), "Household equivalence scales are deflators that are more sophisticated than mere head counting and by which the budgets of different household types can be converted to a needs-corrected basis."(p.192)

Uma segunda possibilidade de tratamento seria a consideração da composição etária das diferentes famílias como fator determinante do consumo per capita (Blisard \& Blaylock, 1993).

\section{v. Dispêndio zero: dados censurados}

Em geral os questionários das pesquisas de orçamentos familiares perguntam qual o valor despendido e quantidade adquirida de cada produto em um determinado período (que para os alimentos varia de uma a duas semanas). É óbvio que a quantidade adquirida não corresponde, necessariamente, à quantidade consumida (ingerida).

A 'não aquisição' de um produto pode ser associada a diversas situações: $i$. ele não foi adquirido porque a $h$-ésima família não o consome; $i i$. ela o consome eventualmente, mas isso não foi detectado pela pesquisa; iii. ela o consome freqüentemente, mas não o adquiriu no período em que sua residência foi avaliada. A possibilidade da 'não aquisição' não refletir o 'não consumo' torna-se especialmente verdadeira no caso dos gastos alimentares, dado o curto período de registro das aquisições.

Na literatura esse caso é tratado como de 'amostras censuradas'. Segundo Greene (1993), a censura é essencialmente um problema dos dados amostrais - se eles não fossem censurados, presumidamente os dados seriam representativos da população de interesse e não apenas de uma sub-população.

Para a questão específica da demanda alimentar, foram dois os métodos mais encontrados para contornar o problema. Um que considera que a própria variável dependente (o consumo) é censurada, e outro, que admite que a variável dependente (o consumo) é censurada por uma segunda - a 'aquisição'.

O primeiro método pode ser compreendido da seguinte forma: quando a variável é censurada, uma fração significativa das suas observações são todas reportadas como assumindo um único valor - neste caso, o valor 'zero'. Assumindo que a variável de interesse apresenta distribuição normal, a figura 1 ilustra o problema: 


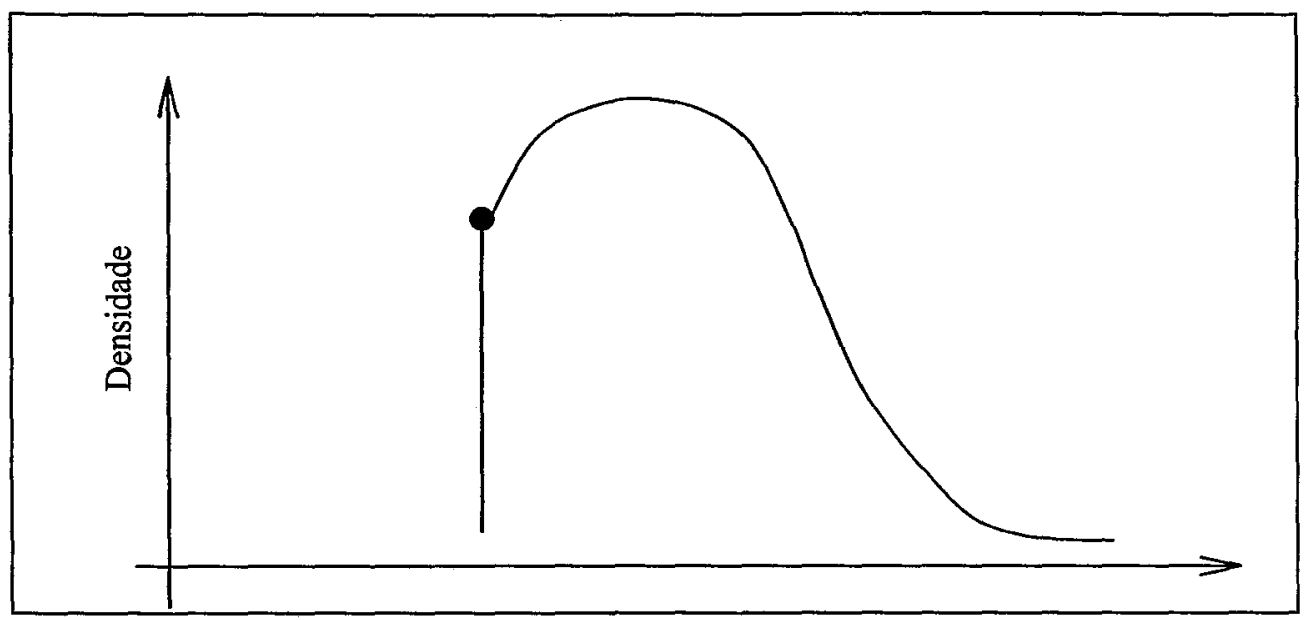

Figura 1: Distribuição Normal Censurada.

A simples visualização permite inferir que a variável, no problema colocado, assume uma distribuição contínua até o ponto de 'truncagem,', e então, apresenta uma concentração de observações em um determinado valor.

Assumindo que o ponto de censura da variável seja 'zero', a questão é formalizada por Greene (1993). É definida uma nova variável aleatória, $y$, transformada da original $y^{*}$, de tal forma que:

$$
\left\{\begin{array}{lll}
y=0 & \text { se } & y^{*} \leq 0 \\
y=y^{*} & \text { se } & y^{*}>0
\end{array}\right.
$$

A distribuição que se aplica se $y^{*} \sim N\left(\mu, \sigma^{2}\right)$ é:

$$
\operatorname{Pr}(y=0)=\operatorname{Pr}\left(y^{*} \leq 0\right)=\Phi\left(-\frac{\mu}{\sigma}\right)=1-\Phi\left(\frac{\mu}{\sigma}\right) \text {, onde } \Phi \text { é a função de distribuição normal }
$$

reduzida; e, se $y^{*}>0, y$ tem a densidade de $y^{*}$. Desta forma, essa distribuição é uma mistura de partes contínuas e discretas, com probabilidade total necessariamente igual a 1 .

O modelo de regressão baseado na discussão precedente é chamado por Modelo de Regressão Censurada, ou simplesmente Tobit, e foi aplicado ao consumo alimentar por Blisard \& Blaylock (1993) e Mc DOWELL et al (1997), entre outros.

\footnotetext{
${ }^{16}$ Ponto a partir do qual não existem mais observações da variável.
} 
O segundo método para contornar a censura dos dados será apresentado no capítulo metodológico, uma vez que é o adotado nesse estudo. Trata-se do Modelo de Seleção Amostral adotado por Hein e Duram (1991) e Park et al. (1996).

Não existe consenso quanto ao método mais apropriado para tratar a questão, mas as críticas são mais contundentes ao Modelo de Regressão Censurada (Tobit), por ser ele um caso particular do Modelo de Seleção Amostral, portanto mais restrito.

\subsection{Variáveis que condicionam o padrão alimentar}

O objetivo estrito do presente estudo é de avaliar a influência de algumas variáveis socioeconômicas sobre o consumo alimentar do 'brasileiro metropolitano'. Apesar da análise ser estática, representando uma 'fotografia' do padrão de consumo à época da POF, privilegiou-se o uso de variáveis associadas às mudanças demográficas e sociais mais relevantes no período recente da sociedade brasileira como explicativas do consumo alimentar. Assim procedendo acredita-se que os resultados obtidos possam ser úteis não apenas para a compreensão do atual cenário, mas também avaliar em que medida as variáveis socioeconômicas que estão em mutação podem estar ditando a dinâmica do padrão alimentar das pessoas.

A variável 'renda' (dados os preços), como-aponta a teoria; é tida como o principal condicionante da demanda. $\mathrm{O}$ conhecimento do impacto das suas variações sobre o nível de consumo dos alimentos, expresso nos coeficientes de elasticidade, é de suma importância para os cálculos econômicos, que vão desde a formulação de estratégias de oferta dos produtos a médio e longo prazos até o planejamento de políticas sociais - voltadas para a área de carência nutricional, sempre necessárias em países com grande contingente de pobres na população.

Barros e Mendonça (1995) afirmam que, apesar de sua distribuição ter sidơ diferenciada entre as classes de renda, a renda real dos brasileiros cresceu entre os anos de 1960 e 1990 . Com isso, apesar de ter ocorrido uma piora na distribuição de renda dessa população, o nível de pobreza diminuiu ao longo do período.

Nas figuras 2 e 3 pode-se observar o comportamento tanto da pobreza como da distribuição de renda entre as pessoas economicamente ativas (com rendimento) para o período mais recente. Como medida de pobreza é utilizado o Índice de Sen, e de desigualdade o Índice de Gini ambos obtidos em Hoffmann (2000a). Nota-se, nessas curvas, que a tendência declinante da 
pobreza persiste enquanto o padrão de desigualdade entre os brasileiros parece manter-se relativamente estável ao longo dos 17 anos assinalados.

Uma vez que a elasticidade-renda do dispêndio é maior para níveis de renda mais baixos, a redução da pobreza tende a ter forte impacto no sentido de aumentar o consumo alimentar. De maneira geral, o consumo de alimentos tende a crescer com a renda, mas o efeito é maior quando é a renda dos pobres que cresce mais, ou seja, quando o crescimento da renda for acompanhado de uma redução da desigualdade da sua distribuição.

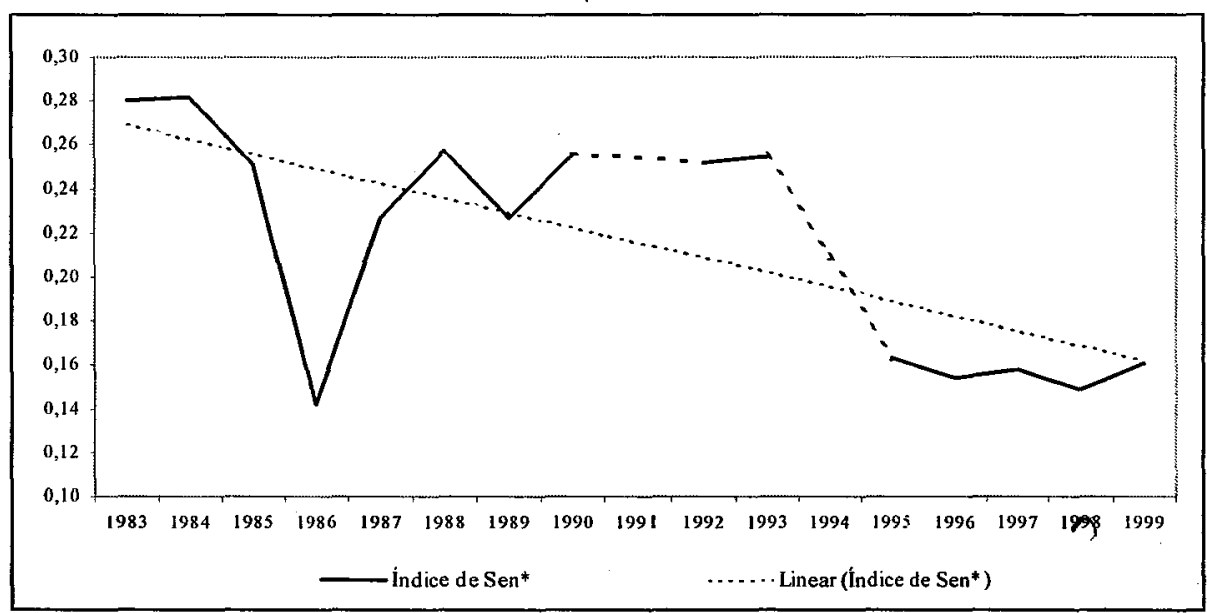

Figura 2. Índice Sen de Pobreza

"adotando como linha de pobreza o valor real do salário mínimo de agosto de 1980, utilizando o INPC como deflator. Brasil, 1983-1999

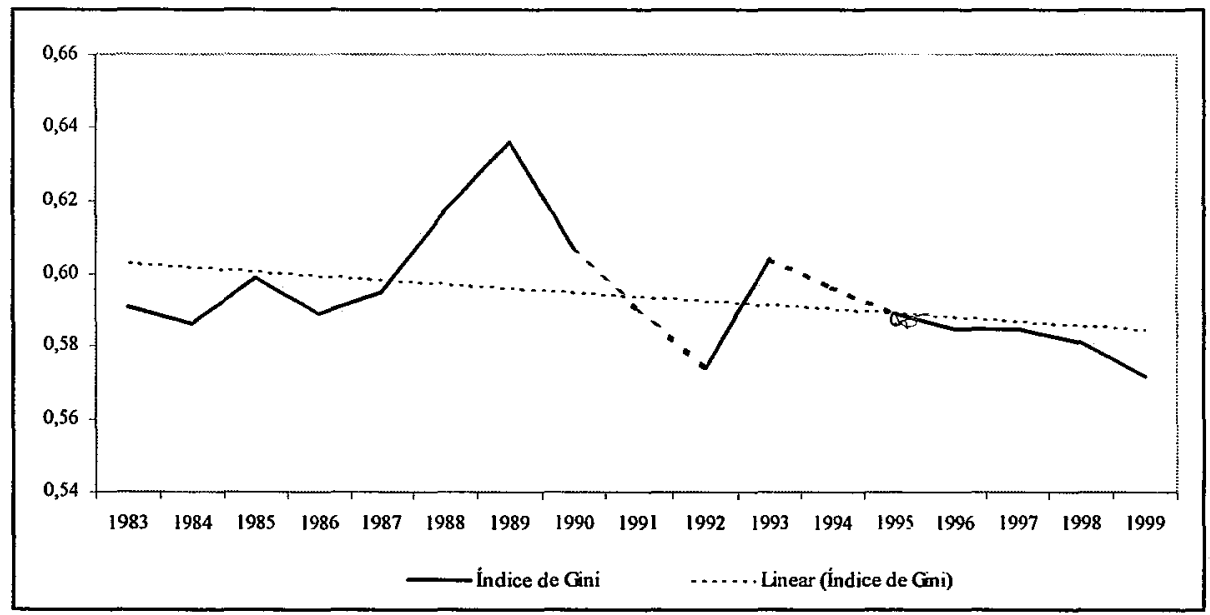

Figura 3. Desigualdade da distribuição de renda entre os brasileiros economicamente ativos com rendimento: Índice de Gini 
A 'idade' é outra das variáveis comumente exploradas em estudos de demanda alimentar. São dois os efeitos que essa variável pode exercer sobre o consumo: $i$.pessoas de diferentes faixas etárias apresentam diferentes necessidades nutricionais; $i i$. pessoas de diferentes gerações podem apresentar hábitos diversos. Além disso, em consonância com o primeiro argumento, o uso das diferentes faixas etárias das pessoas que compreendem a família como explicativas do consumo alimentar viabiliza as medidas de consumo per capita, dado o exposto na seção 2.1.2.1.i.v. dispensando a necessidade de recorrer às 'escalas de equivalência.'

A estrutura etária brasileira, por sua vez, tem mudado rapidamente de perfil. Assim, no médio/longo prazo, se é fato que a 'idade' influencia as escolhas alimentares, é interessante saber em que sentido. Na figura 4 pode ser observada a população brasileira, segundo grupos etários, para os anos de 1970, 1996 e as projeções do IBGE para o ano de 2020. Claramente há um processo de 'envelhecimento' da população, cujos impactos no padrão de consumo alimentar podem ser relevantes.

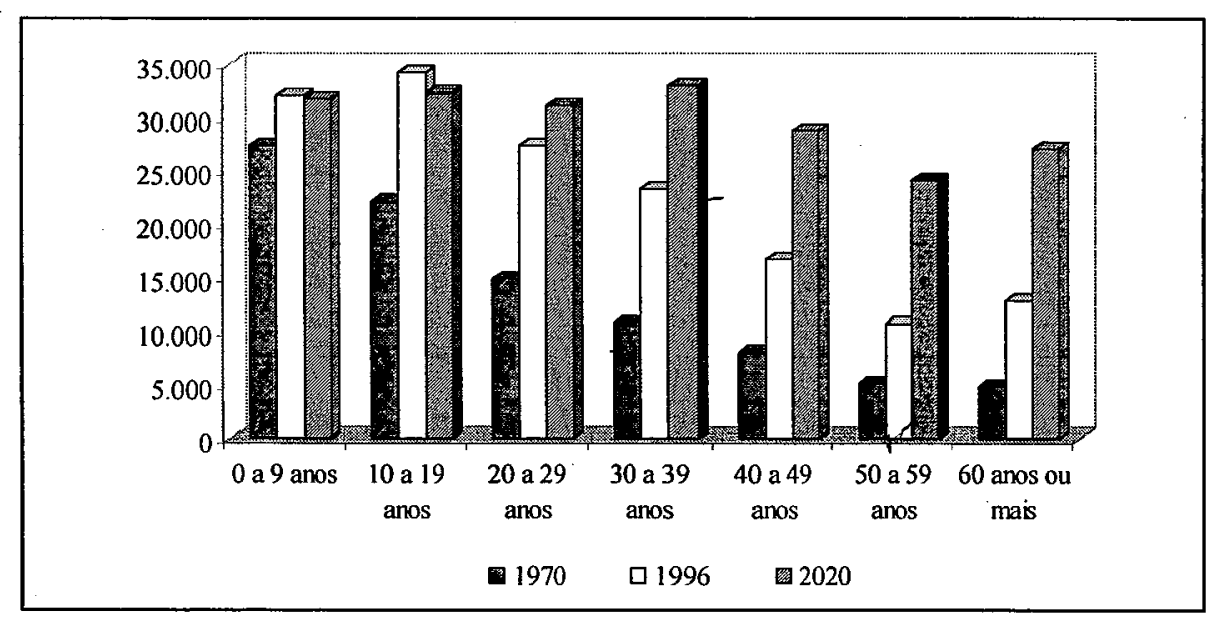

Figura 4. População brasileira residente, em milhares de pessoas, segundo grupos de idade. IBGE (1997)

O 'tamanho ${ }^{17}$ das familias, é outra das variáveis comumente apontadas como explicativas do consumo alimentar. A partir dessa variável é possível testar a existência (ou não) das economias de escala no consumo de alimentos, ou seja, verificar se o dispêndio per capita com os alimentos decresce à medida que o tamanho da família cresce.

${ }^{17}$ A variável 'tamanho' da família é dada pelo número de pessoas da família. 
No Brasil o tamanho das famílias vem diminuindo rapidamente. Em 1970 a população residente no Brasil era de 91,3 milhões de pessoas e o número de famílias de 19,1 milhões (IBGE, 1971). Em 1996, esses números passaram a 156 e 44 milhões, respectivamente (IBGE, 1997). Assim, se no ano de 1970 o tamanho médio das famílias era de 4,8 pessoas, em 1996 esse número chegou a 3,5 pessoas por família.

Um outro conjunto de variáveis que pode estar influindo na determinação do consumo alimentar e que se pretende avaliar, são as transformações na organização familiar, como a crescente inserção da mulher no mercado de trabalho e as organizações familiares em si.

Acredita-se que haja essa influência por dois motivos: $i$. a mulher ainda exerce um papel chave nas decisões alimentares; $i$. a composição familiar determina, em grande parte, o estilo de vida e a posição socioeconômica dos seus membros (Kinsey, 1994), o que pode se traduzir em diferentes padrões de consumo alimentar.

Kinsey (1994) diz que talvez nada influencie mais 'o que' e 'onde' as famílias comem do que a participação da esposa/mãe no mercado de trabalho.

Evidências no caso brasileiro de como a mulher exerce um papel determinante no nível nutricional infantil foram encontradas, entre outros, por Kassouf (1994) - o que presumidamente poderia ser projetado para um papel mais amplo da mulher no âmbito do consumo alimentar das famílias. Em seu estudo, foram três as indicações neste sentido: $i$. o nível de educação das mães age positivamente sobre o grau de nutrição dos seus filhos; ii. A participação da mulher do mercado de trabalho age positivamente sobre o nível da renda familiar per capita, que é um fator que exerce influência positiva sobre o nível de nutrição infantil; mas, iii. uma vez que as atividades no mercado de trabalho são tempo intensivas, há uma influência negativa do trabalho feminino sobre o nível nutricional das crianças.

Se em 1970 as brasileiras representavam apenas $20,8 \%$ (6,15 em 29,55 milhões de pessoas) da PEA nacional (Pessoas Economicamente Ativas), em 1997, esse percentual passou a 40,4\% (30,38 em 75,21 milhões de brasileiros) [IBGE, 1971 e 1998] - indicando a crescente inserção feminina no mercado de trabalho.

As diferentes organizações familiares, por outro lado, também podem influenciar o modo como as pessoas estão se alimentando. Além do perfil socioeconômico, destacado por Kinsey, existem vários aspectos das mudanças nessas organizações que podem estar mudando os hábitos da população. Sob um aspecto mais psicológico, Bleil (1998) lembra que as refeições na 
residência, até algum tempo atrás, estavam relacionadas à reunião familiar. Nas grandes cidades o gasto excessivo de tempo com a locomoção e a mudança na estrutura familiar estão acabando por descaracterizar esse caráter subjetivo das refeições e muitas vezes, para contornar o sentimento de 'solidão' que acarreta estar só a uma mesa, as pessoas acabam por privilegiar um tipo de alimentação ‘ligeira’, geralmente pouco saudável.

Em um amplo estudo sobre a 'família' brasileira ${ }^{18}$, Goldani (1990) avalia as mudanças nessa estrutura. Entre outros aspectos, a autora estuda a composição dos domicílios e a sua evolução no tempo. Em grandes linhas, adota-se a seguinte classificação para essas unidades:

a. Domicílios Familiares:

a.i. Nucleares - Casal com ou sem filhos, ou 'Pai' ou 'Mãe' com filhos;

a.ii. Estendidos - Família nuclear e outros parentes;

a.iii. Complexos - Família nuclear ou estendida e não parentes.

b. Domicílios não-Familiares:

b.i. Pessoas vivendo sozinhas

b.ii. Outras não-famílias

A evolução da participação desses grupos, através de dados dos Censos de 1960, 1970 e 1980 e PNADs dos anos de 1976 e 1984 são apresentados na tabela 1.

Tabela 1. Distribuição da organização familiar e não familiar nos domicílios brasileiros $1960-84$, em \%

\begin{tabular}{lccccc}
\hline & 1960 & 1970 & 1976 & 1980 & 1984 \\
\hline Domicílios Familiares & 92,8 & 93,6 & 94,1 & 92,5 & 93,2 \\
I. Nuclear & 68,9 & 73,3 & 75,6 & 72,4 & 70,3 \\
II. Estendido & 22,6 & 16,2 & 15,2 & 17,6 & 14,1 \\
III. Complexo & 1,5 & 4,1 & 3,5 & 2,5 & 8,7 \\
Domicílios não Familiares & 7,2 & 6,4 & 5,9 & 7,5 & 6,8 \\
I. Homem ou Mulher vivendo sozinho & 5,3 & 5,1 & 4,8 & 6,6 & 5,5 \\
II. Outros não-familiares & 1,9 & 1,3 & 0,9 & 0,9 & 1,3 \\
\hline Total & 100,0 & 100,0 & 100,0 & 100,0 & 100,0 \\
\hline
\end{tabular}

Fonte: Goldani (1990)

\footnotetext{
${ }^{18}$ Este estudo engloba tanto o meio urbano como o rural, que normalmente é mais tradicionalista quanto à organização familiar.
} 
Com esses dados observa-se que os domicílios familiares continuam sendo a grande maioria no Brasil e, entre os não-familiares, há uma ligeira tendência de elevação na participação dos domicílios de pessoas que moram sozinhas (domicílios unitários). Entre os domicílios familiares, a autora chama a atenção para o declínio na proporção das ‘famílias estendidas' em favor da organização familiar complexa.

Acredita-se que a utilização de uma classificação dos domicílios em diferentes tipos (adaptando a classificação anterior) pode assegurar uma melhor compreensão do perfil de consumo do brasileiro. 


\section{MATERIAL E MÉTODOS}

Este capítulo tem o objetivo de apresentar, em grandes linhas, a pesquisa de orçamentos familiares realizada pelo IBGE, entre os anos de 1995 e 1996 (POF 95/96) - que é a base de dados do estudo -, os métodos propostos para a avaliação do comportamento do consumidor e os recursos computacionais utilizados.

Duas são as metodologias aplicadas: o modelo de seleção amostral e o de 'ajustamento nas médias'. Ambos utilizam todos os dados individuais da pesquisa primária, se distinguindo pela forma como os trata. $O$ primeiro, tal como exposto no capítulo anterior, trata a amostra como 'censurada' e, estima o consumo a partir dos dados individuais. $O$ segundo, tem suas estimativas baseadas no consumo médio dos indivíduos, segundo classes de renda, tornando desnecessário um tratamento especial para as observações de 'dispêndio zero'.

O uso da segunda metodologia tem como propósito único a comparação das elasticidades'renda' do dispêndio em alimentos entre os dois métodos. Sendo essas elasticidades um dos principais sub-produtos dos modelos de estimação de demanda, julga-se relevante contrastar os resultados de uma metodologia que privilegia a análise do comportamento individual dos consumidores à que avalia o seu comportamento médio.

No Brasil, a estimação com dados médios tem sido uma tradição, já que somente nos anos mais recentes os resultados das pesquisas primárias tem sido disponibilizados na sua íntegra.

\subsection{A pesquisa de Orçamentos Familiares 95/96}

O objetivo precípuo da realização da Pesquisa de Orçamentos Familiares pelo IBGE é a atualização da estrutura de ponderação dos índices de preços ao consumidor calculados pela instituição. Essa estrutura nada mais é que o retrato do padrão médio de consumo da população alvo da pesquisa. 
Os dados aqui analisados referem-se aos resultados da investigação realizada entre $1^{\circ}$ de outubro de 1995 e 30 de setembro de 1996. Trata-se de um período de bom desempenho econômico e inflação cadente, marcado pela consolidação do plano de estabilização monetária implantado no ano de 1994 - o 'Plano Real'. As taxas de crescimento real do Produto Interno Bruto do país foram de 5,9\%, 4,2\% e 2,7\% para os anos de 1994, 95 e 96 respectivamente e, as taxas anuais de inflação, com base no IGP-DI da Fundação Getulio Vargas, foram de 2.123,6\%, $59,7 \%$ e 11,1\% para os mesmos períodos (Boletim do Banco Central do Brasil, 1999).

A POF é uma pesquisa domiciliar por amostragem, cuja unidade básica é o "Domicílio Particular Permanente"19 - podendo ser aberta para a unidade familiar, contendo inclusive algumas informações sobre as pessoas que a compõe.

A coleta de dados da pesquisa de 1995/96 se estendeu pelas regiões metropolitanas de Belém, Recife, Fortaleza, Salvador, Belo Horizonte, Rio de Janeiro, São Paulo, Curitiba e Porto Alegre, além dos municípios de Brasília-DF e Goiânia, caracterizando-se por ser eminentemente urbana.

O Plano Amostral foi delineado a partir dos resultados do Censo Demográfico de 1991, considerando dois cortes: a abrangência geográfica e a representatividade das diferentes classes de renda. Os fatores de expansão da amostra foram determinados com base na contagem populacional realizada pela instituição no ano de 1996.

A investigação de campo se estendeu por doze meses, de forma que os dados da pesquisa refletem o padrão médio anual de consumo, captando, inclusive, o perfil sazonal das variáveis tanto de consumo como de recebimento (como os itens de vestuário, 13o salário, bônus, etc.). Todos os registros de 'valor' da POF foram reportados na forma de dados 'anuais', com data base em 16 de setembro de 1996 (corrigidos da data de registro até esse dia pelo Índice Nacional de Preços ao Consumidor - INPC/IBGE).

No acompanhamento junto aos entrevistados, os pesquisadores obtinham inicialmente informações sobre o domicílio e seus moradores, para apenas então serem registradas as despesas e os recebimentos. Alguns dados de 'valor' foram obtidos através de questionários, recorrendo à memória dos entrevistados (como as despesas com a habitação e com a aquisição

\footnotetext{
${ }^{19}$ Para o IBGE, um domicílio é uma moradia, estruturalmente separada e independente, constituída por um ou mais cômodos, sendo que a condição de separação de despesas e independência de acesso devem ser satisfeitas. O Domicílio Particular Permanente destina-se à moradia de uma ou mais pessoas, ligadas por laços de parentesco, dependência doméstica ou normas de convivência, sendo todo ou parte destinado à moradia. A POF pesquisou somente Domicílios Particulares Permanentes (IBGE, 1997).
} 
de bens duráveis; assim como dados de rendimentos, recebimentos e as respectivas deduções e encargos); e outros foram registrados num sistema de 'caderneta', onde os próprios moradores dos domicilios anotavam suas despesas.

Os registros de dispêndio com produtos alimentares, de limpeza e higiene foram feitos segundo essa última metodologia. As pessoas moradoras do domicílio se comprometiam a registrar os gastos com esses produtos ao longo de 7 dias consecutivos.

\subsection{Os métodos de estimação propostos}

\subsubsection{O modelo de Seleção Amostral ou Procedimento de Heckman}

Como abordado no capítulo anterior, a proposta de análise do comportamento do consumidor a partir dos dados individuais de pesquisas de orçamentos familiares conduz à escolha de métodos específicos. Neste estudo é adotado o procedimento de Heckman para a estimação do consumo.

A pergunta que norteia a proposta metodológica de Heckman (1979), adaptada ao presente estudo é: Quem, das pessoas entrevistadas pelo IBGE, é consumidor dos alimentos em análise? Somente os que os adquiriram? E os demais? Saber 'quem' é consumidor é uma pressuposição básica para cumprir a tarefa de estimação do consumo.

Heckman (1979) trata o problema de amostras censuradas como de 'seletividade amostral' ao procurar representar o comportamento da população tomando dados de uma amostra que na verdade representaria apenas uma parte dela (uma sub-população), as estimativas de mínimos quadrados seriam tendenciosas e inconsistentes. Nessa situação, segundo o autor “(...) fitted regression functions confound the behavioral parameters of interest with parameters of the function determining the probability of entrance into the sample." (p.154).

Com o procedimento estabelecido por Heckman (1979), é possível estimar o consumo dos alimentos, considerada a probabilidade de eles serem adquiridos - eliminando a tendenciosidade derivada da seleção amostral.

Nas seções que se seguem o modelo será apresentado formalmente, assim como o método de estimação e outras questões relevantes para a análise dos resultados em geral. 


\subsubsection{O problema formal}

O desafio imposto pela estimação de um modelo com a variável dependente censurada é o de adotar um método que leve a que a esperança dos desvios seja nula. Como pôde ser observado na figura 1 , exibida no segundo capítulo, o ponto médio da distribuição de uma variável normal é deslocado quando a amostra é censurada.

Pela metodologia de Heckman (1979), o problema proposto será dado por um sistema de duas equações:

$$
\left\{\begin{array}{l}
c_{h}=\boldsymbol{\beta}^{\prime} \mathbf{x}_{h}+u_{h}, \\
a_{h}=\gamma^{\prime} \mathbf{z}_{h}+\varepsilon_{h} .
\end{array}\right.
$$

Onde,

$c_{h}$ é o 'consumo' per capita do i-ésimo produto alimentar pelo consumidor da $h$-ésima família, que seria dado pelo vetor de características $\left(\mathbf{x}_{h}\right)$ dessa família mais um desvio $\left(u_{h}\right) ; \mathrm{e}$,

$a_{h}$ é a 'aquisição' do i-ésimo produto alimentar pela $h$-ésima família, que seria dảda pelo vetor de características $\left(\mathbf{z}_{h}\right)$ dessa família mais um desvio $\left(\varepsilon_{h}\right)$.

Como nem todas as $n$ famílias da amostra apresentaram informações de 'consumo' (a variável dependente $c_{h}$ ), tem-se que a função de regressão para os dados disponíveis será:

$E\left(c_{h} \mid \mathbf{x}_{h}\right.$, regra de seleção amostral $)=\boldsymbol{\beta}^{\prime} \mathbf{x}_{h}+E\left(u_{h} \mid\right.$ regra de seleção amostral $)$

Se o comportamento dos dados de consumo $\left(c_{h}\right)$ for dado pelo da aquisição $\left(a_{h}\right)$, tal que a informação de consumo só seja disponível quando a aquisição for positiva, e admitindo-se que $u_{h}$ e $\varepsilon_{h}$ apresentam densidade conjunta, então a esperança do erro da função consumo será dada por:

$$
\begin{aligned}
E\left(u_{h} \mid \text { regra de seleção amostral }\right) & =E\left(u_{h} \mid \mathbf{x}_{h}, a_{h}>0\right) \\
& =E\left(u_{h} \mid \mathbf{x}_{h}, \varepsilon_{h}>-\gamma \mathbf{z}_{h}\right)
\end{aligned}
$$


Assim, o valor médio esperado para a variável consumo $\left(c_{h}\right)$ será dado por $^{20}$ :

$E\left(c_{h} \mid \mathbf{x}_{h}, a_{h}>0\right)=\boldsymbol{\beta}^{\prime} \mathbf{x}_{h}+E\left(u_{h} \mid \varepsilon_{h}>-\gamma^{\prime} \mathbf{z}_{h}\right)$

Note-se que se houvesse independência entre $u_{h}$ e $\varepsilon_{h}$ então as informações de $c_{h}$ teriam se 'perdido' de forma aleatória e a média condicional de $u_{h}$ seria zero. Assim estaria descaracterizado o problema de seleção amostral.

Em Greene (2000, p.927), pode-se verificar que o valor médio esperado da distribuição normal 'acidentalmente truncada' conjunta de duas variáveis $y$ e $z$, com médias $\mu_{y}$ e $\mu_{z}$, desvios padrões $\sigma_{y}$ e $\sigma_{z}$ e correlação $\rho$, é dado por:

$$
E[y \mid z>t]=\mu_{y}+\rho \sigma_{y} \lambda\left(\alpha_{z}\right)
$$

Onde $\quad t$ representa o ponto de 'truncagem' da amostra;

$$
\begin{aligned}
& \alpha=\frac{t-\mu}{\sigma}, \quad \text { sendo } \alpha_{z}=\left(\frac{t-\mu_{z}}{\sigma_{z}}\right) ; \\
& \lambda(\alpha)=\frac{\phi(\alpha)}{1-\Phi(\alpha)} \text { para a 'truncagem' } z>t, \text { sendo } \phi(\alpha) \text { a densidade de }
\end{aligned}
$$

probabilidade da variável normal reduzida e $\Phi(\alpha)$ a função distribuição da variável normal reduzida.

A variável $\lambda$ é conhecida tanto por 'inverso da razão de Mills' como 'hazard rate'. Segundo Heckman (1979), trata-se de uma função monotônicamente decrescente da probabilidade de uma observação ser selecionada na amostra.

\footnotetext{
${ }^{20}$ Neste ponto é fácil compreender a diferença entre o método de dois estágios e o 'Tobit'. No último considera-se um problema univariado, ou seja, a restrição da censura é imposta pela própria variável $\left[E\left(c_{h} \mid c_{h}>0\right)\right]$, enquanto que no primeiro, a restrição é dada por uma segunda variável $\left[E\left(c_{h} \mid \mathbf{x}_{h}\right.\right.$, dada a regra de seleçãoamostral $\left.)=E\left(c_{h} \mid \mathbf{x}_{h}, a_{h}\right)\right]$, denotando um problema bivariado. Nas palavras de Heckman (1979) e sendo feitas as devidas adaptações de nomenclatura : '... the model just outlined contains a variety of previous models as special cases. For example, if $h\left(u_{h}, \varepsilon_{h}\right)$ is assumed to be a singular normal density $\left(\mathrm{u}_{h} \equiv \varepsilon_{h}\right)$ and $\mathbf{x}_{h} \equiv \mathbf{z}_{h}, \beta \equiv \gamma$, the "Tobit" model emerges' (p.155)
} 
Assim, considerando que os desvios ( $u_{h}$ e $\varepsilon_{h}$ ) apresentam distribuição normal bivariada, com média zero e correlação $\rho$, e que o ponto de 'truncagem' da amostra é zero, segue que (Greene, 2000, p.929):

$$
\begin{aligned}
E\left[c_{h} \mid c_{h} \text { é observável }\right] & =E\left[c_{h} \mid a_{h}>0\right] \\
& =E\left[c_{h} \mid \varepsilon_{h}>-\gamma^{\prime} \mathbf{z}_{h}\right] \\
& =\boldsymbol{\beta}^{\prime} \mathbf{x}_{h}+E\left[u_{h} \mid \varepsilon_{h}>-\gamma^{\prime} \mathbf{z}_{h}\right] \\
& =\boldsymbol{\beta}^{\prime} \mathbf{x}_{h}+\rho \sigma_{u} \lambda_{h}\left(\alpha_{\varepsilon}\right) \\
& =\boldsymbol{\beta}^{\prime} \mathbf{x}_{h}+\beta_{\lambda} \lambda_{h}\left(\alpha_{\varepsilon}\right)
\end{aligned}
$$

onde $\alpha_{\varepsilon}=\frac{-\gamma^{\prime} \mathbf{Z}_{h}}{\sigma_{\varepsilon}}$; e $\lambda\left(\alpha_{\varepsilon}\right)=\frac{\phi\left(\gamma^{\prime} \mathbf{z}_{h} / \sigma_{\varepsilon}\right)}{\Phi\left(\gamma^{\prime} \mathbf{z}_{h} / \sigma_{\varepsilon}\right)}$, pois $1-\Phi\left(-\gamma^{\prime} \mathbf{z}_{h} / \sigma_{\varepsilon}\right)=\Phi\left(\gamma^{\prime} \mathbf{z}_{h} / \sigma_{\varepsilon}\right)$

Então, o consumo per capita dos indivíduos da h-ésima família, passa a ser dado por:

$$
c_{h} \mid a_{h}>0=E\left[c_{h} \mid a_{h}>0\right]+v_{h}=\boldsymbol{\beta}^{\prime} \mathbf{x}_{h}+\beta_{\lambda} \lambda_{h}\left(\alpha_{\varepsilon}\right)+v_{h}
$$

Ou seja, a esperança do consumo do i-ésimo produto alimentar pelo $h$-ésimo consumidor não é dada somente por ' $\boldsymbol{\beta}$ ' $\mathbf{x}_{h}$ ', como seria esperado em uma regressão simples - existe mais uma variável explicativa para $c_{h}\left(0^{\prime} \lambda_{h}\right.$ '), que deve ser introduzida no modelo. Desta forma, se o problema da seletividade amostral for ignorado, a equação de estimação do consumo apresentará erro de especificação ao omitir a variável $\lambda_{h}$ e o modelo será tendencioso e inconsistente.

É importante notar que mesmo com $\lambda_{h}$ observável, as estimativas de mínimos quadrados ordinários, apesar de não tendenciosas, serão ineficientes, uma vez que o modelo é estruturalmente heterocedástico.

Estimativas consistentes dos parâmetros são propostas por Greene (2000, p.931-933). 


\subsection{A identificação do modelo}

Como para qualquer modelo de equações simultâneas, é importante analisar as condições de identificação do modelo acima apresentado. Para tanto, recorrer-se-á a Maddala (1983).

Este autor apresenta um modelo teórico com três equações, onde a primeira definiria, no caso aqui explorado, o consumo, a segunda o nível de consumo mínimo que levaria um consumidor se dispor a fazer compras, de forma que a equação de seleção amostral, a terceira, se daria no intervalo onde a diferença entre o consumo e o consumo mínimo fosse positivo - ou seja, somente seria registrado o consumo para as observações onde o consumidor tivesse o seu estoque de alimentos abaixo do nível mínimo, pois isso levaria à aquisição.

Esse sistema seria dado por:

$$
\left\{\begin{array}{lc}
c_{h}=\boldsymbol{\beta}^{\prime} \mathbf{x}_{h}+u_{h}, & \text { Consumo } \\
C m_{h}=\boldsymbol{\omega}^{\prime} \mathbf{w}_{h}+v_{h} . & \text { Consumo Mínimo }
\end{array}\right.
$$

A regra de seleção amostral se daria de forma que:

$$
\left\{\begin{array}{l}
a_{h}=c_{h} \text { se } c_{h}>C m_{h}, \\
a_{h}=0 \text { para as demais observações. }
\end{array}\right.
$$

A identificação desse modelo se daria sob uma das seguintes opções:

1. A covariância entre os erros das equações de Consumo $\left(c_{h}\right)$ e Consumo Mínimo $\left(\mathrm{Cm}_{h}\right)$ ser nula;

2. Existir ao menos uma variável em $\mathbf{x}_{h}$ que não é incluída no vetor $\mathbf{w}_{h}$.

No modelo apresentado na seção 3.2.1.1., o nível de estoque mínimo foi assumido como 'zero', e o programa computacional a ser utilizado na sua estimação tem como opção trivial a primeira condição de identificaçãa ${ }^{21}$. Assim será adotada a pressuposição de que não existe correlação entre os desvios das equações de determinação do consumo e do estoque mínimo que

\footnotetext{
${ }^{21}$ Esse 'default' pode ser observado no manual do software 'LIMDEP', versão 7.0 (1995, p.669), na seção dos 'Switching Regression Models', onde são explícitas as pressuposições para modelos de três equações, como apresentado por Maddala para os modelos de seleção amostral (Maddala, 1983, p.228).
} 
levaria um consumidor às compras - e, as variáveis explicativas para a determinação da aquisição e do consumo serão as mesmas.

Ademais, no modelo acima a variável 'aquisição' seria dada pela diferença entre o nível observado de consumo e o consumo mínimo $\left(c_{h}-C m_{h}\right)$, sendo necessário, para que se cumprisse a segunda condição de identificação, que existisse ao menos uma variável determinante do primeiro $\left(c_{h}\right)$ que não fosse do segundo $\left(C m_{h}\right)$. Embora não tenha sido encontrada nenhuma referência ao tema, é difícil imaginar qual a variável que seria determinante do nível de consumo, que não fosse explicativa para o nível de estoque mínimo de alimentos que levaria a que um consumidor saísse às compras.

Assim, todas as variáveis consideradas explicativas do consumo $\left(c_{h}\right)$, também serão consideradas determinantes da aquisição $\left(a_{h}\right)$ : a 'renda' familiar per capita dos consumidores, o 'tamanho' das famílias, a composição etária e organização das famílias, a inserção da mulher no mercado de trabalho (mulheres que chefiam a família ou são 'cônjuge'), além da diferenciação regional e das estações do ano. Será considerada explicativa da aquisição alimentar, ainda, a variável 'nível de instrução' do chefe da família (variável que seria mais um determinante do nível de estoque mínimo de alimentos que levaria uma família às compras).

\subsection{Os efeitos Marginais}

Como observado acima, o modelo a ser estimado, dada a correção proposta por Hekman, é dado por:

$$
E\left[c_{h} \mid a_{h}>0\right]=\boldsymbol{\beta}^{\prime} \mathbf{x}_{h}+\beta_{\lambda} \lambda_{h}\left(\alpha_{\varepsilon}\right)
$$

$O$ efeito marginal da variável explicativa $x_{k}$ sobre o nível de consumo, quando ela afeta tanto a probabilidade de aquisição como o nível de consumo em si, na amostra observada, será dado por:

$$
\begin{aligned}
\frac{\partial E\left[c_{h} \mid a_{h}>0\right]}{\partial x_{k}} & =\beta_{k}+\beta_{\lambda}\left(\frac{\partial \lambda_{h}}{\partial \alpha_{\varepsilon}} \frac{\partial \alpha_{\varepsilon}}{\partial x_{k}}\right) \\
& =\beta_{k}-\gamma_{k}\left(\frac{\rho \sigma_{u}}{\sigma_{\varepsilon}}\right) \delta_{h}\left(\alpha_{\varepsilon}\right),
\end{aligned}
$$


onde $\delta_{h}\left(\alpha_{\varepsilon}\right)=\lambda_{h}^{2}-\alpha_{h} \lambda_{h}$, verificando-se que $0<\delta_{h}\left(\alpha_{\varepsilon}\right)<1$.

Verifica-se que, o efeito marginal do $k$-ésimo regressor sobre a variável consumo ' $c_{h}$ ', na amostra observada, se decompõe em duas partes: $i$. no efeito direto sobre a média do consumo das pessoas que adquiriram os alimentos, que é dado pelos $\beta_{\kappa}$; e $i i$. no efeito indireto sobre o nível de consumo das pessoas que adquiriram os alimentos, dado seu efeito sobre a probabilidade de aquisição - compreendido na função consumo através da variável $\lambda$. Assim, sendo a variável $x_{k}$ explicativa tanto do nível de consumo, como da probabilidade de aquisição, o efeito marginal total dessa variável sobre o consumo se dará pela soma dos efeitos direto e indireto (Greene, 2000 e Saha et al, 1997).

Conforme a eq. (20), o 'sinal' do efeito marginal indireto da $k$-ésima característica familiar é dado pelo simétrico do sinal do produto dos coeficientes da equação de seleção $\left(\gamma_{k}\right)$ para essa característica e da variável lambda $\left(\beta_{\lambda}=\rho \sigma_{u}\right)$. Essa 'inversão' do sinal decorre da relação decrescente entre a variável lambda e a variável normal reduzida $(z)$ - o que pode ser observado na figura 5.

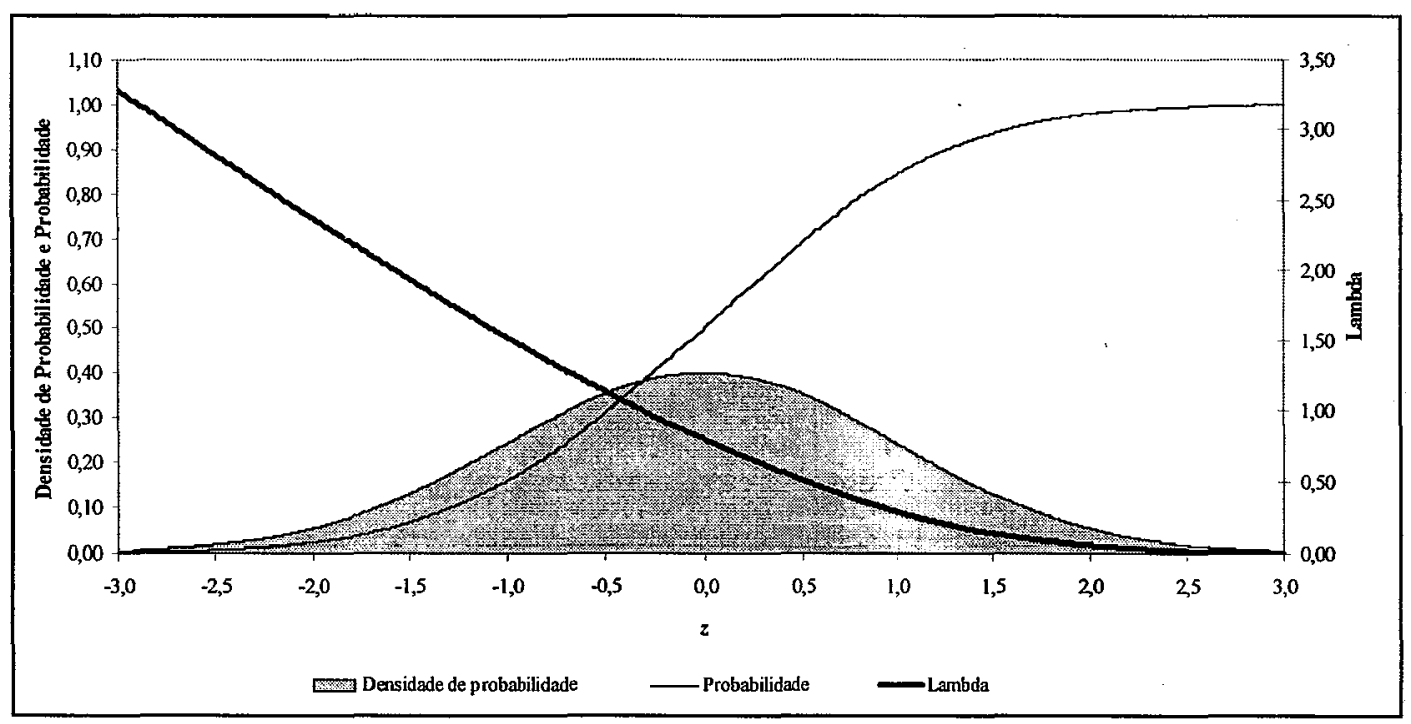

Figura 5. Distribuição da variável normal reduzida $z[\phi(z)]$, a respectiva função de distribuição $[\Phi(z)]$ e o comportamento da variável lambda $(\lambda)$

O presente estudo, tem como objetivo a análise dos efeitos das variáveis socioeconômicas sobre o consumo das pessoas em geral, e não somente sobre o consumo das pessoas que 
adquirem os alimentos. Sendo assim, será analisado o efeito marginal de uma variável $x_{k}$ sobre o valor esperado da variável consumo, e não sobre esse valor esperado apenas para as pessoas que adquirem o alimento. $O$ valor esperado do consumo para todas as pessoas é:

$$
\begin{aligned}
E\left(c_{h}\right) & =E\left[c_{h} \mid a_{h}>0\right] \times \operatorname{Pr}\left[a_{h}>0\right]+E\left[c_{h} \mid a_{h}=0\right] \times \operatorname{Pr}\left[a_{h}=0\right] \\
& =E\left[c_{h} \mid \varepsilon_{h}>-\gamma^{\prime} \mathbf{z}_{h}\right] \times\left[1-\Phi\left(\frac{-\gamma^{\prime} \mathbf{z}_{h}}{\sigma_{\varepsilon}}\right)\right]
\end{aligned}
$$

Lembrando a eq. (16), obtém - se

$E\left(c_{h}\right)=\left[\boldsymbol{\beta}^{\prime} \mathbf{x}_{h}+\beta_{\lambda} \lambda_{h}\left(\alpha_{\varepsilon}\right)\right] \times \Phi\left(\frac{\gamma^{\prime} \mathbf{z}_{h}}{\sigma_{\varepsilon}}\right)$

Assim, o efeito marginal 'ampliado' da variável explicativa $x_{k}$ sobre o consumo, no modelo proposto, seria dado por:

$$
\begin{aligned}
& \frac{\partial E\left(c_{h}\right)}{\partial x_{k}}=\frac{\partial E\left[c_{h} \mid a_{h}>0\right]}{\partial x_{k}} \times \operatorname{Pr}\left[c_{h} \mid a_{h}>0\right]+E\left[c_{h} \mid a_{h}>0\right] \times \frac{\partial \operatorname{Pr}\left[c_{h} \mid a_{h}>0\right]}{\partial x_{k}} \\
& =\left\{\left[\beta_{k}-\gamma_{k}\left(\frac{\rho \sigma_{u}}{\sigma_{\varepsilon}}\right) \delta_{h}\left(\alpha_{\varepsilon}\right)\right] \times \Phi\left(\frac{\gamma^{\prime} \mathbf{z}_{h}}{\sigma_{\varepsilon}}\right)\right\}+\left\{\left[\boldsymbol{\beta}^{\prime} \mathbf{x}_{h}+\beta_{\lambda} \lambda_{h}\left(\alpha_{\varepsilon}\right)\right] \times \phi\left(\frac{\gamma^{\prime} \mathbf{z}_{h}}{\sigma_{\varepsilon}}\right) \times \frac{\gamma_{k}}{\sigma_{\varepsilon}}\right\}
\end{aligned}
$$

Sendo $\sigma_{\varepsilon}=1$ (Greene, p.930), essa igualdade fica:

$\frac{\partial E\left(c_{h}\right)}{\partial x_{k}}=\left\{\left[\beta_{k}-\gamma_{k}\left(\frac{\rho \sigma_{u}}{\sigma_{\varepsilon}}\right) \delta_{h}\left(\alpha_{\varepsilon}\right)\right] \times \Phi\left(\gamma^{\prime} \mathbf{z}_{h}\right)\right\}+\left\{\left[\boldsymbol{\beta}^{\prime} \mathbf{x}_{h}+\beta_{\lambda} \lambda_{h}\left(\alpha_{\varepsilon}\right)\right] \times \phi\left(\gamma^{\prime} \mathbf{z}_{h}\right) \times \gamma_{k}\right\}$

Essa expressão mostra que o efeito marginal 'ampliado' da variável explicativa $x_{k}$ sobre o consumo do $h$-ésimo consumidor também é composto por dois efeitos: $i$. um primeiro, devido às variações do consumo de quem adquire o alimento, considerada a probabilidade de adquirir (com sinal igual ao do efeito marginal total da variável $x_{k}$ sobre o consumo daqueles que adquirem os alimentos); ii. um segundo, devido às variações na probabilidade de adquirir (com o sinal dado pelo efeito da variável $x_{k}$ na probabilidade de aquisição do alimento). 


\subsubsection{A estimação}

O procedimento de Heckman estabelece um processo de estimação em dois estágios (Greene, 2000, p.930):

Num primeiro estima-se a equação de seleção utilizando o modelo próbite, por máxima verossimilhança, donde obtêm-se as estimativas dos coeficientes do vetor de variáveis $\mathbf{z}_{h} \mathrm{e}$, para cada observação na amostra selecionada é computado $\hat{\lambda}\left(\alpha_{\varepsilon}\right)=\frac{\phi\left(\hat{\gamma}^{\prime} \mathbf{z}_{h} / \sigma_{\varepsilon}\right)}{\Phi\left(\hat{\gamma}^{\prime} \mathbf{z}_{h} / \sigma_{\varepsilon}\right)}$.

No segundo estágio estima-se $\beta$ e $\beta_{\lambda}$ em uma regressão de mínimos quadrados ponderados de ' $c_{h}$ ' contra $\mathbf{x}_{h}$ e $\hat{\lambda}_{h}$. O fator de ponderação é dado pelo número de pessoas das famílias, multiplicado pelos respectivos fatores de expansão.

A matriz de variâncias e covariâncias assintótica é obtida conforme apresentado em Greene (2000, p.931-933)

É importante notar que a função próbite é estimada para todas as observações da amostra, enquanto que a regressão da função consumo é estimada somente para a sub-amostra onde os dados da variável dependente são observáveis. Isto é, o consumo estimado terá como base as informações dos consumidores efetivos (aqueles que adquiriram o produto ao longo do período de acompanhamento do IBGE em suas residências), levada em consideração a probabilidade de aquisição, expressa nos $\lambda_{h}$.

A avaliação do desempenho das diferentes categorias alimentares se fará de forma individual, não constituindo um sistema de demanda.

\subsubsection{As formas funcionais}

A forma funcional da função consumo a ser estimada pelo procedimento de Heckman será a duplo-logaritmica (ou, como é mais conhecida, a log-log) adotada por Prais e Houthakker em 1955 , à qual serão incorporadas as demais variáveis explicativas. Sua especificação estocástica é dada por:

$$
\ln c_{h}=\alpha+\beta_{1} \ln y_{h}+\sum_{r=1}^{k} \beta_{r} d_{h r}+u_{h}
$$


Neste modelo, o logaritmo do dispêndio per capita com o i-ésimo produto alimentar, pelo consumidor da $h$-ésima família ( $\ln c_{h}$ ), é uma função do logaritmo da 'renda' familiar per capita $\left(\ln y_{h}\right)$ e das $k$ variáveis socioeconômicas associadas à sua família $\left(d_{h}\right)$, mais um desvio $\left(u_{h}\right)$.

O modelo $\log$-log foi escolhido por propiciar uma interpretação fácil da influência das variáveis explicativas sobre o 'consumo' - favorecendo, inclusive, a interpretação dos efeitos marginais indiretos, uma vez que todas as variáveis explicativas são singulares (não compostas, como em formas quadráticas, por exemplo). Além disso, a variável consumo na forma logarítmica arrefece o problema de heterocedasticia e aproxima a sua distribuição da normal - o dispêndio com itens alimentares tem distribuição aproximada à lognormal, tal como a renda e a despesa global, o que estimula o uso da variável no logaritmo para a estimação de modelos de regressão linear.

A principal crítica a esse modelo, além da não adequação teóriça, é que a elasticidade-renda do dispêndio é constante - dada pelo coeficiente $\beta_{1}$, não podendo expressar as variações pertinentes entre os diferentes níveis de renda pessoal.

Reformulando o problema teórico apresentado na seção 3.2.1.1., a equação de determinação da probabilidade de aquisição será dada por:

$$
\begin{aligned}
& P_{h}=\Phi\left(a_{h}\right), \\
& a_{h}=\delta+\omega \ln y_{h}+\sum_{r=1}^{k} \eta_{r} d_{h r}+\varepsilon_{h} .
\end{aligned}
$$

onde $\quad P_{h}$ é a probabilidade de a família ter adquirido o produto; $a_{h}$ é o probite correspondente a $P_{h}$; In $\mathrm{y}_{h}$ é o logaritmo da 'renda' per capita do h-ésimo consumidor; $d_{h r}, \operatorname{com} r=1, \ldots, k$, indica as $k$ variáveis socioeconômicas associadas à $h$-ésima familia.

É importante notar que a especificação de $a_{h}$ ainda é pouco explorada na literatura. Com relação à sua formulação e interpretação, Heien \& Duran (1991) dizem 'Little, if any, theoretical 
work has been done regarding the specification of $(26)^{22}$. However prices and demographic effects should play roles similar to those expected in traditional demand analysis.' (p.192).

\subsubsection{O ajustamento 'nas médias'}

Essa metodologia, em contraste com a discutida na seção 3.2.1., tem como base os dados médios amostrais, eliminando a problemática de tratamento dos dados individuais.

Na verdade essas metodologias tratam de problemas diferentes: uma procura avaliar o comportamento médio dos indivíduos - quando a amostra, pelos problemas já discutidos, deve ser tratada como censurada; outra estima o comportamento do 'indivíduo médio' da população, sendo desnecessária aquela caracterização.

Aqui, o objetivo mais específico da utilização dessa segunda metodologia será o cálculo das elasticidades-renda do dispêndio para determinados alimentos. Assim, serão determinados os valores médios de dispêndio alimentar per capita para diferentes estratos de renda familiar per capita e a relação de determinação entre a 'renda' e o consumo alimentar médio per capita serão estimados - será então uma regressão ajustada às médias dos estratos (Perez, 1973).

\subsubsection{A forma funcional e sua estimação}

O modelo a ser ajustado será o da poligonal, sugerido por Hoffmann (2000):

$\ln Y_{k}=\alpha+\beta \ln X_{k}+\sum_{h=1}^{2} \delta_{h} Z_{h k}\left(\ln X_{k}-\ln \theta_{h}\right)+U_{k}$

onde $\ln Y_{k}$ é o dispêndio médio per capita com o i-ésimo produto alimentar pelos consumidores da $k$-ésima classe de renda per capita e $X_{k}$ a renda per capita para a classe correspondente. $\theta_{h}$ é o limite superior do $h$-ésimo estrato de renda per capita, $Z_{h k}$ são variáveis binárias tais que $Z_{h k}=0$ para $X_{k} \leq \theta_{h}$ e $Z_{h k}=1$ para $X_{k}>\theta_{h}$.

Admite-se que os $U_{k}$ são erros independentes com média zero e variância inversamente proporcional ao número de famílias na classe. Assim, o ajustamento do modelo é feito por mínimos quadrados ponderados, utilizando o número de famílias por classe de renda per capita como fator de ponderação.

\footnotetext{
${ }^{22}$ Aqui foi alterado o número da equação para adaptar ao presente texto.
} 
Os três segmentos da poligonal correspondem a três grandes estratos delimitados por $\theta_{1}$ e $\theta_{2}$. Dentro do primeiro estrato $\left(X_{k} \leq \theta_{l}\right)$, a elasticidade-'renda' é igual a $\beta$, no segundo $\left(\theta_{l}<X_{k} \leq \theta_{2}\right)$ a elasticidade-renda é igual a $\beta+\delta_{1}$; e, no último $\left(X_{k}>\theta_{2}\right)$ a elasticidade será dada por $\beta+\delta_{1}+\delta_{2}$ (Hoffmann, 2000).

A elasticidade-renda média para a população será dada pela média ponderada das elasticidades obtidas por estrato, sendo o fator de ponderação a participação de cada estrato no total das despesas com o produto alimentar em questão (conforme Hoffmann, 1983).

Este modelo também não satisfaz, a priori, as pressuposições do modelo neoclássico, mas é mais flexível que o bilogarítmico $(\log -\log )$ ao permitir que a elasticidade-renda varie entre os diferentes estratos de despesa. A sua escolha deu-se pelo largo emprego na estimação de elasticidades-renda do dispêndio alimentar no Brasil. Entre outros pode-se citar Hoffmann \& Furtuoso (1981), Martins (1998) e Hoffmann (2000).

\subsection{Recursos Computacionais}

Além da disponibilidade dos dados da pesquisa primária em sua forma original, o crescente desenvolvimento e acessibilidade dos recursos computacionais são cruciais para a consecução de trabalhos como este, que se propõem a gerar estatísticas baseadas em milhares de dados.

Os softwares aqui utilizados são o SAS, para a geração dos dados selecionados e estatísticas descritivas; o LIMDEP, para a estimação dos modelos de seleção amostral; e, ainda, um programa desenvolvido pelo Professor Rodolfo Hoffmann para a estimação do modelo da poligonal.

Serão disponibilizadas, no anexo 1 , as saídas de cada um dos programas de estimação para o item 'alimentação em geral'. 


\section{RESULTADOS}

Este capítulo se aterá tanto à apresentação das variáveis analisadas, segundo os resultados da POF, seu comportamento (análise descritiva) e forma de inserção nos modelos, como à discussão dos resultados dos modelos propostos.

\subsection{A amostra e as variáveis socioeconômicas}

Embora a unidade básica da POF seja o domicílio, a referência deste estudo é a 'família' que, segundo a denominação do IBGE (IBGE, 1997, p.20), 'é a unidade constituída por um único morador ou conjunto de moradores que compartilham da mesma fonte de alimentação, isto é, que utilizam um mesmo estoque de alimentos e/ou realizam um conjunto de despesas alimentares comuns. ${ }^{23}$.

Foram entrevistadas um total de 16.060 familias nas 11 regiões analisadas. Aqui a amostra utilizada é de 16.042 famílias $^{24}$, o que representa 12.535 .724 famílias e 46.365 .681 pessoas na população.

Ter a família como unidade de referência parece ser conveniente no sentido de que as escolhas alimentares se dão de acordo com os gostos e necessidades das pessoas que dividem as decisões de consumo - e qualquer tentativa de promover mudanças nesses hábitos perpassa pela sua compreensão.

\footnotetext{
${ }^{23}$ Nessa conceituação são consideradas 'pessoas da família' a pessoa de referência, o cônjuge, os filhos, outros parentes, agregados, pensionistas, conviventes, empregados domésticos e parentes de empregados domésticos.

${ }^{24}$ Duas das famílias eliminadas não discriminaram a idade de seus componentes; 15 não declararam qualquer item de despesa em geral (contra 35 que não apresentaram declaração de renda); e a última família suprimida, apresentou nível de renda e despesas per capita muito discrepantes das demais unidades avaliadas.
} 
Assim entendendo, criou-se uma tipologia para as 'relações familiares', baseada em parte no estudo de Goldani (1990), onde a organização domiciliar será classificada em cinco categorias, segundo as pessoas residentes:

i. Familias Tradicionais: domicílios compostos pela pessoa de referência e seu cônjuge; com ou sem filhos, outros parentes e empregados (empregados domésticos e seus parentes); e sem não-parentes (agregados, pensionistas e conviventes);

ii. Novas familias: domicílios compostos pela pessoa de referência e filhos, sem cônjuge; com ou sem outros parentes e empregados (e seus parentes); e sem nãoparentes;

iii. Famílias Complexas: domicílios habitados pelos tipos familiares acima citados, incluindo obrigatoriamente a presença de não-parentes; ou a simples coabitação de parentes que não cônjuges ou filhos (com ou sem não-parentes ou empregados - e seus parentes);

iv. Domicillios Unitários: domicílios habitados somente pela pessoa de referência, com ou sem empregados (e seus parentes);

v. Outros domicílios: categoria residual.

Na população abrangida pela POF, 68,4\% das famílias classificaram-se como 'tradicionais' (8.575.053 unidades), 17,0\% como 'novas famílias' (2.128.571) e 5,4\% como 'famílias complexas' (676.861). Das unidades restantes, 8,5\% eram domicílios unitários (1.069.206) e apenas $0,7 \%$ das observações (86.033) entraram na classificação residual.

Em número de pessoas, esses percentuais passam a: 75,3\% como integrantes de 'famílias tradicionais', 17,2\% como 'novas famílias', 4,8\% como 'famílias complexas', 2,3\% moram 'sozinhos' ${ }^{25}$, restando $0,4 \%$ na classificação 'outros' domicílios.

Como já explorado, além da diferenciação dessas unidades, serão avaliadas outras características das famílias como explicativas do consumo: a discriminação do nível de renda familiar, o seu número de componentes, a composição etária, a inserção feminina no mercado de

\footnotetext{
${ }^{25} \mathrm{O}$ paralelo traçado entre os 'domicílios unitários' e pessoas que 'moram sozinhas' deve ser entendido num sentido aproximado - há a possibilidade de coabitação entre a pessoa de referência e empregados (e seus parentes).
} 
trabalho, a localização geográfica e a estação do ano em que se deu a 'aquisição' são outras características que podem auxiliar na compreensão do problema.

O 'tamanho' das famílias é dado pelo número de pessoas em cada uma delas. $O$ 'tamanho' médio das famílias das áreas investigadas pela POF foi de 3,7 pessoas.

A composição etária das famílias, por sua vez, foi caracterizada segundo faixas de idade: de 0 a 5; de 6 a 10; de 11 a 20; de 21 a 30; de 31 a 50; e mais de 51 anos. As proporções que essas faixas assumem em cada família serão usadas como variáveis que explicarão o consumo alimentar. A composição etária familiar média das regiões analisadas pode ser observada na tabela 2 .

Tabela 2. Composição etária familiar média nas 11 áreas investigadas pela POF/IBGE

\begin{tabular}{ccccccc}
\hline \multicolumn{6}{c}{ Faixas etárias } \\
\hline 0 a 5 anos & 6 a 10 anos & 11 a 20 anos & 21 a 30 anos & 31 a 50 anos mais de 51 anos \\
\hline $9,0 \%$ & $7,9 \%$ & $16,7 \%$ & $18,0 \%$ & $28,0 \%$ & $20,3 \%$ \\
\hline Fonte: Microdados/IBGE. & & & & &
\end{tabular}

Como já salientado, a inserção da mulher que chefia ou compartilha a tarefa de 'sustentar' a família com o seu cônjuge no mercado de trabalho reflete, de certa forma, uma restrição de 'tempo' de dedicação às tarefas domésticas, o que apresentaria impactos sobre o tipo de alimentação adotado pela família.

Para avaliar essa assertiva, foram identificadas as mulheres que se declararam como 'referência' ou 'cônjuge', que apresentavam ocupação remunerada. As famílias que contavam com essas mulheres aqui serão chamadas por famílias com mulheres 'que trabalham'. Na população estimada, $42,1 \%$ das famílias (5.279.656 em 12.535 .724 unidades) possuíam mulheres 'que trabalham'.

Como exposto na seção 3.1., as variáveis que denotam 'valor' apuradas pelo IBGE foram reportadas na forma de dados 'anuais', com data base em 16 de setembro de 1996. Aqui esses dados serão apresentados na forma 'mensal' (dados anuais divididos por doze), para a mesma data.

A renda, por exemplo, tem como referência os valores dos recebimentos obtidos ao longo dos seis meses anteriores à entrevista, que o IBGE multiplicou por 2, transformando-os em dados anuais - que aqui serão 'mensalizados'. Essa variável é tratada por 'recebimento' pelo IBGE e 
retrata um conceito bastante abrangente, incluindo todos os rendimentos auferidos pelos indivíduos (trabalho, transferências, aluguéis, e outros ${ }^{26}$ ).

A variável 'despesa global' ou 'desembolso global', aqui usada como proxy do que entitulouse na teoria de 'renda permanente', refere-se a todos os gastos monetários efetuados pela família com a aquisição de bens e serviços de qualquer espécie e natureza, incluindo não apenas as despesas correntes, mas também o aumento do ativo e a diminuição do passivo (IBGE, 1997, p.22). Essa variável é tida como a principal condicionante do consumo e grande parte da análise se aterá ao seu comportamento.

Os valores dos recebimentos e da despesa global médios per capita estimados foram de $\mathrm{R} \$ 435,19$ e $\mathrm{R} \$ 377,28$, respectivamente. Os valores 'per capita' aqui registrados referem-se a médias ponderadas, levando em consideração tanto o fator de expansão de cada domicílio da amostra, como o número de pessoas de cada família.

As distribuições de freqüência da despesa global per capita e do seu logaritmo podem ser observadas nas figuras $6 \mathrm{e} 7$.

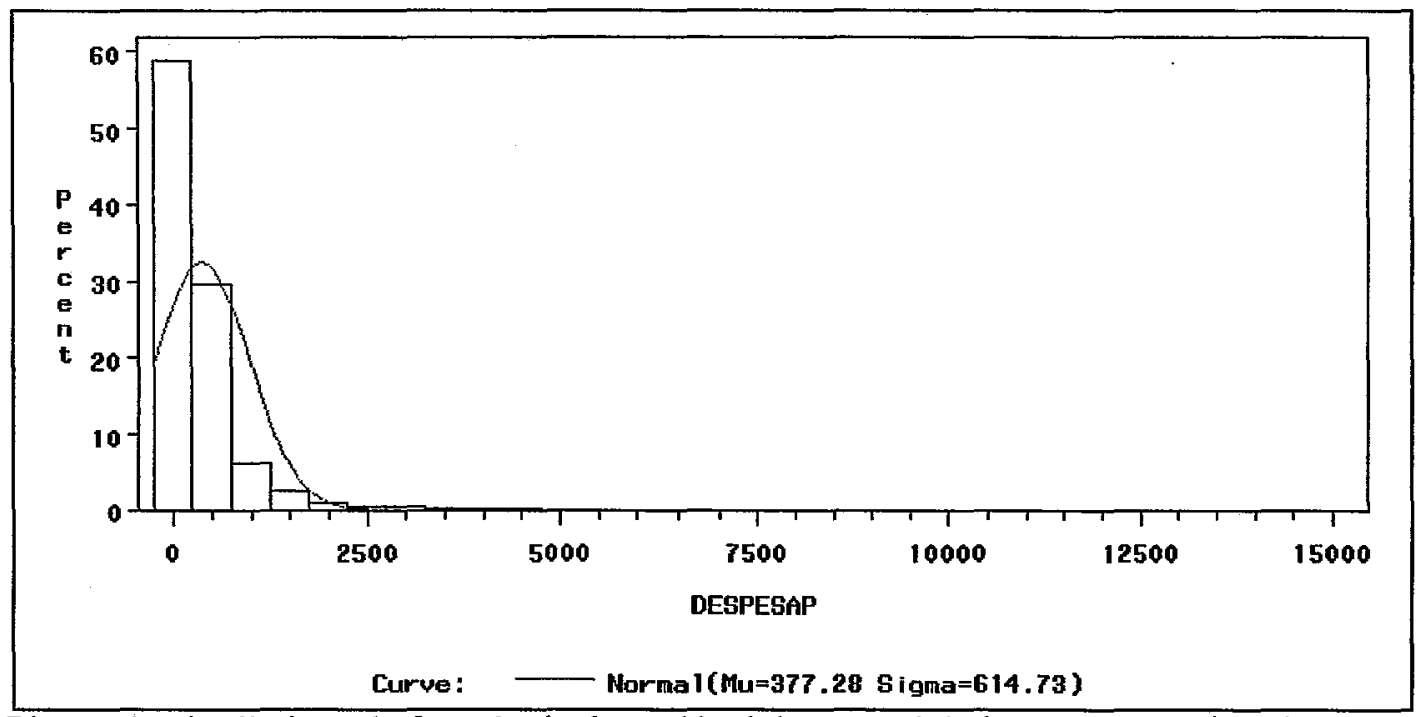

Figura 6. Distribuição de freqüência da variável despesa global per capita (R $\$$ set/96)

${ }^{26} \mathrm{O}$ IBGE, em suas publicações dos resultados da POF95/96, adotou diferentes metodologias para o estabelecimento das classes de recebimento e do recebimento médio. No primeiro caso foi computado como item do recebimento o saldo líquido dos resgates das aplicações financeiras, enquanto que para as médias são os resgates brutos que entram no cálculo, gerando médias superiores às obtidas pela primeira metodologia. Aqui foi adotada a metodologia usada para o estabelecimento das classes de recebimento. 


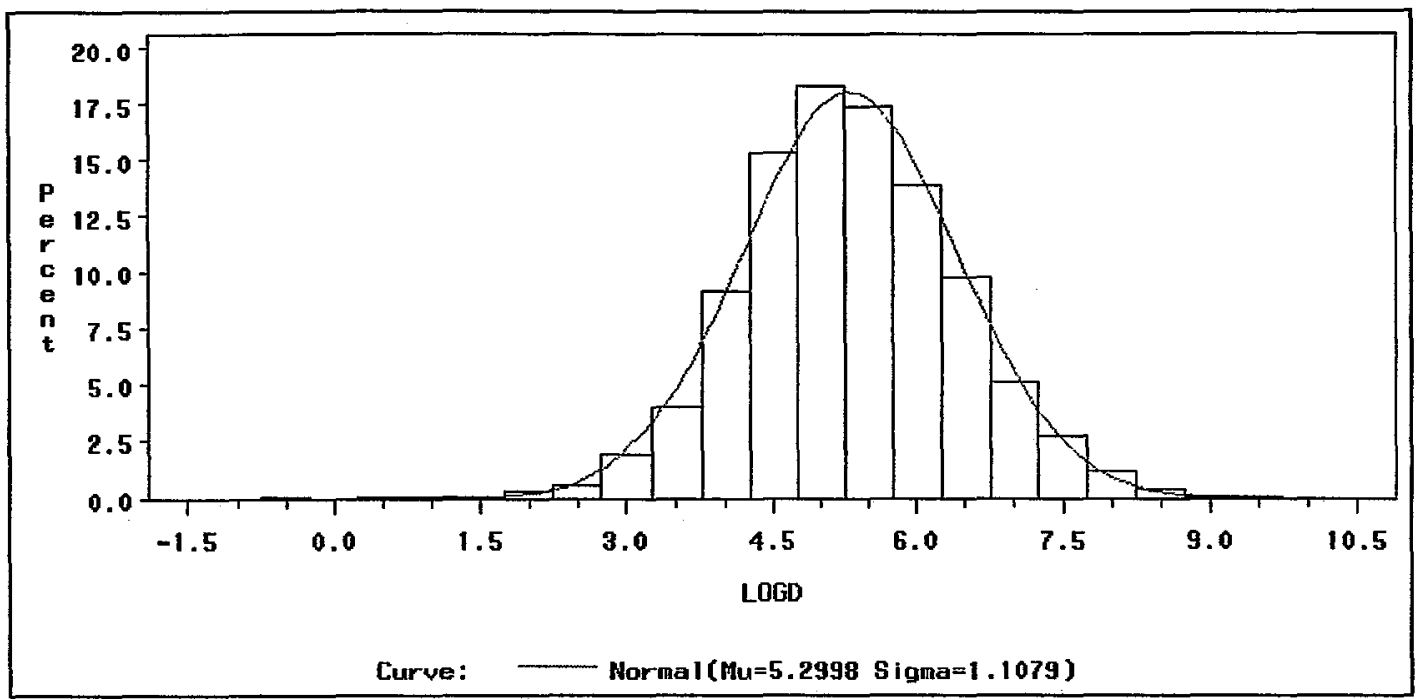

Figura 7. Distribuição de frequêencia da variável logaritmo da despesa global per capita (R\$ set/96)

Na tabela 3, observa-se a relação entre o nível de despesa global per capita, o tamanho e a composição etária familiar média. Famílias de baixos níveis de despesa global per capita tendem a ser mais numerosas e 'mais jovens' que as demais. Relações como essa destacam como a variável 'despesa global' apresenta relações com as demais - principalmente em se tratando de regiões onde a distribuição de renda é fortemente desigual, como no Brasil.

Tabela 3. O tamanho e a composição etária familiar média segundo classes de 'despesa global' per capita (em \%)

\begin{tabular}{c|c|c|c|c|c|c|c|c|c}
\hline $\begin{array}{c}\text { Percentis que } \\
\text { delimitam as } \\
\text { classes }\end{array}$ & \multirow{2}{*}{$\begin{array}{c}\text { Número de } \\
\text { famílias }\end{array}$} & $\begin{array}{c}\text { Tamanho } \\
\text { famíliar } \\
\text { médio }\end{array}$ & $\begin{array}{c}\text { 0 a } 5 \\
\text { anos }\end{array}$ & $\begin{array}{c}6 \text { a } 10 \\
\text { anos }\end{array}$ & $\begin{array}{c}11 \text { a } 20 \\
\text { anos }\end{array}$ & $\begin{array}{c}21 \text { a } 30 \\
\text { anos }\end{array}$ & $\begin{array}{c}31 \text { a } 50 \\
\text { anos }\end{array}$ & $\begin{array}{c}\text { mais de } \\
51 \text { anos }\end{array}$ \\
\hline até o $10^{\circ}$ & 965.176 & 4,8 & 16,5 & 12,6 & 20,1 & 14,5 & 20,1 & 16,3 \\
do $10^{\circ}$ ao $20^{\circ}$ & 1.048 .255 & 4,4 & 12,8 & 11,5 & 20,8 & 14,0 & 23,9 & 17,1 \\
do $20^{\circ}$ ao $30^{\circ}$ & 1.078 .857 & 4,3 & 10,5 & 10,4 & 21,6 & 14,9 & 24,7 & 18,0 \\
do $30^{\circ}$ ao $40^{\circ}$ & 1.179 .092 & 3,9 & 9,9 & 9,6 & 18,6 & 17,2 & 25,1 & 19,5 \\
do $40^{\circ}$ ao $50^{\circ}$ & 1.196 .764 & 3,9 & 11,0 & 7,7 & 18,8 & 19,2 & 25,9 & 17,3 \\
do $50^{\circ}$ ao $60^{\circ}$ & 1.271 .595 & 3,6 & 9,1 & 7,9 & 16,9 & 19,4 & 28,2 & 18,4 \\
do $60^{\circ}$ ao $70^{\circ}$ & 1.345 .075 & 3,4 & 7,4 & 7,5 & 16,0 & 18,6 & 28,7 & 21,8 \\
do $70^{\circ}$ ao $80^{\circ}$ & 1.382 .471 & 3,4 & 6,7 & 5,9 & 14,8 & 20,0 & 29,8 & 22,7 \\
do $80^{\circ}$ ao $90^{\circ}$ & 1.411 .374 & 3,3 & 5,9 & 5,7 & 15,1 & 19,7 & 33,2 & 20,3 \\
acima do $90^{\circ}$ & 1.657 .065 & 2,8 & 5,3 & 3,8 & 9,8 & 19,8 & 34,0 & 27,3 \\
\hline Média Geral & 12.535 .724 & 3,7 & 9,0 & 7,9 & 16,7 & 18,0 & 28,0 & 20,3 \\
\hline
\end{tabular}

Fonte: Microdados/IBGE.

"Intervalos fechados no limite superior 
A discriminação das estações do ano e das regiões pode caracterizar não somente a resposta dos consumidores a eventuais mudanças sazonais e regionais de preços, mas também diferentes comportamentos - o que muitas vezes pode dificultar a análise. Os consumidores do Nordeste do país, por exemplo, podem ter o hábito de comer mais frutas que os do Sul, não havendo, necessariamente, uma distinção clara de preços entre as regiões - principalmente porque esse nível de agregação permite que as frutas típicas de cada região estejam compondo o item alimentar em análise.

As regiões investigadas pela POF/IBGE foram agregadas em quatro grandes áreas: o Sul que compreende as regiões metropolitanas de Curitiba e Porto Alegre; o Sudeste que agrega a grande São Paulo, Belo Horizonte e Rio de Janeiro; o Centro-Oeste que reúne o município de Goiânia e o Distrito Federal (Brasília); e, o Nordeste, que perfaz as regiões metropolitanas de Salvador, Fortaleza, Recife e Belém. A representação de cada uma dessas áreas pode ser observada na tabela 4.

Tabela 4. POF $95 / 96$ - Número de famílias e pessoas por região.

\begin{tabular}{|c|c|c|c|c|}
\hline Regiões Investigadas & $\begin{array}{l}\text { Número de } \\
\text { famílias }\end{array}$ & $\begin{array}{c}\text { Participação } \\
(\%)\end{array}$ & $\begin{array}{c}\text { Número de } \\
\text { pessoas }\end{array}$ & $\begin{array}{c}\text { Participação } \\
(\%)\end{array}$ \\
\hline Sudeste & 8.181 .367 & 65,3 & 29.462 .731 & 63,5 \\
\hline Rio de Janeiro & 2.955 .522 & 23,6 & 10.044 .034 & 21,7 \\
\hline Belo Horizonte & 934.676 & 7,5 & 3.550 .908 & 7,7 \\
\hline São Paulo & 4.291 .169 & 34,2 & 15.867 .789 & 34,2 \\
\hline Sul & $\mathbf{1 . 5 1 3 . 8 5 4}$ & 12,1 & 5.283 .137 & 11,4 \\
\hline Porto Alegre & 913.743 & 7,3 & 3.073 .621 & 6,6 \\
\hline Curitiba & 600.111 & 4,8 & 2.209 .516 & 4,8 \\
\hline Nordeste & 2.142.094 & 17,1 & 8.950.119 & 19,3 \\
\hline Fortaleza & 572.052 & 4,6 & 2.508 .813 & 5,4 \\
\hline Recife & 715.267 & 5,7 & 2.903 .645 & 6,3 \\
\hline Belém & 210.837 & 1,7 & 943.252 & 2,0 \\
\hline Salvador & 643.938 & 5,1 & 2.594 .409 & 5,6 \\
\hline Centro-Oeste & 698.409 & 5,6 & 2.669 .694 & 5,8 \\
\hline Goiânia & 270.333 & 2,2 & 990.346 & 2,1 \\
\hline Brasília - Distrito Federal & 428.076 & 3,4 & 1.679 .348 & 3,6 \\
\hline Total & 12.535.724 & 100,0 & 46.365 .681 & 100,0 \\
\hline
\end{tabular}

"Valores expandidos.

As 'estações do ano' foram estabelecidas segundo as datas de entrevista reportadas pelo IBGE. 
Por fim, a variável 'nível de instrução' da pessoa de referência da família, associada à decisão de aquisição dos alimentos, não será considerada explicativa do nível de consumo. Isto porque os anos de estudo devem influenciar independentemente a decisão de ir às compras, mas não o nível de consumo, onde seus efeitos já estão contemplados no nível de renda das pessoas.

\subsection{Os produtos alimentares}

As informações de dispêndio alimentar referem-se a dados de despesas efetuadas ao longo de 7 dias consecutivos, registradas pelos membros das famílias investigadas. Esses dados, tãis como os demais em 'valor', também são aqui explorados na versão 'mensalizada'.

Os agregados alimentares em análise podem ser observados no quadro 1. A proposta é de procurar estabelecer as relações das variáveis socioeconômicas com padrões de alimentação 'tradicionais' e 'modernos'. A alimentação 'tradicional' se daria no domicílio, representada pelos agregados 'cereais, leguminosas e oleaginosas', 'alimentos frescos', 'proteicos' e 'leite e derivados'; e, a 'moderna' se concentraria em agregados como os 'refrigerantes', 'enlatados e conservas' e 'alimentos preparados', a serem consumidos no domicílio, e na alimentação fora do domicílio.

O nível de agregação dos produtos alimentares reflete o objetivo de avaliação genérica do padrão de consumo do brasileiro metropolitano.

Quadro 1. Os agregados alimentares e seus principais componentes

\begin{tabular}{|l|l|}
\hline Agregados Alimentares & Principais Componentes \\
\hline I. Alimentação em Geral & \\
\hline I.i. Alimentação no domicílio & \\
\hline Cereais, leguminosas e oleaginosas & Arroz e feijão \\
\hline Alimentos frescos & Tubérculos, raízes, legumes, verduras e frutas \\
\hline Alimento proteicos & $\begin{array}{l}\text { Carne bovina de primeira e segunda, de suínos, } \\
\text { frango, pescados e ovos }\end{array}$ \\
\hline Leite e derivados & Leite e queijos \\
\hline Refrigerantes & \\
\hline Enlatados e conservas & \\
\hline Alimentos preparados & Almoço e jantar \\
\hline I.ii. Alimentação fora do domicílio & $\begin{array}{l}\text { Sanduíches, salgados, sucos, refrigerantes, cervejas, } \\
\text { 'cafezinho', entre outros }\end{array}$ \\
\hline Refeições &
\end{tabular}


As despesas médias e medianas per capita com os diversos agregados alimentares estão apresentadas na tabela 5 . Como pode ser observado, os valores médios são persistentemente mais elevados que os medianos, revelando uma distribuição assimétrica à direita para todos os agregados analisados.

Tabela 5. Dispêndio médio e mediano per capita com agregados alimentares ( $\mathrm{R}$ set/96)

\begin{tabular}{lc|c}
\hline \multicolumn{1}{c}{ Tipo de despesa } & $\begin{array}{c}\text { Dispêndio médio com o } \\
\text { produto }\end{array}$ & $\begin{array}{c}\text { Dispêndio mediano com o } \\
\text { produto }\end{array}$ \\
\hline Alimentação em Geral & 62,73 & 40,55 \\
Alimentação no domicílio & 46,83 & 30,50 \\
Cereais, leguminosas e oleaginosas & 2,66 & 0,00 \\
Alimentos frescos & 5,40 & 1,67 \\
Alimentos protéicos & 11,20 & 6,94 \\
Leite e derivados & 6,76 & 3,81 \\
Refrigerantes & 1,80 & 0,00 \\
Enlatados e conservas & 0,45 & 0,00 \\
Alimentos preparados & 1,40 & 0,00 \\
Alimentação fora do domicílio & 15,90 & 3,22 \\
Refeições (Almoço ou jantar) & 8,08 & 0,00 \\
Outros & 7,82 & 1,71 \\
\hline
\end{tabular}

Fonte: Microdados/IBGE.

Os valores médios dos recebimentos e dos dispêndios per capita segundo os diferentes cortes socioeconômicos podem ser observados nas tabelas 6 a 8 . Deve-se lembrar que, a esse nível de agregação, as variáveis que denotam 'despesa' envolvem o chamado 'efeito qualidade' - os diferenciais de dispêndio muitas vezes se devem às diferenças de preços entre os pontos de venda e da qualidade dos alimentos abarcados nos agregados -, e assim, o menor dispêndio não necessariamente se materializa em menor consumo físico, tal como foi discutido na seção 2.1.2.1. $i$.

$\mathrm{Na}$ tabela 6 são exibidos os valores correspondentes às sub-amostras de famílias 'com' e 'sem' mulheres 'que trabalham'. Pode-se constatar que o nível de recebimento e de despesa global per capita do primeiro grupo é superior ao do segundo, mas uma parte pequena desse diferencial é direcionado a gastos com alimentação em geral. Entre os agregados alimentares mais específicos, o dispêndio per capita das pessoas que participam de famílias com mulheres 'que trabalham' é maior com itens mais elaborados para a alimentação no domicílio, como os 'enlatados' e os 'alimentos preparados', e com a ‘alimentação fora do domicílio'.

Vale destacar que dentro da designação de famílias com mulheres 'que trabalham' podem coexistir grupos bastante diversos. Para exemplificar, calculou-se o recebimento e despesa 
global média per capita para os sub-grupos onde as mulheres foram registradas como 'Referência' e como 'Cônjuge'. No primeiro caso, o recebimento foi de $\mathrm{R} \$ 411,02$ e a despesa global de $R \$ 361,02$, enquanto para o segundo os valores foram $R \$ 503,03$ e $R \$ 443,21$, respectivamente. Assim os dados permitem um maior detalhamento da discussão sobre o papel feminino na determinação do consumo.

Tabela 6. Recebimento e dispêndios per capita médios, segundo a inserção feminina no mercado de trabalho

\begin{tabular}{l|c|c}
\hline \multicolumn{1}{c|}{ Valores } & $\begin{array}{c}\text { Sem mulheres 'que } \\
\text { trabalham' }\end{array}$ & $\begin{array}{c}\text { Com mulheres 'que } \\
\text { trabalham' }\end{array}$ \\
\hline Recebimento & 404,44 & 476,68 \\
Despesa global & 345,69 & 419,87 \\
Alimentação em Geral & 60,21 & 66,11 \\
Alimentação no domicílio & 46,01 & 47,98 \\
Cereais, leguminosas e oleaginosas & 2,65 & 2,67 \\
Alimentos frescos & 5,30 & 5,54 \\
Alimentos proteicos & 11,03 & 11,43 \\
Leite e derivados & 6,63 & 6,95 \\
Refrigerantes & 1,74 & 1,89 \\
Enlatados e conservas & 0,40 & 0,52 \\
Alimentos preparados & 1,19 & 1,67 \\
Alimentação fora do domicílio & 14,21 & 18,13 \\
Refeições (Almoço ou jantar) & 7,20 & 9,25 \\
Outros & 7,01 & 8,87 \\
\hline
\end{tabular}

Fonte: Microdados/IBGE.

Os recebimentos e despesas globais per capita médios, por região geográfica, podem ser observados na tabela 7 . No Centro-Oeste deu-se o maior recebimento per capita médio ${ }^{27}$, e, no Sul, a maior despesa global per capita média.

A forte dispersão encontrada entre os valores de recebimentos e de despesas globais médios não se repetiu, na mesma intensidade, entre os gastos alimentares. A participação média dos gastos alimentares na despesa global, por outro lado, mostrou-se bastante diferente entre as regiões.

No Nordeste, onde o recebimento médio é acentuadamente menor que nas demais regiões, despende-se uma proporção relativamente maior do orçamento familiar com a alimentação (conforme a 'Lei de Engel'), com destaque para os alimentos a serem consumidos no domicílio.

${ }^{27}$ O maior recebimento médio no Centro-Oeste é compreensível, uma vez que a POF só compreendeu o Distrito Federal (não incluindo a periferia de Brasília) e o Município de Goiânia. 
No Sudeste, por sua vez, gasta-se mais com a alimentação fora do domicílio, tanto em termos absolutos como proporcionais.

Aqui também a análise poderia ser refinada ao considerar as regiões metropolitanas individualmente.

Tabela 7. Recebimento e dispêndios per capita médios, segundo as regiões geográficas

\begin{tabular}{lccccc}
\hline \multicolumn{1}{c|}{ Valores } & Sul & Sudeste & Centro-Oeste & Nordeste \\
\hline Recebimento & 494,20 & 473,30 & 511,77 & 252,09 \\
Despesa global & 437,24 & 406,89 & 423,72 & 230,57 \\
Alimentação em Geral & 67,69 & 65,23 & 60,17 & 52,33 \\
Alimentação no domicílio & 51,75 & 47,83 & 45,72 & 40,98 \\
Cereais, leguminosas e oleaginosas & 2,04 & 2,70 & 3,41 & 2,67 \\
Alimentos frescos & 5,42 & 5,60 & 6,10 & 4,52 \\
Alimentos proteicos & 11,97 & 10,95 & 10,37 & 11,82 \\
Leite e derivados & 7,47 & 6,91 & 6,86 & 5,81 \\
Refrigerantes & 2,68 & 1,82 & 2,02 & 1,18 \\
Enlatados e conservas & 0,65 & 0,45 & 0,38 & 0,33 \\
Alimentos preparados & 1,88 & 1,56 & 1,12 & 0,63 \\
Alimentação fora do domicílio & 15,94 & 17,40 & 14,45 & 11,35 \\
Refeições (Almoço ou jantar) & $\mathbf{8 , 5 9}$ & 9,33 & 7,30 & 3,89 \\
Outros & 7,35 & $\mathbf{8 , 0 7}$ & 7,15 & 7,46 \\
\hline
\end{tabular}

Fonte: Microdados/IBGE.

Os valores de recebimento e despesas globais per capita médios para os diferentes 'tipos' de família são apresentados na tabela 8 .

Como esperado, os níveis de recebimento e despesa global per capita médios das pessoas que 'moram sozinhas' (nos 'domicílios unitários') são superiores aos dos demais tipos familiares. A surpresa para este grupo foram os elevados gastos com a alimentação no domicílio - que ocorreram não apenas com os itens mais elaborados -, e a diferença encontrada entre o valor médio gasto por este grupo e os demais em alimentação fora do domicílio. Esses números podem decorrer tanto do 'efeito qualidade', já discutido, como das 'deseconomias de escala' do consumo alimentar associados a esse grupo - em geral o 'desperdício' é maior nas famílias menores.

Outra constatação que leva a alguma surpresa é a superação dos valores médios do recebimento e da despesa global per capita médios apurados para as 'famílias complexas' em relação às 'famílias tradicionais'. É verdade que em geral os 'não-parentes' tendem a contribuir com a renda familiar, mas, acreditava-se que esse tipo de coabitação ocorresse especialmente nos domicílios de baixa renda, o que não se verificou. 
Na tabela 9 pode-se observar a distribuição das pessoas pertencentes aos diversos tipos familiares, segundo seu nível de despesa global per capita. As pessoas de 'famílias complexas', de fato, não se concentram nos menores décimos de despesa global per capita, o que se verifica para as 'familias tradicionais'. É possível observar nesta tabela, ainda, a correlação positiva entre o nível de despesa global per capita e a proporção de 'domicílios unitários'.

Tabela 8. Recebimento e dispêndios per capita médios, segundo os tipos familiares.

\begin{tabular}{l|c|c|c|c|c}
\hline \multicolumn{1}{c|}{ Valores } & $\begin{array}{c}\text { Famílias } \\
\text { Tradicionais }\end{array}$ & $\begin{array}{c}\text { Novas } \\
\text { Famílias }\end{array}$ & $\begin{array}{c}\text { Familias } \\
\text { Complexas }\end{array}$ & $\begin{array}{c}\text { Domicílios } \\
\text { Unitários }\end{array}$ & $\begin{array}{c}\text { Outros } \\
\text { Domicílios }\end{array}$ \\
\hline Recebimento & 433,66 & 316,55 & 448,41 & $1.206,32$ & $1.130,09$ \\
Despesa global & 376,89 & 280,59 & $\mathbf{3 8 3 , 8 2}$ & $1.008,10$ & $\mathbf{8 2 3 , 1 3}$ \\
Alimentação em Geral & 62,38 & 52,88 & 62,02 & 137,25 & 122,52 \\
Alimentação no domicílio & 47,26 & 40,55 & 46,50 & 78,18 & 56,93 \\
Cereais, leguminosas e oleaginosas & 2,64 & 2,54 & 2,94 & 3,79 & 1,24 \\
Alimentos frescos & 5,49 & 4,23 & 5,35 & 11,28 & 5,11 \\
Alimentos proteicos & 11,46 & 9,42 & 10,32 & 17,28 & 14,79 \\
Leite e derivados & 6,79 & 6,03 & 6,87 & 11,15 & 5,51 \\
Refrigerantes & 1,86 & 1,47 & 1,64 & 2,74 & 1,77 \\
Enlatados e conservas & 0,45 & 0,38 & 0,45 & 0,69 & 1,03 \\
Alimentos preparados & 1,40 & 1,09 & 1,19 & 4,21 & 0,51 \\
Alimentação fora do domicílio & 15,12 & 12,33 & 15,52 & 59,08 & 65,59 \\
Refeições (Almoço ou jantar) & 7,68 & 5,38 & 6,93 & 39,28 & 30,44 \\
Outros & 7,44 & 6,95 & $\mathbf{8 , 5 9}$ & 19,79 & 35,15 \\
\hline
\end{tabular}

Fonte: Microdados/IBGE.

Tabela 9. Participação das pessoas nos 'tipos familiares', segundo as classes de despesa global per capita (em \%).

\begin{tabular}{c|c|c|c|c|c|c}
$\begin{array}{c}\text { Percentis que } \\
\text { delimitam as } \\
\text { classes }\end{array}$ & $\begin{array}{c}\text { Número de } \\
\text { pessoas }\end{array}$ & $\begin{array}{c}\text { Famílias } \\
\text { Tradicionais }\end{array}$ & $\begin{array}{c}\text { Novas } \\
\text { Famílias }\end{array}$ & $\begin{array}{c}\text { Famílias } \\
\text { Complexas }\end{array}$ & $\begin{array}{c}\text { Domicílios } \\
\text { Unitários }\end{array}$ & $\begin{array}{c}\text { Outros } \\
\text { Domicílios }\end{array}$ \\
\hline Até o $10^{\circ}$ & 4.638 .732 & 70,0 & 24,6 & 4,2 & 1,2 & 0,1 \\
do $10^{\circ}$ ao $20^{\circ}$ & 4.630 .463 & 75,0 & 20,5 & 3,6 & 1,0 & 0,0 \\
do $20^{\circ}$ ao $30^{\circ}$ & 4.640 .050 & 76,2 & 18,5 & 4,1 & 1,2 & 0,0 \\
do $30^{\circ}$ ao $40^{\circ}$ & 4.638 .509 & 75,1 & 16,9 & 5,9 & 1,8 & 0,4 \\
do $40^{\circ}$ ao $50^{\circ}$ & 4.644 .239 & 71,7 & 23,3 & 3,8 & 1,2 & 0,0 \\
do $50^{\circ}$ ao $60^{\circ}$ & 4.633 .922 & 79,0 & 13,5 & 5,4 & 1,9 & 0,2 \\
do $60^{\circ}$ ao $70^{\circ}$ & 4.635 .654 & 77,5 & 15,6 & 4,7 & 2,1 & 0,1 \\
do $70^{\circ}$ ao $80^{\circ}$ & 4.632 .642 & 76,2 & 13,8 & 5,9 & 2,8 & 1,3 \\
do $80^{\circ}$ ao $90^{\circ}$ & 4.636 .353 & 75,6 & 14,4 & 5,9 & 3,1 & 1,1 \\
Acima do $90^{\circ}$ & 4.635 .117 & 76,6 & 10,7 & 4,5 & 7,2 & 1,0 \\
\hline Média Geral 46.365 .681 & 75,3 & 17,2 & 4,8 & 2,3 & 0,4 \\
\hline Fonte: Microdados/1BGE.
\end{tabular}




\subsection{Os modelos e seu resultados}

Como já discutido no capítulo metodológico, são dois os modelos explorados neste estudo.

Inicialmente são apresentados os resultados do modelo log-log, estimado segundo o procedimento de Heckman. São comentadas as principais evidências captadas pelo modelo, como os efeitos das variáveis explicativas sobre a probabilidade de aquisição e sobre o nível de consumo, discriminando, inclusive, os efeitos marginais diretos, indiretos e totais sobre o consumo de quem adquire alimentos, assim como o efeito marginal ampliado e seus componentes: $i$. o 'efeito $\mathrm{A}$ ', que se refere à parcela da variação no consumo per capita devida às variações do consumo de quem adquire o alimento; e $i$. o 'efeito B', que se refere à parcela da variação no consumo per capita devida às variações na probabilidade de adquirir. As variáveis socioeconômicas acima levantadas, na forma que assumiram na determinação da probabilidade de aquisição e do consumo alimentar per capita são:

i. O logaritmo da despesa global familiar per capita: LNDESP, que, à partir daqui será tratado como a variável 'renda';

ii. O logaritmo do tamanho das famílias: LNTAM;

iii. A composição etária das famílias, representada pela proporção de pessoas da família em cada faixa etária. $\mathrm{O}$ grupo etário mais freqüente será eliminado do modelo para evitar a multicolinearidade perfeita ( 31 a 50 anos). Assim, ficaram na equação as variáveis: FAIXAE1 (0 a 5 anos); FAIXAE2 (6 a 10 anos); FAIXAE3 (11 a 20 anos); FAIXAE4 (21 a 30 anos); e FAIXAE6 (51 anos ou mais);

iv. A inserção da mulher no mercado de trabalho, na forma de uma variável binária, onde a categoria básica é a de famílias com mulheres 'que não trabalham'. Assim, as famílias com mulheres 'que trabalham' serão representadas pela variável MTRAB;

v. Os diferentes 'tipos' familiares, na forma de variáveis binárias, com a 'Família 'Tradicional' como base. Serão: 'Novas Famílias' - NOVASF; 'Famílias Complexas' - FCOMPLEX; 'Domicílios Unitários' - DUNITARI; 'Outros Domicílios' OUTROSDM;

vi. As regiões e estações do ano, também na forma binária, com as bases sendo a região Sudeste e o Verão. 
Na equação de determinação da 'aquisição' alimentar constará, ainda, a variável 'nível de instrução' da pessoa de referência da família (a variável 'INST'), representada por um índice do número de 'séries' escolares concluídas pela mesma (desde pessoas sem instrução - com valor 1 -, até pessoas com mestrado/doutorado completo - com valor 16).

Numa segunda sub-seção, são apresentados os resultados do modelo poligonal log-log e são confrontadas as elasticidades-'renda' do dispêndio alimentar obtidas por meio de cada um dos métodos explorados.

\subsubsection{O modelo $\log$-log}

Nas tabelas 10 e 11 são apresentados os efeitos marginais da equação de próbites e os coeficientes estimados para a função consumo. O nível de significância adotado é de até $10 \%$.

A análise dos efeitos marginais, e não dos coeficientes gerados diretamente pela regressão de próbites, deve-se ao interesse de avaliar o impacto dos regressores diretamente sobre a probabilidade de aquisição do produto. O LIMDEP, programa computacional utilizado para a estimação, gera os resultados marginais para os valores médios das variáveis explicativas.

As regressões de próbites para os diversos agregados alimentares se mostraram significativas ao nível de 1\% pelo teste qui-quadrado (LIMDEP - User's Manual, 1995, p.417), referente à hipótese de que todos os coeficientes de regressão (exceto a constante) são nulos. Isso indica que o conjunto de variáveis explicativas de fato são determinantes da aquisição de alimentos 'na semana'.

$\mathrm{Na}$ determinação do nível de consumo, os testes ' $\mathrm{F}$ ' também indicaram a significância do conjunto de variáveis explicativas para o modelo ajustado, ao nível de $1 \%$, e os coeficientes de determinação $\left(\mathrm{R}^{2}\right)$, embora aparentemente baixos, são compativeis com a natureza dos dados. 
Tabela 10. Os efeitos marginais da regressão de próbites

\begin{tabular}{|c|c|c|c|c|c|c|}
\hline Variáveis & $\begin{array}{c}\text { Alimentação } \\
\text { em Geral }\end{array}$ & $\begin{array}{l}\text { Alimentação } \\
\text { no domicílio }\end{array}$ & $\begin{array}{c}\text { Cereais, leg. e } \\
\text { oleaginosas }\end{array}$ & $\begin{array}{l}\text { Alimentos } \\
\text { frescos }\end{array}$ & $\begin{array}{c}\text { Alimentos } \\
\text { Proteicos }\end{array}$ & $\begin{array}{c}\text { Leite e } \\
\text { derivados }\end{array}$ \\
\hline Qui-Quadrado & 942,47 & 1266,39 & 1979,65 & 256,06 & 672,29 & 1797,96 \\
\hline CONSTANTE & $\begin{array}{c}-0,019^{* * *} \\
(0,007)\end{array}$ & $\begin{array}{l}-0,017^{*} \\
(0,011)\end{array}$ & $\begin{array}{l}-0,680 \\
(0,036)\end{array}$ & $\begin{array}{c}-0,653^{* \neq *} \\
(0,035)\end{array}$ & $\begin{array}{c}-0,249^{* * *} \\
(0,029)\end{array}$ & $\begin{array}{c}-0,351^{* * *} \\
(0,029)\end{array}$ \\
\hline LNDESP & $\begin{array}{l}0,015^{* * *} \\
(0,001)\end{array}$ & $\begin{array}{l}0,018^{* * *} \\
(0,001)\end{array}$ & $\begin{array}{l}0,050^{* * *} \\
(0,005)\end{array}$ & $\begin{array}{l}0,100^{* * *} \\
(0,004)\end{array}$ & $\begin{array}{l}0,059^{* * *} \\
(0,004)\end{array}$ & $\begin{array}{l}0,072^{* * *} \\
(0,004)\end{array}$ \\
\hline LNTAM & $\begin{array}{l}0,020^{* * *} \\
(0,003)\end{array}$ & $\begin{array}{l}0,036^{* * *} \\
(0,004)\end{array}$ & $\begin{array}{l}0,189^{* * *} \\
(0,012)\end{array}$ & $\begin{array}{l}0,180^{* * *} \\
(0,012)\end{array}$ & $\begin{array}{l}0,134^{* * *} \\
(0,010)\end{array}$ & $\begin{array}{l}0,124^{* * *} \\
(0,010)\end{array}$ \\
\hline FAIXAE1 & $\begin{array}{c}0,006 \\
(0,008)\end{array}$ & $\begin{array}{c}0,008 \\
(0,011)\end{array}$ & $\begin{array}{c}0,065^{*} \\
(0,036)\end{array}$ & $\begin{array}{l}-0,062^{*} \\
(0,034)\end{array}$ & $\begin{array}{l}-0,020 \\
(0,028)\end{array}$ & $\begin{array}{l}0,197^{* * *} \\
(0,029)\end{array}$ \\
\hline FAIXAE2 & $\begin{array}{l}-0,008 \\
(0,008)\end{array}$ & $\begin{array}{c}0,010 \\
(0,012)\end{array}$ & $\begin{array}{l}0,140^{* * *} \\
(0,039)\end{array}$ & $\begin{array}{l}-0,043 \\
(0,037)\end{array}$ & $\begin{array}{l}0,060^{* *} \\
(0,031)\end{array}$ & $\begin{array}{l}0,102^{* * *} \\
(0,031)\end{array}$ \\
\hline FAIXAE3 & $\begin{array}{c}-0,007 \\
(0,007)\end{array}$ & $\begin{array}{c}-0,002 \\
(0,010)\end{array}$ & $\begin{array}{c}0,043 \\
(0,031)\end{array}$ & $\begin{array}{c}-0,103^{* * *} \\
(0,030)\end{array}$ & $\begin{array}{l}0,066^{* * *} \\
(0,025)\end{array}$ & $\begin{array}{l}0,064^{* * *} \\
(0,025)\end{array}$ \\
\hline FAIXAE4 & $\begin{array}{c}-0,014^{* * *} \\
(0,005)\end{array}$ & $\begin{array}{l}-0,012^{*} \\
(0,007)\end{array}$ & $\begin{array}{c}0,005 \\
(0,023)\end{array}$ & $\begin{array}{l}-0,029 \\
(0,021)\end{array}$ & $\begin{array}{c}0,007 \\
(0,018)\end{array}$ & $\begin{array}{c}-0,026 \\
(0,018)\end{array}$ \\
\hline FAIXAE6 & $\begin{array}{l}-0,010^{6 *} \\
(0,005)\end{array}$ & $\begin{array}{c}0,005 \\
(0,007)\end{array}$ & $\begin{array}{l}0,117^{* * *} \\
(0,023)\end{array}$ & $\begin{array}{l}0,055^{* * *} \\
(0,022)\end{array}$ & $\begin{array}{c}0,026 \\
(0,018)\end{array}$ & $\begin{array}{l}0,073^{* * *} \\
(0,018)\end{array}$ \\
\hline MTRAB & $\begin{array}{c}0,004^{*} \\
(0,002)\end{array}$ & $\begin{array}{c}0,005^{*} \\
(0,003)\end{array}$ & $\begin{array}{l}0,021^{* * *} \\
(0,008)\end{array}$ & $\begin{array}{c}0,005 \\
(0,008)\end{array}$ & $\begin{array}{l}-0,001 \\
(0,007)\end{array}$ & $\begin{array}{c}0,002 \\
(0,007)\end{array}$ \\
\hline INSTR & $\begin{array}{c}-0,001^{* * *} \\
(0,000)\end{array}$ & $\begin{array}{c}-0,001^{* * *} \\
(0,000)\end{array}$ & $\begin{array}{c}-0,009^{* * *} \\
(0,001)\end{array}$ & $\begin{array}{c}-0,003^{* * *} \\
(0,001)\end{array}$ & $\begin{array}{c}-0,008^{* * *} \\
(0,001)\end{array}$ & $\begin{array}{l}-0,004^{* * *} \\
(0,001)\end{array}$ \\
\hline NOVASF & $\begin{array}{l}-0,001 \\
(0,002)\end{array}$ & $\begin{array}{l}-0,003 \\
(0,004)\end{array}$ & $\begin{array}{l}0,024^{* *} \\
(0,011)\end{array}$ & $\begin{array}{l}0,037^{* * *} \\
(0,011)\end{array}$ & $\begin{array}{c}-0,022^{* * *} \\
(0,009)\end{array}$ & $\begin{array}{c}0,014 \\
(0,009)\end{array}$ \\
\hline FCOMPLEX & $\begin{array}{c}0,009^{*} \\
(0,005)\end{array}$ & $\begin{array}{c}0,013^{*} \\
(0,007)\end{array}$ & $\begin{array}{c}0,028 \\
(0,019)\end{array}$ & $\begin{array}{c}-0,014 \\
(0,018)\end{array}$ & $\begin{array}{c}-0,057^{* * *} \\
(0,015)\end{array}$ & $\begin{array}{l}0,031^{* *} \\
(0,016)\end{array}$ \\
\hline DUNITARI & $\begin{array}{l}-0,008 \\
(0,005)\end{array}$ & $\begin{array}{c}-0,019^{* * *} \\
(0,008)\end{array}$ & $\begin{array}{c}0,039 \\
(0,033)\end{array}$ & $\begin{array}{c}0,002 \\
(0,029)\end{array}$ & $\begin{array}{c}-0,057^{* * *} \\
(0,023)\end{array}$ & $\begin{array}{l}-0,038^{*} \\
(0,023)\end{array}$ \\
\hline OUTROSDM & $\begin{array}{c}0,022 \\
(0,023)\end{array}$ & $\begin{array}{c}-0,014 \\
(0,016)\end{array}$ & $\begin{array}{c}-0,064 \\
(0,068)\end{array}$ & $\begin{array}{c}0,060 \\
(0,061)\end{array}$ & $\begin{array}{c}-0,063 \\
(0,047)\end{array}$ & $\begin{array}{l}-0,098^{* *} \\
(0,046)\end{array}$ \\
\hline SUL & $\begin{array}{l}0,008^{* *} \\
(0,003)\end{array}$ & $\begin{array}{l}0,015^{* * *} \\
(0,005)\end{array}$ & $\begin{array}{l}0,134^{* * *} \\
(0,013)\end{array}$ & $\begin{array}{l}0,192^{* * *} \\
(0,013)\end{array}$ & $\begin{array}{l}0,122^{* * *} \\
(0,011)\end{array}$ & $\begin{array}{l}0,092^{* * *} \\
(0,011)\end{array}$ \\
\hline NORDESTE & $\begin{array}{l}0,018^{* * *} \\
(0,003)\end{array}$ & $\begin{array}{l}0,025^{* * *} \\
(0,004)\end{array}$ & $\begin{array}{l}0,299^{* * *} \\
(0,011)\end{array}$ & $\begin{array}{l}0,207^{* * *} \\
(0,011)\end{array}$ & $\begin{array}{l}0,129^{* * *} \\
(0,009)\end{array}$ & $\begin{array}{c}-0,003 \\
(0,009)\end{array}$ \\
\hline COESTE & $\begin{array}{c}-0,004 \\
(0,004)\end{array}$ & $\begin{array}{c}-0,006 \\
(0,005)\end{array}$ & $\begin{array}{l}0,103^{* * *} \\
(0,017)\end{array}$ & $\begin{array}{l}0,074^{* * *} \\
(0,017)\end{array}$ & $\begin{array}{c}-0,014 \\
(0,014)\end{array}$ & $\begin{array}{l}0,047^{* * *} \\
(0,015)\end{array}$ \\
\hline PRIMAVER & $\begin{array}{l}-0,002 \\
(0,003)\end{array}$ & $\begin{array}{c}0,002 \\
(0,004)\end{array}$ & $\begin{array}{l}0,022^{* *} \\
(0,011)\end{array}$ & $\begin{array}{c}0,015 \\
(0,011)\end{array}$ & $\begin{array}{c}-0,004 \\
(0,009)\end{array}$ & $\begin{array}{c}0,001 \\
(0,009)\end{array}$ \\
\hline OUTONO & $\begin{array}{c}-0,001 \\
(0,003)\end{array}$ & $\begin{array}{c}0,004 \\
(0,004)\end{array}$ & $\begin{array}{c}-0,018 \\
(0,011)\end{array}$ & $\begin{array}{c}-0,006 \\
(0,011)\end{array}$ & $\begin{array}{c}0,004 \\
(0,009)\end{array}$ & $\begin{array}{c}-0,013 \\
(0,009)\end{array}$ \\
\hline INVERNO & $\begin{array}{c}0,002 \\
(0,003) \\
\end{array}$ & $\begin{array}{c}-0,001 \\
(0,004)\end{array}$ & $\begin{array}{c}-0,062^{* * *} \\
(0,012)\end{array}$ & $\begin{array}{c}-0,029^{* * *} \\
(0,011)\end{array}$ & $\begin{array}{l}-0,021^{* *} \\
(0,009)\end{array}$ & $\begin{array}{c}-0,005 \\
(0,009)\end{array}$ \\
\hline
\end{tabular}

Desvio padrão entre parênteses. Nível de significância: ${ }^{*+*} \alpha=1 \% ;{ }^{* *} \alpha=2 \%$ e ${ }^{*} \alpha=10 \%$. 
Tabela 10. Os efeitos marginais da regressão de próbites. Continuação

\begin{tabular}{|c|c|c|c|c|c|c|}
\hline Variáveis & Refrigerantes & $\begin{array}{l}\text { Enlatados e } \\
\text { conservas }\end{array}$ & $\begin{array}{l}\text { Alimentos } \\
\text { preparados }\end{array}$ & $\begin{array}{c}\text { Alimentação } \\
\text { fora do } \\
\text { Domicílio }\end{array}$ & $\begin{array}{l}\text { Refeições } \\
\text { (Almoço ou } \\
\text { jantar) }\end{array}$ & Outros \\
\hline Qui-Quadrado & 1185,12 & 886,62 & 407,93 & 2513,06 & 2834,15 & 1975,57 \\
\hline \multirow[t]{2}{*}{ CONSTANTE } & $-0,918^{* * *}$ & $-0,687^{* * F}$ & $-0,774^{* * 7}$ & $-1,087^{* * F}$ & $-1,542^{* * *}$ & $-0,982^{* * *}$ \\
\hline & $(0,036)$ & $(0,023)$ & $(0,023)$ & $(0,037)$ & $(0,034)$ & $(0,038)$ \\
\hline \multirow[t]{2}{*}{ LNDESP } & $0,121^{* * *}$ & $0,067^{* * *}$ & $0,084^{* * *}$ & $0,174^{* * *}$ & $0,189^{* * *}$ & $0,150^{* * *}$ \\
\hline & $(0,005)$ & $(0,003)$ & $(0,003)$ & $(0,005)$ & $(0,004)$ & $(0,005)$ \\
\hline LNTAM & $\begin{array}{l}0,114^{* * *} \\
(0,012)\end{array}$ & $\begin{array}{l}0,059^{* * *} \\
(0,008)\end{array}$ & $\begin{array}{l}0,055^{* * *} \\
(0,008)\end{array}$ & $\begin{array}{l}0,236 * * \\
(0,012)\end{array}$ & $\begin{array}{l}0,237^{* * *} \\
(0,011)\end{array}$ & $\begin{array}{l}0,220^{* * *} \\
(0,013)\end{array}$ \\
\hline \multirow[t]{2}{*}{ FAIXAE1 } & $0,067^{* * 4}$ & 0,036 & $0,108^{* * *}$ & $-0,174^{* * *}$ & $-0,169^{* * *}$ & $-0,181^{* * *}$ \\
\hline & $(0,035)$ & $(0,023)$ & $(0,022)$ & $(0,034)$ & $(0,032)$ & $(0,036)$ \\
\hline FAIXAE2 & $\begin{array}{l}0,078^{* *} \\
(0,038)\end{array}$ & $\begin{array}{c}0,046^{*} \\
(0,025)\end{array}$ & $\begin{array}{l}0,091^{* *} \\
(0,024)\end{array}$ & $\begin{array}{c}-0,120^{* * *} \\
(0,038)\end{array}$ & $\begin{array}{c}-0,266^{* * *} \\
(0,036)\end{array}$ & $\begin{array}{l}-0,065^{*} \\
(0,039)\end{array}$ \\
\hline \multirow[t]{2}{*}{ FAIXAE3 } & 0,023 & $0,041^{* *}$ & $0,061^{* * *}$ & $-0,023$ & $-0,131^{* * *}$ & $-0,034$ \\
\hline & $(0,031)$ & $(0,020)$ & $(0,019)$ & $(0,031)$ & $(0,028)$ & $(0,031)$ \\
\hline FAIXAE4 & $-0,010$ & $-0,012$ & $-0,010$ & $0,049^{* *}$ & 0,027 & $0,065^{* * *}$ \\
\hline FAIXAE6 & $\begin{array}{c}(0,022) \\
-0,079^{* * *} \\
(0,023)\end{array}$ & $\begin{array}{c}(0,014) \\
-0,006 \\
(0,015)\end{array}$ & $\begin{array}{c}(0,014) \\
-0,036^{* * *} \\
(0,014)\end{array}$ & $\begin{array}{c}(0,022) \\
-0,249^{* * *} \\
(0,022)\end{array}$ & $\begin{array}{c}(0,020) \\
-0,152^{* * *} \\
(0,021)\end{array}$ & $\begin{array}{c}(0,023) \\
-0,240^{* * *} \\
(0,023)\end{array}$ \\
\hline MTRAB & $\begin{array}{c}-0,007 \\
(0,008)\end{array}$ & $\begin{array}{l}0,010^{* *} \\
(0,005)\end{array}$ & $\begin{array}{c}-0,004 \\
(0,005)\end{array}$ & $\begin{array}{l}0,022^{* * *} \\
(0,008)\end{array}$ & $\begin{array}{l}0,018^{* *} \\
(0,007)\end{array}$ & $\begin{array}{l}0,030^{* * *} \\
(0,008)\end{array}$ \\
\hline INSTR & $\begin{array}{c}0,001 \\
(0,001)\end{array}$ & $\begin{array}{l}-0,001^{*} \\
(0,001)\end{array}$ & $\begin{array}{l}-0,001^{*} \\
(0,001)\end{array}$ & $\begin{array}{c}-0,001 \\
(0,001)\end{array}$ & $\begin{array}{l}0,002^{* * *} \\
(0,001)\end{array}$ & $\begin{array}{c}-0,004^{* * *} \\
(0,001)\end{array}$ \\
\hline NOVASF & $\begin{array}{c}-0,004 \\
(0,011)\end{array}$ & $\begin{array}{c}0,003 \\
(0,007)\end{array}$ & $\begin{array}{c}0,001 \\
(0,007)\end{array}$ & $\begin{array}{l}0,034^{* *} \\
(0,011)\end{array}$ & $\begin{array}{c}0,003 \\
(0,010)\end{array}$ & $\begin{array}{l}0,039^{* * *} \\
(0,011)\end{array}$ \\
\hline FCOMPLEX & $\begin{array}{c}-0,052^{* * * *} \\
(0,019)\end{array}$ & $\begin{array}{c}-0,006 \\
(0,012)\end{array}$ & $\begin{array}{c}-0,002 \\
(0,012)\end{array}$ & $\begin{array}{c}-0,014 \\
(0,019)\end{array}$ & $\begin{array}{l}-0,020 \\
(0,017)\end{array}$ & $\begin{array}{l}-0,003 \\
(0,019)\end{array}$ \\
\hline DUNITARI & $\begin{array}{c}-0,115^{* * *} \\
(0,033)\end{array}$ & $\begin{array}{c}-0,033 \\
(0,023)\end{array}$ & $\begin{array}{c}0,026 \\
(0,020)\end{array}$ & $\begin{array}{l}0,074^{* * *} \\
(0,031)\end{array}$ & $\begin{array}{l}0,142^{* * *} \\
(0,029)\end{array}$ & $\begin{array}{c}0,038 \\
(0,032)\end{array}$ \\
\hline OUTROSDM & $\begin{array}{l}-0,124^{* *} \\
(0,062)\end{array}$ & $\begin{array}{l}0,107^{* * *} \\
(0,032)\end{array}$ & $\begin{array}{l}-0,055 \\
(0,042)\end{array}$ & $\begin{array}{l}0,256 \\
(0,079)\end{array}$ & $\begin{array}{c}0,078 \\
(0,052)\end{array}$ & $\begin{array}{l}0,161^{* *} \\
(0,068)\end{array}$ \\
\hline SUL & $\begin{array}{l}0,162^{* * *} \\
(0,012)\end{array}$ & $\begin{array}{l}0,069^{* * *} \\
(0,007)\end{array}$ & $\begin{array}{l}0,016^{* *} \\
(0,007)\end{array}$ & $\begin{array}{l}0,080^{* * *} \\
(0,013)\end{array}$ & $\begin{array}{l}0,037^{* * *} \\
(0,011)\end{array}$ & $\begin{array}{l}0,095^{* * *} \\
(0,013)\end{array}$ \\
\hline NORDESTE & $\begin{array}{c}0,000 \\
(0,011)\end{array}$ & $\begin{array}{l}0,041^{* * *} \\
(0,007)\end{array}$ & $\begin{array}{c}0,004 \\
(0,007)\end{array}$ & $\begin{array}{l}0,185^{* * 4} \\
(0,011)\end{array}$ & $\begin{array}{l}0,036^{* * *} \\
(0,010)\end{array}$ & $\begin{array}{l}0,210^{* * *} \\
(0,011)\end{array}$ \\
\hline COESTE & $\begin{array}{c}0,000 \\
(0,017)\end{array}$ & $\begin{array}{l}-0,019^{*} \\
(0,012)\end{array}$ & $\begin{array}{l}-0,026^{* *} \\
(0,011)\end{array}$ & $\begin{array}{l}-0,029^{*} \\
(0,017)\end{array}$ & $\begin{array}{c}-0,019 \\
(0,015)\end{array}$ & $\begin{array}{c}-0,002 \\
(0,017)\end{array}$ \\
\hline PRIMAVER & $\begin{array}{c}0,004 \\
(0,011)\end{array}$ & $\begin{array}{c}-0,008 \\
(0,007)\end{array}$ & $\begin{array}{l}0,019^{* * *} \\
(0,007)\end{array}$ & $\begin{array}{l}0,049^{* * *} \\
(0,011)\end{array}$ & $\begin{array}{l}0,030^{* * *} \\
(0,010)\end{array}$ & $\begin{array}{l}0,061^{* * *} \\
(0,011)\end{array}$ \\
\hline OUTONO & $\begin{array}{c}-0,060^{* * *} \\
(0,011)\end{array}$ & $\begin{array}{c}-0,022^{* * *} \\
(0,007)\end{array}$ & $\begin{array}{c}0,001 \\
(0,007)\end{array}$ & $\begin{array}{c}-0,029^{* * *} \\
(0,011)\end{array}$ & $\begin{array}{l}0,044^{* * *} \\
(0,010)\end{array}$ & $\begin{array}{c}-0,062^{* * *} \\
(0,011)\end{array}$ \\
\hline INVERNO & $\begin{array}{c}-0,086^{* * *} \\
(0,011)\end{array}$ & $\begin{array}{c}-0,010 \\
(0,007)\end{array}$ & $\begin{array}{l}-0,002 \\
(0,007)\end{array}$ & $\begin{array}{l}-0,022^{* *} \\
(0,011)\end{array}$ & $\begin{array}{l}0,052^{* * *} \\
(0,010)\end{array}$ & $\begin{array}{c}-0,066^{* * *} \\
(0,012)\end{array}$ \\
\hline
\end{tabular}


Tabela 11. A Função Consumo $\log$-log

\begin{tabular}{|c|c|c|c|c|c|c|}
\hline Variáveis & $\begin{array}{c}\text { Alimentação } \\
\text { em Geral }\end{array}$ & $\begin{array}{l}\text { Alimentação } \\
\text { no domicílio }\end{array}$ & $\begin{array}{c}\text { Cereais, leg. e } \\
\text { oleaginosas }\end{array}$ & $\begin{array}{c}\text { Alimentos } \\
\text { frescos }\end{array}$ & $\begin{array}{c}\text { Alimentos } \\
\text { Proteicos }\end{array}$ & $\begin{array}{c}\text { Leite e } \\
\text { derivados }\end{array}$ \\
\hline $\mathrm{R}^{2}$ & 0,478 & 0,345 & 0,179 & 0,325 & 0,259 & 0,305 \\
\hline$F$ & 748 & 424 & 86 & 279 & 231 & 278 \\
\hline CONSTANTE & $\begin{array}{l}0,938^{* * 7-} \\
(0,149)\end{array}$ & $\begin{array}{l}1,280^{\text {*fF }} \\
(0,184)\end{array}$ & $\begin{array}{l}2,635^{* * *-} \\
(0,308)\end{array}$ & $\begin{array}{c}-3,125^{* * *} \\
(0,679)\end{array}$ & $\begin{array}{l}1,090^{* * *} \\
(0,148)\end{array}$ & $\begin{array}{c}-1,566^{* * *} \\
(0,317)\end{array}$ \\
\hline LNDESP & $\begin{array}{l}0,566^{* * *} \\
(0,017)\end{array}$ & $\begin{array}{l}0,482^{* * *} \\
(0,017)\end{array}$ & $\begin{array}{l}0,147^{* * *} \\
(0,015)\end{array}$ & $\begin{array}{l}0,717^{* * *} \\
(0,053)\end{array}$ & $\begin{array}{l}0,372^{* * *} \\
(0,011)\end{array}$ & $\begin{array}{l}0,559^{* * *} \\
(0,025)\end{array}$ \\
\hline LNTAM & $\begin{array}{c}-0,126^{* * *} \\
(0,036)\end{array}$ & $\begin{array}{c}-0,231^{* * *} \\
(0,044)\end{array}$ & $\begin{array}{c}-0,694^{* * *} \\
(0,061)\end{array}$ & $\begin{array}{l}-0,135 \\
(0,110)\end{array}$ & $\begin{array}{c}-0,343^{* * *} \\
(0,035)\end{array}$ & $\begin{array}{c}-0,193^{* * *} \\
(0,054)\end{array}$ \\
\hline FAIXAE1 & $\begin{array}{c}-0,091 \\
(0,089)\end{array}$ & $\begin{array}{c}0,141^{*} \\
(0,085)\end{array}$ & $\begin{array}{c}0,048 \\
(0,106)\end{array}$ & $\begin{array}{c}-0,073 \\
(0,126)\end{array}$ & $\begin{array}{c}-0,552^{* * *} \\
(0,073)\end{array}$ & $\begin{array}{l}1,115^{* * *} \\
(0,103)\end{array}$ \\
\hline FAIXAE2 & $\begin{array}{c}0,037 \\
(0,098)\end{array}$ & $\begin{array}{c}0,131 \\
(0,093)\end{array}$ & $\begin{array}{c}0,107 \\
(0,119)\end{array}$ & $\begin{array}{l}-0,249^{*} \\
(0,132)\end{array}$ & $\begin{array}{c}-0,245^{* * *} \\
(0,079)\end{array}$ & $\begin{array}{l}0,316^{* * *} \\
(0,092)\end{array}$ \\
\hline FAIXAE3 & $\begin{array}{c}0,002 \\
(0,079)\end{array}$ & $\begin{array}{c}0,117 \\
(0,075)\end{array}$ & $\begin{array}{c}0,001 \\
(0,094)\end{array}$ & $\begin{array}{c}-0,318^{* * *} \\
(0,121)\end{array}$ & $\begin{array}{c}-0,266^{* * *} \\
(0,065)\end{array}$ & $\begin{array}{l}0,164^{* *} \\
(0,072)\end{array}$ \\
\hline FAIXAE4 & $\begin{array}{c}0,070 \\
(0,059)\end{array}$ & $\begin{array}{c}-0,047 \\
(0,056)\end{array}$ & $\begin{array}{l}0,137^{* *} \\
(0,069)\end{array}$ & $\begin{array}{c}-0,316^{* * *} \\
(0,078)\end{array}$ & $\begin{array}{c}-0,227^{* * *} \\
(0,047)\end{array}$ & $\begin{array}{c}-0,058 \\
(0,050)\end{array}$ \\
\hline FAIXAE6 & $\begin{array}{l}0,233^{* * *} \\
(0,059)\end{array}$ & $\begin{array}{l}0,303^{* * *} \\
(0,055)\end{array}$ & $\begin{array}{c}-0,035 \\
(0,079)\end{array}$ & $\begin{array}{l}0,436^{* * *} \\
(0,084)\end{array}$ & $\begin{array}{c}0,046 \\
(0,047)\end{array}$ & $\begin{array}{l}0,453^{* * *} \\
(0,059)\end{array}$ \\
\hline MTRAB & $\begin{array}{l}-0,047^{* *} \\
(0,021)\end{array}$ & $\begin{array}{c}-0,084^{* * *} \\
(0,020)\end{array}$ & $\begin{array}{c}-0,037 \\
(0,025)\end{array}$ & $\begin{array}{c}-0,009 \\
(0,028)\end{array}$ & $\begin{array}{c}-0,024 \\
(0,017)\end{array}$ & $\begin{array}{c}-0,053^{* * *} \\
(0,018)\end{array}$ \\
\hline NOVASF & $\begin{array}{c}-0,006 \\
(0,028)\end{array}$ & $\begin{array}{c}-0,021 \\
(0,026)\end{array}$ & $\begin{array}{l}-0,123^{* * *} \\
(0,032)\end{array}$ & $\begin{array}{c}-0,044 \\
(0,043)\end{array}$ & $\begin{array}{c}-0,064^{* * *} \\
(0,022)\end{array}$ & $\begin{array}{c}-0,016 \\
(0,024)\end{array}$ \\
\hline FCOMPLEX & $\begin{array}{c}-0,132^{* * *} \\
(0,047)\end{array}$ & $\begin{array}{c}-0,164^{* * *} \\
(0,046)\end{array}$ & $\begin{array}{c}0,05 \\
(0,056)\end{array}$ & $\begin{array}{l}-0,154^{* *} \\
(0,065)\end{array}$ & $\begin{array}{l}-0,071^{*} \\
(0,042)\end{array}$ & $\begin{array}{l}-0,101^{* *} \\
(0,042)\end{array}$ \\
\hline DUNITARI & $\begin{array}{l}0,285^{* *} \\
(0,090)\end{array}$ & $\begin{array}{c}0,143 \\
(0,094)\end{array}$ & $\begin{array}{c}0,125 \\
(0,108)\end{array}$ & $\begin{array}{c}-0,284^{* * *} \\
(0,108)\end{array}$ & $\begin{array}{c}0,068 \\
(0,071)\end{array}$ & $\begin{array}{c}-0,094 \\
(0,076)\end{array}$ \\
\hline OUTROSDM & $\begin{array}{c}0,045 \\
(0,146)\end{array}$ & $\begin{array}{c}0,020 \\
(0,160)\end{array}$ & $\begin{array}{l}-0,296 \\
(0,232)\end{array}$ & $\begin{array}{l}-0,347^{*} \\
(0,208)\end{array}$ & $\begin{array}{c}-0,015 \\
(0,135)\end{array}$ & $\begin{array}{c}-0,409^{* * *} \\
(0,155)\end{array}$ \\
\hline SUL & $\begin{array}{c}0,022 \\
(0,032)\end{array}$ & $\begin{array}{c}0,062^{*} \\
(0,033)\end{array}$ & $\begin{array}{c}-0,744^{* * *} \\
(0,051)\end{array}$ & $\begin{array}{l}0,264^{* *} \\
(0,112)\end{array}$ & $\begin{array}{c}-0,115^{* * *} \\
(0,032)\end{array}$ & $\begin{array}{l}0,114^{* * *} \\
(0,041)\end{array}$ \\
\hline NORDESTE & $\begin{array}{l}0,132^{* * *} \\
(0,030)\end{array}$ & $\begin{array}{l}0,148^{* * *} \\
(0,031)\end{array}$ & $\begin{array}{c}-0,769^{* * *} \\
(0,077)\end{array}$ & $\begin{array}{l}0,394^{* * *} \\
(0,117)\end{array}$ & $\begin{array}{l}0,212^{* * *} \\
(0,029)\end{array}$ & $\begin{array}{c}0,018 \\
(0,023)\end{array}$ \\
\hline COESTE & $\begin{array}{l}-0,054 \\
(0,045)\end{array}$ & $\begin{array}{l}-0,022 \\
(0,043)\end{array}$ & $\begin{array}{l}-0,107^{*} \\
(0,056)\end{array}$ & $\begin{array}{l}0,180^{* * *} \\
(0,071)\end{array}$ & $\begin{array}{l}-0,005 \\
(0,036)\end{array}$ & $\begin{array}{c}-0,03 \\
(0,040)\end{array}$ \\
\hline PRIMAVER & $\begin{array}{l}0,076^{* * *} \\
(0,028)\end{array}$ & $\begin{array}{c}0,018 \\
(0,027)\end{array}$ & $\begin{array}{c}0,023 \\
(0,033)\end{array}$ & $\begin{array}{l}0,083^{* *} \\
(0,038)\end{array}$ & $\begin{array}{l}0,046^{* *} \\
(0,023)\end{array}$ & $\begin{array}{c}0,037 \\
(0,024)\end{array}$ \\
\hline OUTONO & $\begin{array}{c}-0,018 \\
(0,029)\end{array}$ & $\begin{array}{l}-0,059^{* *} \\
(0,027)\end{array}$ & $\begin{array}{c}0,063^{*} \\
(0,034)\end{array}$ & $\begin{array}{l}-0,086^{* *} \\
(0,038)\end{array}$ & $\begin{array}{c}-0,020 \\
(0,023)\end{array}$ & $\begin{array}{l}-0,047^{*} \\
(0,025)\end{array}$ \\
\hline INVERNO & $\begin{array}{l}-0,055^{*} \\
(0,029)\end{array}$ & $\begin{array}{c}-0,041 \\
(0,028)\end{array}$ & $\begin{array}{l}0,124^{* * *} \\
(0,038)\end{array}$ & $\begin{array}{c}-0,095^{* *} \\
(0,042)\end{array}$ & $\begin{array}{c}0,003 \\
(0,024)\end{array}$ & $\begin{array}{c}0,002 \\
(0,025)\end{array}$ \\
\hline LAMBDA & $\begin{array}{c}-2,473^{* * *} \\
(0,409)\end{array}$ & $\begin{array}{c}-1,838^{* * *} \\
(0,432)\end{array}$ & $\begin{array}{c}-0,788^{* * *} \\
(0,151)\end{array}$ & $\begin{array}{l}1,641^{* * *} \\
(0,397)\end{array}$ & $\begin{array}{c}-0,563^{* * 4} \\
(0,124)\end{array}$ & $\begin{array}{l}0,732^{* * *} \\
(0,253)\end{array}$ \\
\hline
\end{tabular}

Desvio padrão entre parênteses. Nivel de significância: ${ }^{* *} \alpha=1 \% ;{ }^{* *} \alpha=2 \% \mathrm{e}^{*} \alpha=10 \%$. 
Tabela 11. A Função Consumo log-log. Continuação

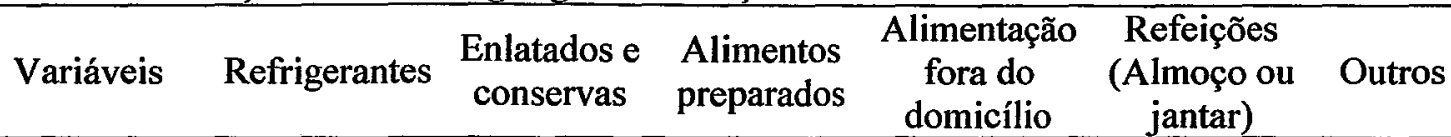

\begin{tabular}{|c|c|c|c|c|c|c|}
\hline $\mathrm{R}^{2}$ & 0,341 & 0,351 & 0,365 & 0,400 & 0,342 & 0,288 \\
\hline $\mathrm{F}$ & 159 & 60 & 56 & 364 & 118 & 206 \\
\hline \multirow[t]{2}{*}{ CONSTANTE } & $-0,529$ & $-8,431^{*}$ & $-3,085$ & $-0,543$ & $2,896^{* *}$ & 0,390 \\
\hline & $(1,305)$ & $(4,840)$ & $(4,878)$ & $(0,506)$ & $(1,501)$ & $(0,555)$ \\
\hline \multirow[t]{2}{*}{ LNDESP } & $0,419^{* * *}$ & $0,978^{* * *}$ & $0,748^{*}$ & $0,664^{* * * *}$ & $0,310^{* *}$ & $0,449^{* * *}$ \\
\hline & $(0,116)$ & $(0,364)$ & $(0,422)$ & $(0,052)$ & $(0,151)$ & $(0,052)$ \\
\hline \multirow[t]{2}{*}{ LNTAM } & $-0,539^{* * *}$ & $-0,115$ & $-0,660^{* *}$ & $-0,236^{* * *}$ & $-0,853^{* * *}$ & $-0,389^{* * *}$ \\
\hline & $(0,114)$ & $(0,353)$ & $(0,307)$ & $(0,081)$ & $(0,191)$ & $(0,088)$ \\
\hline \multirow[t]{2}{*}{ FAIXAE1 } & 0,007 & 0,508 & $-0,033$ & $-0,272^{* *}$ & $-0,075$ & $-0,134$ \\
\hline & $(0,110)$ & $(0,324)$ & $(0,570)$ & $(0,121)$ & $(0,213)$ & $(0,128)$ \\
\hline \multirow[t]{2}{*}{ FAIXAE2 } & $-0,104$ & $0,857^{* *}$ & $-0,425$ & $-0,740^{* * *}$ & $-0,192$ & $-0,533^{* * *}$ \\
\hline & $(0,121)$ & $(0,377)$ & $(0,509)$ & $(0,123)$ & $(0,282)$ & $(0,118)$ \\
\hline \multirow[t]{2}{*}{ FAIXAE3 } & $0,141^{*}$ & 0,477 & 0,113 & $-0,409^{* * *}$ & $-0,580^{* * *}$ & 0,024 \\
\hline & $(0,082)$ & $(0,322)$ & $(0,373)$ & $(0,092)$ & $(0,174)$ & $(0,093)$ \\
\hline \multirow[t]{2}{*}{ FAIXAE4 } & $0,110^{* *}$ & 0,112 & $-0,133$ & 0,034 & $-0,353^{* * *}$ & $0,195^{* * *}$ \\
\hline & $(0,057)$ & $(0,185)$ & $(0,158)$ & $(0,067)$ & $(0,099)$ & $(0,070)$ \\
\hline \multirow[t]{2}{*}{ FAIXAE6 } & $0,170^{*}$ & 0,138 & $-0,249$ & 0,043 & 0,090 & 0,022 \\
\hline & $(0,100)$ & $(0,179)$ & $(0,241)$ & $(0,109)$ & $(0,164)$ & $(0,116)$ \\
\hline \multirow[t]{2}{*}{ MTRAB } & 0,014 & 0,124 & 0,092 & $0,100^{* * *}$ & $-0,001$ & $0,075^{* * *}$ \\
\hline & $(0,021)$ & $(0,085)$ & $(0,058)$ & $(0,025)$ & $(0,041)$ & $(0,026)$ \\
\hline \multirow[t]{2}{*}{ NOVASF } & $-0,054^{* *}$ & 0,135 & $-0,057$ & 0,028 & $-0,024$ & 0,006 \\
\hline & $(0,028)$ & $(0,088)$ & $(0,075)$ & $(0,034)$ & $(0,054)$ & $(0,035)$ \\
\hline \multirow[t]{2}{*}{ FCOMPLEX } & $-0,004$ & 0,031 & $-0,05$ & $0,128^{* *}$ & 0,123 & $0,142^{* * *}$ \\
\hline & $(0,072)$ & $(0,155)$ & $(0,139)$ & $(0,058)$ & $(0,091)$ & $(0,057)$ \\
\hline \multirow[t]{2}{*}{ DUNITARI } & $-0,165$ & $-0,311$ & 0,101 & $0,566^{* * *}$ & 0,033 & $0,463^{* * *}$ \\
\hline & $(0,155)$ & $(0,335)$ & $(0,255)$ & $(0,104)$ & $(0,177)$ & $(0,106)$ \\
\hline \multirow[t]{2}{*}{ OUTROSDM } & $-0,445^{* *}$ & 0,568 & $-1,559^{* * *}$ & $-0,029$ & 0,222 & 0,076 \\
\hline & $(0,205)$ & $(0,686)$ & $(0,553)$ & $(0,171)$ & $(0,230)$ & $(0,170)$ \\
\hline \multirow[t]{2}{*}{ SUL } & 0,002 & 0,445 & $-0,308^{* * *}$ & $-0,345^{* * *}$ & $-0,233^{* * *}$ & $-0,384^{* * *}$ \\
\hline & $(0,150)$ & $(0,393)$ & $(0,111)$ & $(0,044)$ & $(0,062)$ & $(0,050)$ \\
\hline \multirow[t]{2}{*}{ NORDESTE } & $-0,129^{* * *}$ & 0,244 & $-0,418^{* * *}$ & $-0,224^{* * *}$ & $-0,400^{* * *}$ & $-0,177^{* *}$ \\
\hline & $(0,028)$ & $(0,235)$ & $(0,077)$ & $(0,061)$ & $(0,058)$ & $(0,077)$ \\
\hline \multirow[t]{2}{*}{ COESTE } & 0,01 & $-0,209$ & $-0,405^{* *}$ & $-0,156^{* * *}$ & $-0,052$ & $-0,183^{* * *}$ \\
\hline & $(0,043)$ & $(0,183)$ & $(0,190)$ & $(0,053)$ & $(0,080)$ & $(0,052)$ \\
\hline \multirow[t]{2}{*}{ PRIMAVER } & $-0,084^{* * *}$ & $-0,124$ & $0,305^{* * *}$ & $0,095^{* * *}$ & 0,020 & $0,061^{*}$ \\
\hline & $(0,027)$ & $(0,093)$ & $(0,118)$ & $(0,036)$ & $(0,058)$ & $(0,038)$ \\
\hline \multirow[t]{2}{*}{ OUTONO } & $-0,087$ & $-0,095$ & $0,186^{* *}$ & 0,034 & $-0,070$ & 0,017 \\
\hline & $(0,064)$ & $(0,154)$ & $(0,077)$ & $(0,035)$ & $(0,064)$ & $(0,041)$ \\
\hline \multirow[t]{2}{*}{ INVERNO } & $-0,177^{* *}$ & $-0,122$ & $0,372^{* * *}$ & $0,062^{\circ}$ & $-0,065$ & 0,046 \\
\hline & $(0,087)$ & $(0,102)$ & $(0,079)$ & $(0,035)$ & $(0,068)$ & $(0,042)$ \\
\hline \multirow[t]{2}{*}{ LAMBDA } & 0,151 & 2,148 & 0,754 & $-0,658^{* * *}$ & $-0,640^{*}$ & $-0,673^{* * *}$ \\
\hline & $(0,534)$ & $(1,363)$ & $(1,204)$ & $(0,224)$ & $(0,361)$ & $(0,255)$ \\
\hline
\end{tabular}


O número de famílias para as quais foi observada a aquisição, e o previsto pelo modelo - à partir das variáveis socioeconômicas -, pode ser observado na tabela 12 . Em geral o número previsto foi maior que o observado para os alimentos cuja a proporção de 'aquisições' era superior a $50 \%$, o oposto ocorrendo para os demais.

Tabela 12. Número de famílias com aquisições: número observado e número previsto, considerando a previsão para cada família.

\begin{tabular}{l|rr|rc|c|c}
\hline \multirow{2}{*}{ Tipo de despesa } & \multicolumn{3}{c|}{ Amostra } & \multicolumn{2}{c|}{ Proporção do Total } & Sinal da \\
\cline { 2 - 6 } & Observada & Prevista & Observada & Prevista & $\begin{array}{l}\text { Previsão } \\
\text { plimentação em geral }\end{array}$ \\
\hline Alimentação no Domicílio & 15.577 & 16.037 & 97,1 & 100,0 & + \\
Cereais, leguminosas e oleaginosas & 75.287 & 16.040 & 95,3 & 100,0 & + \\
Alimentos frescos & 7.499 & 6.394 & 46,7 & 39,9 & - \\
Alimentos proteicos & 11.019 & 14.303 & 68,7 & 89,2 & + \\
Leite e derivados & 12.577 & 15.578 & 78,4 & 97,1 & + \\
Refrigerantes & 12.086 & 15.532 & 75,3 & 96,8 & + \\
Enlatados e conservas & 5.846 & 2.721 & 36,4 & 17,0 & - \\
Alimentos preparados & 2.110 & 20 & 13,2 & 0,1 & - \\
Alimentação fora do domicílio & 1.877 & 62 & 11,7 & 0,4 & - \\
Refeições (Almoço ou jantar) & 10.417 & 12.491 & 64,9 & 77,9 & + \\
Outros & 4.324 & 2.324 & 27,0 & 14,5 & - \\
\hline
\end{tabular}

Fonte: Microdados/IBGE.

*Amostra integral: 16.042 observações.

O ajuste do modelo de próbites vai se refletir na estimação do nível de consumo através da variável lambda $(\lambda)$.

Segundo Heckman $(1979$, p.158) o teste ' $t$ ' para o coeficiente dessa variável poderia ser usado para avaliar a hipótese da 'não ocorrência' de seleção amostral. Todos os alimentos 'modernos' a serem consumidos no domicílio ('refrigerantes', 'enlatados', 'alimentos preparados') apresentaram esses coeficientes não significativos. Os níveis de significância mínimos a que essa hipótese seria rejeitada seriam: refrigerantes: 77,7\%; enlatados e conservas: 11,5\%; alimentos preparados: 53,1\%. Dada a construção teórica e a natureza da base de dados, é possível imaginar que esse resultado deriva da dificuldade de estimação da probabilidade de aquisição com base em dados socioeconômicos, e não da falsidade da hipótese de ocorrência de seleção amostral. É relevante notar que esses agregados alimentares foram os que apresentaram menor número de aquisições positivas. 
Os coeficientes da variável lambda foram negativos para a maior parte dos alimentos - sendo exceção os agregados 'alimentos frescos' e 'leite e derivados', além dos produtos que apresentaram resultados não significativos. $O$ efeito negativo significa que os fatores não mensurados que elevam a probabilidade de aquisição desses alimentos tendem a reduzir o nível de consumo das pessoas (dado que $\beta_{\lambda}=\rho \sigma_{u}$ ).

Vale ressaltar, ainda, que os efeitos marginais são estimados à partir dos resultados médios obtidos.

\subsubsection{O efeito da variável 'nível de instrução' sobre probabilidade de aquisição alimentar}

O nível de instrução da pessoa de referência da família tem, em geral, efeito negativo e significativo sobre a probabilidade de aquisição de alimentos a serem consumidos 'no domicílio'. Assim, pessoas de famílias com 'chefes' de maior nível de escolaridade devem concentrar suas compras ao longo do tempo, diminuindo a freqüência de aquisições semanais - o que ocorre em maior grau para os alimentos 'tradicionais' a serem consumidos 'nos domicílios' do que para os 'modernos'.

Para a 'alimentação fora do domicílio', por outro lado, quanto maior o nível de instrução do chefe da família, mais se faz 'refeições fora do domicílio' e menos se adquire os 'outros' alimentos.

\subsubsection{O efeito da variável 'renda'}

O efeito da variável 'renda' (aqui expressa pelo logaritmo da despesa global per capita) sobre a probabilidade de aquisição de todos os grupos alimentares analisados é positivo e significativo. Quanto maior a 'renda', maior a probabilidade de aquisição desses produtos.

Conforme os coeficientes apresentados na tabela 10, variações na 'renda' têm um impacto mais forte sobre a freqüência da alimentação fora do domicílio (principalmente sobre as 'refeições' feitas fora de casa) do que sobre as aquisições de alimentos a serem consumidos no domicílio. Para essa última categoria, as diferenças encontradas entre os coeficientes dos alimentos 'tradicionais' e 'modernos' não foram muito grandes - poderia-se imaginar que os alimentos 'modernos', por serem produtos mais caros, seriam comprados mais amiúde, mas, por 
outro lado, os 'tradicionais' estão associados a uma maior perecibilidade, o que poderia ter eliminado eventuais diferenças no efeito da renda sobre a freqüência das aquisições.

Na função consumo $\log$-log, o coeficiente da variável renda é a própria elasticidade-renda direta do dispêndio. Na tabela 13 podem ser observadas as elasticidades-'renda' direta e total do dispêndio alimentar das pessoas que adquirem os alimentos, além dos sinais dos efeitos marginais indiretos. Sendo o efeito da 'renda' positivo sobre a probabilidade de aquisição, o sinal do efeito marginal indireto será dado pelo sinal da variável lambda (como discutido na seção 3.2.1.1.2.).

É interessante notar, por exemplo, que a elasticidade-'renda' total do dispêndio em refeições fora do domicílio é maior que a direta. Ou seja, quando considerado o efeito positivo da 'renda' sobre a probabilidade de aquisição de refeições fora do domicílio, assim como o efeito da própria 'probabilidade de aquisição' desses alimentos sobre o nível de consumo (expresso no coeficiente negativo da variável lambda), a elasticidade-'renda' do dispêndio com esses alimentos, pelas pessoas que os adquirem, se eleva.

Esse comportamento ocorreu para todos os alimentos que apresentaram o coeficiente da variável lambda negativo. Seria esperado que os alimentos 'modernos' a serem consumidos no domicílio também apresentassem o efeito indireto positivo. Entretanto, dada a não significância da variável Lambda para esses produtos, é difícil estabelecer conclusões à respeito.

Tabela 13. Elasticidade-'renda' do dispêndio alimentar - efeitos direto e total/ Função $\log$-log, e sinais dos efeitos marginais indiretos

\begin{tabular}{|c|c|c|c|}
\hline \multirow{2}{*}{ Tipo de despesa } & \multicolumn{2}{|c|}{ Elasticidade-despesa global } & \multirow{2}{*}{$\begin{array}{c}\text { Sinal do Efeito } \\
\text { Marginal Indireto }\end{array}$} \\
\hline & Efeito Direto & Efeito Total & \\
\hline Alimentação em geral & $0,566^{* * *}$ & 0,650 & + \\
\hline Alimentação no domicílio & $0,482^{* * *}$ & 0,551 & + \\
\hline Cereais, leguminosas e oleaginosas & $0,147^{* * *}$ & 0,214 & + \\
\hline Alimentos frescos & $0,717^{* * *}$ & 0,486 & - \\
\hline Alimentos protéicos & $0,372^{* * *}$ & 0,421 & + \\
\hline Leite e derivados & $0,559^{* * *}$ & 0,477 & - \\
\hline Refrigerantes & $0,419^{* * *}$ & 0,384 & - \\
\hline Enlatados e conservas & $0,978^{* * *}$ & 0,358 & - \\
\hline Alimentos preparados & $0,748^{*}$ & 0,458 & - \\
\hline Alimentação fora do domicílio & $0,664^{* * *}$ & 0,831 & + \\
\hline Refeições (Almoço ou jantar) & $0,310^{* *}$ & 0,610 & + \\
\hline Outros & $0,449^{* * *}$ & 0,598 & + \\
\hline
\end{tabular}

Fonte: Microdados/IBGE. Nível de significância: ${ }^{* *} \alpha=1 \%{ }^{* *} \alpha=2 \%$ e ${ }^{*} \alpha=10 \%$. 
Na tabela 14 constam os efeitos marginais ampliados e seus componentes, assim como a probabilidade de aquisição estimada pelas regressões de próbites. Pode-se observar que tanto o efeito A, como o B foram positivos, como esperado, uma vez que o efeito da renda é positivo tanto sobre o nível de consumo de quem adquire os alimentos como sobre a freqüência de compras.

É possível observar, também, que o efeito $B$ (efeito devido às variações na probabilidade de adquirir) foi proporcionalmente maior para os alimentos que apresentaram menor probabilidade de serem adquiridos.

Ao observar as figuras 8 e 9 é possível visualizar porque o efeito B da variável 'renda' sobre o consumo de alimentos de baixa freqüência de aquisição, como os alimentos preparados, é proporcionalmente mais forte que para os alimentos de amplo consumo. Apesar do resultado do modelo de seleção amostral não ter sido significativo para os 'alimentos preparados', observa-se na figura 9 que a freqüência de aquisição desses alimentos cresce sensivelmente com elevações na renda - o mesmo não ocorrendo para os alimentos em geral (figura 8).

Tabela 14. Probabilidade média de aquisição dos agregados alimentares e elasticidade-'renda' ampliada do dispêndio alimentar

\begin{tabular}{lc|ccc}
\hline & $\begin{array}{c}\text { Probabilidade de } \\
\text { aquisição (\%) }\end{array}$ & Efeito A & Efeito B & $\begin{array}{c}\text { Efeito Mg } \\
\text { Ampliado }\end{array}$ \\
\hline Alimentação em geral & 98,42 & 0,639 & 0,056 & 0,695 \\
Alimentação no domicílio & 96,96 & 0,535 & 0,062 & 0,596 \\
Cereais, leguminosas e oleaginosas & 40,09 & 0,086 & 0,068 & 0,154 \\
Alimentos frescos & 65,21 & 0,317 & 0,145 & 0,462 \\
Alimentos protéicos & 79,06 & 0,333 & 0,131 & 0,464 \\
Leite e derivados & 79,08 & 0,378 & 0,118 & 0,495 \\
Refrigerantes & 36,60 & 0,141 & 0,137 & 0,278 \\
Enlatados e conservas & 11,43 & 0,041 & 0,049 & 0,090 \\
Alimentos preparados & 10,60 & 0,049 & 0,135 & 0,183 \\
Alimentação fora do domicílio & 66,44 & 0,552 & 0,397 & 0,949 \\
Refeições (Almoço ou jantar) & 24,10 & 0,147 & 0,487 & 0,634 \\
Outros & 59,98 & 0,359 & 0,278 & 0,637 \\
\hline
\end{tabular}

Fonte: Microdados/IBGE.

*Probabilidade de aquisição média estimada 


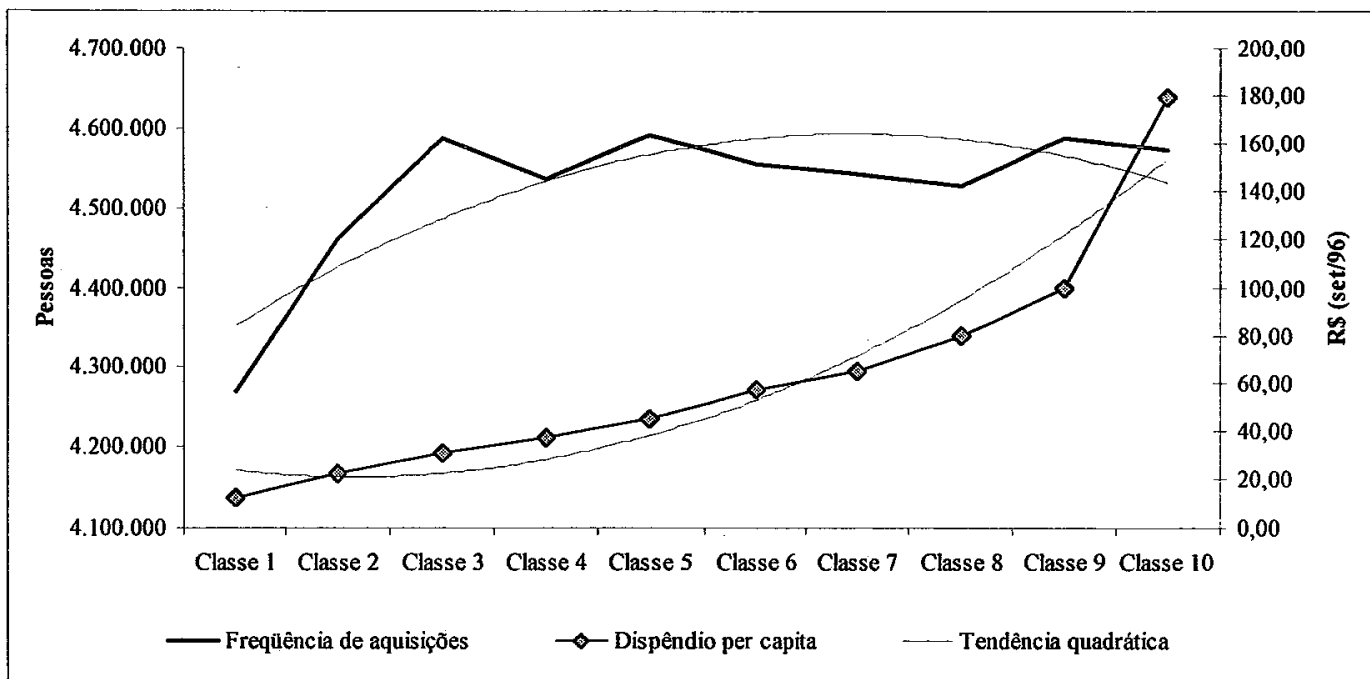

Figura 8. O dispêndio per capita e a freqüência de aquisição, dos alimentos em geral, segundo as classes de 'renda' (delimitadas pelos decis da 'renda' per capita)

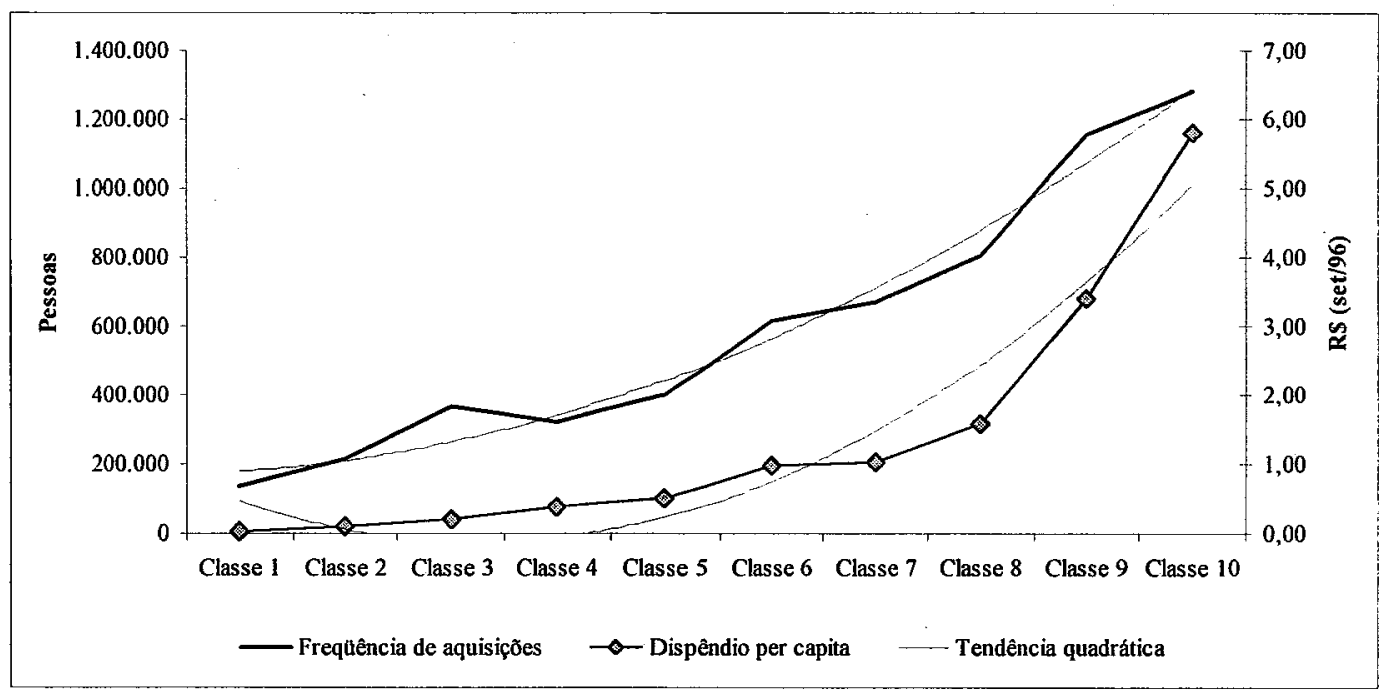

Figura 9. O dispêndio per capita e a freqüência de aquisição, dos alimentos preparados, segundo as classes de 'renda' (delimitadas pelos decis da 'renda' per capita)

\subsubsection{O efeito do 'tamanho' das famílias}

O tamanho da família afeta positivamente a probabilidade de aquisição alimentar, e negativamente o nível de consumo. Isso quer dizer que, em geral, quanto maior o tamanho da família, maior a probabilidade de aquisição 'na semana', mas, menor o nível de consumo per capita. 
O coeficiente da variável logaritmo do tamanho da família, no modelo de consumo log-log, é a própria elasticidade-escala direta do dispêndio. Assim a relação inversa entre essa variável e o nível de consumo per capita denota a existência de economias de escala no consumo familiar de alimentos de quem os adquire.

Como exposto na tabela 3 , existe uma relação negativa entre as variáveis 'tamanho da família' e despesa global per capita, o que é coerente com os sinais opostos encontrados para a elasticidade-escala e elasticidade-'renda' do dispêndio alimentar.

$\mathrm{Na}$ tabela 15 podem ser observados os sinais dos efeitos marginais indiretos sobre as elasticidades-escala do dispêndio alimentar de quem adquire alimentos (considerada a probabilidade de adquirir). Sendo positivo o efeito do tamanho da família sobre a probabilidade de aquisição, o sinal do efeito marginal indireto mais uma vez é determinado pelos efeitos da variável lambda.

Tabela 15. 'Elasticidade-escala' do dispêndio alimentar - efeitos direto e total, e sinais dos efeitos marginais indiretos

\begin{tabular}{|c|c|c|c|}
\hline \multirow{2}{*}{ Tipo de despesa } & \multicolumn{2}{|c|}{ Elasticidade-'escala' } & \multirow{2}{*}{$\begin{array}{c}\text { Sinal do Efeito } \\
\text { Marginal Indireto }\end{array}$} \\
\hline & Efeito Direto & Efeito Total & \\
\hline Alimentação em geral & $-0,126^{\text {*FF }}$ & $-0,016$ & + \\
\hline Alimentação no domicílio & $-0,231^{* * *}$ & $-0,092$ & + \\
\hline Cereais, leguminosas e oleaginosas & $-0,694^{* * *}$ & $-0,438$ & + \\
\hline Alimentos frescos & $-0,135$ & $-0,550$ & - \\
\hline Alimentos proteicos & $-0,343^{* * *}$ & $-0,231$ & + \\
\hline Leite e derivados & $-0,193^{* * *}$ & $-0,335$ & - \\
\hline Refrigerantes & $-0,539^{* * *}$ & $-0,572$ & - \\
\hline Enlatados e conservas & $-0,115$ & $-0,656$ & - \\
\hline Alimentos preparados & $-0,660^{* *}$ & $-0,849$ & - \\
\hline Alimentação fora do domicílio & $-0,236^{* * *}$ & $-0,009$ & + \\
\hline Refeições (Almoço ou jantar) & $-0,853^{* * *}$ & $-0,478$ & + \\
\hline Outros & $-0,389^{* * *}$ & $-0,170$ & + \\
\hline
\end{tabular}

$\mathrm{Na}$ tabela 16, por sua vez, constam as elasticidades escala ampliadas do consumo alimentar. Pode-se observar que as economias geradas pelo 'tamanho' das famílias que adquirem os alimentos podem ser anuladas, ou mesmo revertidas (como para a alimentação fora do domicílio), pela elevação da freqüência de aquisições.

Isso decorre do fato de que, em geral, são as famílias maiores que apresentam uma maior frequiência de aquisições de alimentos, e a 'inclusão' de outras famílias no rol de adquirentes 
('na semana') leva a que as economias de escala sejam reduzidas, ou mesmo eliminadas. Na figura 10 é possível visualizar essa relação para o agregado 'alimentação fora do domicílio'. Quem mais adquire alimentos fora do domicílio (proporcionalmente) são as pessoas de famílias de 5 ou 6 pessoas. Se mais pessoas de famílias de 3 pessoas passarem a adquirir esses alimentos, por exemplo, certamente haveria uma diminuição das economias de escala do consumo alimentar, uma vez que o gasto per capita desse grupo é superior ao verificado para as pessoas de famílias de 5 a 6 pessoas.

Deve-se notar que aqui, as discutidas 'economias' no consumo alimentar não obrigatoriamente estão associadas ao ‘desperdício' físico, uma vez que a análise está sendo feita com dados de dispêndio, e não de quantidade - o que faz com que o 'efeito qualidade' prejudique o paralelismo entre as duas situações. Entretanto, como já foi abstraído o efeito da renda sobre o nível de dispêndio, acredita-se que a aproximação entre o dispêndio e a quantidade consumida, nessa análise, seja bastante razoável.

Tabela 16. Elasticidade-escala ampliada do consumo alimentar

\begin{tabular}{l|cc|c}
\hline & Efeito A & Efeito B & $\begin{array}{c}\text { Efeito Mg } \\
\text { Ampliado }\end{array}$ \\
\hline Alimentação em geral & $-0,015$ & 0,073 & 0,058 \\
Alimentação no domicílio & $-0,089$ & 0,123 & 0,034 \\
Cereais, leguminosas e oleaginosas & $-0,176$ & 0,261 & 0,085 \\
Alimentos frescos & $-0,358$ & 0,261 & $-0,097$ \\
Alimentos protéicos & $-0,183$ & 0,297 & 0,114 \\
Leite e derivados & $-0,265$ & 0,204 & $-0,061$ \\
Refrigerantes & $-0,209$ & 0,129 & $-0,080$ \\
Enlatados e conservas & $-0,075$ & 0,043 & $-0,032$ \\
Alimentos preparados & $-0,090$ & 0,088 & $-0,002$ \\
Alimentação fora do domicílio & $-0,006$ & 0,540 & 0,535 \\
Refeições (Almoço ou jantar) & $-0,115$ & 0,609 & 0,494 \\
Outros & $-0,102$ & 0,406 & 0,304 \\
\hline
\end{tabular}

Fonte: Microdados/IBGE. 


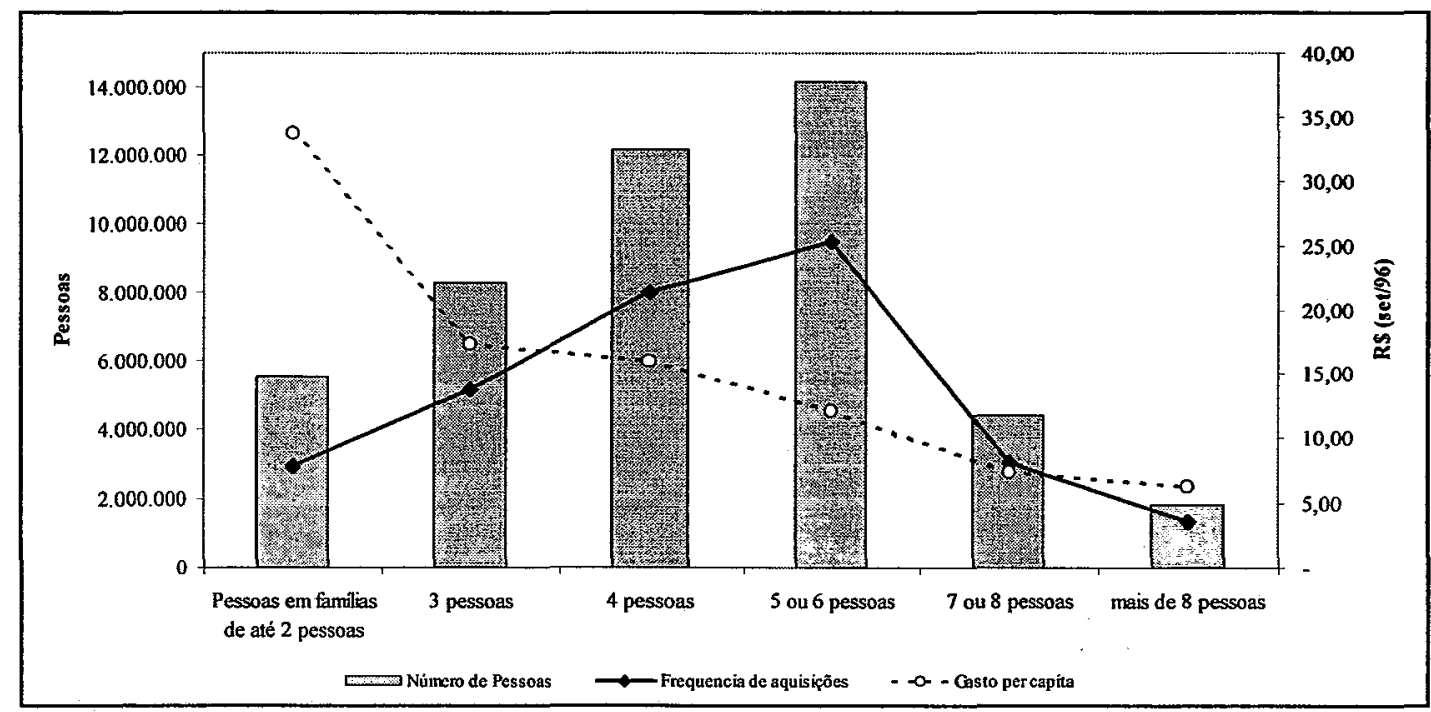

Figura 10. Freqüência de aquisição (observada) e dispêndio médio per capita com a alimentação fora do domicílio, segundo as pessoas de determinados tamanhos de família.

\subsubsection{O efeito da composição etária da família}

A faixa etária excluída do modelo, para evitar a multicolinearidade perfeita, foi a de pessoas de 31 a 50 anos (FAIXAE5) - a mais freqüente. Os efeitos marginais totais das diferentes faixas etárias sobre o consumo e os sinais do efeito marginal indireto podem ser observados na tabela 17, e o efeito marginal ampliado e seus componentes, na tabela 18.

A análise que se segue é baseada no efeito marginal ampliado e seus componentes (tabela 18). Por esses números, a faixa etária que se destaca por influenciar positivamente o nível de consumo da 'alimentação em geral', é a de 51 anos ou mais. $O$ nível de consumo da 'alimentação no domicílio' é influenciado positivamente por todas as faixas etárias analisadas, com exceção dos jovens de 21 a 30 anos, cuja presença influencia negativamente a alimentação 'no domicílio' e positivamente a alimentação 'fora do domicílio'.

Existe um comportamento bastante definido entre as distintas faixas etárias em relação à 'alimentação fora do domicílio'. A elevação da proporção de crianças (FAIXAE1 e FAIXAE2), adolescentes (FAIXAE3) e pessoas de 51 anos ou mais de idade (FAIXAE6) nas famílias, reduzem tanto a freqüência de aquisição das famílias em geral, como o nível de consumo per capita (tanto do agregado mais geral, como dos dois sub-itens: 'refeições' e 'outros' alimentos a serem consumidos fora do domicílio). A elevação da participação de jovens de 21 a 30 anos nas 
famílias, por sua vez, aumenta tanto a freqüência como o nível de consumo per capita da alimentação 'fora do domicílio', sobretudo para os 'outros' alimentos a serem consumidos fora do domicílio.

O único grupo etário que apresenta um comportamento relativamente discriminatório, entre alimentos 'tradicionais' e 'modernos' a serem consumidos no domicílio, é o de pessoas de 51 anos ou mais. À medida que se eleva a proporção dessa faixa etária nas famílias, consome-se mais de todos os agregados (com exceção dos 'alimentos preparados'); mas eleva a freqüência de aquisição dos alimentos 'tradicionais' e diminui a dos 'modernos' - ou seja, se a proporção das pessoas nessa faixa etária se elevar entre as famílias, mais delas tendem a adquirir os alimentos 'tradicionais', e menos adquirirão os alimentos 'modernos'. O efeito ampliado desse grupo etário sobre o consumo alimentar é positivo para os alimentos 'tradicionais' a serem consumidos no domicílio e negativo para os 'modernos' - com exceção dos 'enlatados', cuja influência é levemente positiva. Os demais grupos etários não apresentam um comportamento claramente discriminatório entre os alimentos 'tradicionais' e 'modernos' a serem consumidos no domicílio. 
Tabela 17. Efeito marginal total da composição etária das famílias sobre o consumo alimentar e os sinais dos efeitos indiretos.

\begin{tabular}{|c|c|c|c|c|c|}
\hline \multirow[b]{2}{*}{ Tipo de despesa } & \multicolumn{5}{|c|}{ Faixas etárias } \\
\hline & 0 a 5 anos & $\begin{array}{c}6 \text { a } 10 \\
\text { anos }\end{array}$ & $\begin{array}{c}11 \text { a } 20 \\
\text { anos }\end{array}$ & $\begin{array}{c}21 \text { a } 30 \\
\text { anos }\end{array}$ & $\begin{array}{c}51 \text { anos ou } \\
\text { mais }\end{array}$ \\
\hline \multicolumn{6}{|c|}{ EFEITO MARGINAL TOTAL } \\
\hline Alimentação em geral & $-0,056$ & $-0,009$ & $-0,037$ & $-0,006$ & 0,178 \\
\hline Alimentação no domić́lio & 0,170 & 0,172 & 0,109 & $-0,094$ & 0,322 \\
\hline Cereais, leguminosas e oleaginosas & 0,135 & 0,297 & 0,059 & 0,143 & 0,123 \\
\hline Alimentos frescos & 0,071 & $-0,150$ & $-0,080$ & $-0,249$ & 0,311 \\
\hline Alimentos protéicos & $-0,569$ & $-0,195$ & $-0,212$ & $-0,221$ & 0,068 \\
\hline Leite e derivados & 0,890 & 0,199 & 0,091 & $-0,029$ & 0,370 \\
\hline Refrigerantes & $-0,012$ & $-0,127$ & 0,134 & 0,113 & 0,193 \\
\hline Enlatados e conservas & 0,180 & 0,437 & 0,099 & 0,225 & 0,192 \\
\hline Alimentos preparados & $-0,404$ & $-0,737$ & $-0,096$ & $-0,097$ & $-0,126$ \\
\hline Alimentação fora do domicílio & $-0,439$ & $-0,856$ & $-0,431$ & 0,082 & $-0,196$ \\
\hline Refeições (Almoço ou jantar) & $-0,343$ & $-0,614$ & $-0,787$ & $-0,310$ & $-0,151$ \\
\hline Outros & $-0,314$ & $-0,598$ & $-0,010$ & 0,260 & $-0,217$ \\
\hline \multicolumn{6}{|c|}{ SINAL DO EFEITO MARGINAL INDIRETO } \\
\hline Alimentação em geral & + & - & - & - & - \\
\hline Alimentação no domicílio & + & + & - & - & + \\
\hline Cereais, leguminosas e oleaginosas & + & + & + & + & + \\
\hline Alimentos frescos & + & + & + & + & - \\
\hline Alimentos protéicos & - & + & + & + & + \\
\hline Leite e derivados & - & - & - & + & - \\
\hline Refrigerantes & - & - & - & + & + \\
\hline Enlatados e conservas & - & - & - & + & + \\
\hline Alimentos preparados & - & - & - & + & + \\
\hline Alimentação fora do domicílio & - & - & - & + & - \\
\hline Refeições (Almoço ou jantar) & - & - & - & + & - \\
\hline Outros & - & - & - & + & - \\
\hline
\end{tabular}

Fonte: Microdados/IBGE. 
Tabela 18. O efeito marginal ampliado das faixas etárias e seus componentes

\begin{tabular}{|c|c|c|c|c|c|c|}
\hline \multirow[b]{2}{*}{ Tipo de Despesa } & \multicolumn{3}{|c|}{ FAIXAE1 } & \multicolumn{3}{|c|}{ FAIXAE2 } \\
\hline & Efeito A & Efeito B & $\begin{array}{c}\text { Efeito } \\
\text { Ampliado }\end{array}$ & Efeito A & Efeito B & $\begin{array}{c}\text { Efeito } \\
\text { Ampliado }\end{array}$ \\
\hline Alimentação em geral & $-0,055$ & 0,023 & $-0,032$ & $-0,009$ & $-0,031$ & $-0,040$ \\
\hline Alimentação no domicílio & 0,165 & 0,026 & 0,191 & 0,166 & 0,036 & 0,202 \\
\hline Cereais, leguminosas e oleaginosas & 0,054 & 0,090 & 0,144 & 0,119 & 0,194 & 0,313 \\
\hline Alimentos frescos & 0,047 & $-0,091$ & $-0,044$ & $-0,098$ & $-0,062$ & $-0,160$ \\
\hline Alimentos proteicos & $-0,450$ & $-0,045$ & $-0,495$ & $-0,154$ & 0,134 & $-0,020$ \\
\hline Leite e derivados & 0,704 & 0,323 & 1,027 & 0,158 & 0,167 & 0,325 \\
\hline Refrigerantes & $-0,005$ & 0,076 & 0,071 & $-0,046$ & 0,088 & 0,042 \\
\hline Enlatados e conservas & 0,021 & 0,026 & 0,047 & 0,050 & 0,033 & 0,083 \\
\hline Alimentos preparados & $-0,043$ & 0,172 & 0,129 & $-0,078$ & 0,145 & 0,067 \\
\hline Alimentação fora do domicílio & $-0,292$ & $-0,398$ & $-0,690$ & $-0,568$ & $-0,274$ & $-0,842$ \\
\hline Refeições (Almoço ou jantar) & $-0,083$ & $-0,435$ & $-0,518$ & $-0,148$ & $-0,685$ & $-0,833$ \\
\hline \multirow[t]{2}{*}{ Outros } & $-0,189$ & $-0,334$ & $-0,523$ & $-0,358$ & $-0,120$ & $-0,478$ \\
\hline & \multicolumn{3}{|c|}{ FAIXAE3 } & \multicolumn{3}{|c|}{ FAIXAE4 } \\
\hline Alimentação em geral & $-0,037$ & $-0,026$ & $-0,063$ & $-0,006$ & $-0,050$ & $-0,056$ \\
\hline Alimentação no domicílio & 0,106 & $-0,007$ & 0,099 & $-0,091$ & $-0,041$ & $-0,132$ \\
\hline Cereais, leguminosas e oleaginosas & 0,024 & 0,059 & 0,083 & 0,057 & 0,006 & 0,064 \\
\hline Alimentos frescos & $-0,052$ & $-0,150$ & $-0,202$ & $-0,163$ & $-0,042$ & $-0,205$ \\
\hline Alimentos proteicos & $-0,167$ & 0,145 & $-0,023$ & $-0,175$ & 0,015 & $-0,159$ \\
\hline Leite e derivados & 0,072 & 0,104 & 0,177 & $-0,023$ & $-0,042$ & $-0,065$ \\
\hline Refrigerantes & 0,049 & 0,025 & 0,075 & 0,041 & $-0,011$ & 0,030 \\
\hline Enlatados e conservas & 0,011 & 0,030 & 0,041 & 0,026 & $-0,009$ & 0,017 \\
\hline Alimentos preparados & $-0,010$ & 0,097 & 0,087 & $-0,010$ & $-0,017$ & $-0,027$ \\
\hline Alimentação fora do domicílio & $-0,286$ & $-0,052$ & $-0,339$ & 0,054 & 0,113 & 0,167 \\
\hline Refeições (Almoço ou jantar) & $-0,190$ & $-0,336$ & $-0,526$ & $-0,075$ & 0,069 & $-0,006$ \\
\hline \multirow{2}{*}{ Outros } & $-0,006$ & $-0,063$ & $-0,069$ & 0,156 & 0,120 & 0,276 \\
\hline & \multicolumn{3}{|c|}{ FAIXAE6 } & \multicolumn{3}{|c|}{-} \\
\hline Alimentação em geral & 0,175 & $-0,036$ & 0,139 & & & \\
\hline Alimentação no domicílio & 0,312 & 0,017 & 0,329 & & & \\
\hline Cereais, leguminosas e oleaginosas & 0,049 & 0,161 & 0,210 & & & \\
\hline Alimentos frescos & 0,203 & 0,079 & 0,282 & & & \\
\hline Alimentos proteicos & 0,053 & 0,056 & 0,110 & & & \\
\hline Leite e derivados & 0,292 & 0,120 & 0,413 & & & \\
\hline Refrigerantes & 0,071 & $-0,090$ & $-0,019$ & & & \\
\hline Enlatados e conservas & 0,022 & $-0,004$ & 0,018 & & & \\
\hline Alimentos preparados & $-0,013$ & $-0,057$ & $-0,071$ & & & \\
\hline Alimentação fora do domicílio & $-0,131$ & $-0,568$ & $-0,699$ & & & \\
\hline Refeições (Almoço ou jantar) & $-0,036$ & $-0,391$ & $-0,427$ & & & \\
\hline Outros & $-0,130$ & $-0,444$ & $-0,574$ & & & \\
\hline
\end{tabular}

Fonte: Microdados/IBGE. 


\subsubsection{O efeito da inserção da mulher no mercado de trabalho}

Na tabela 19 constam os efeitos da presença de mulheres 'que trabalham' nas famílias sobre o consumo alimentar per capita, de quem adquire os alimentos, e na tabela 20 o efeito ampliado dessa variável.

A existência de mulheres 'que trabalham' nas famílias não levou a diferenças substanciais na frequiência de aquisição dos alimentos a serem consumidos 'no domicílio' (tabela 10). Para o nível de consumo desses alimentos (entre as famílias que adquirem os alimentos), poucos foram os coeficientes significativos, o que pode sugerir que as diferenças de comportamento entre as famílias com e sem mulheres 'que trabalham', abstraindo a questão da renda, não são marcantes (tabelas 11 e 19). Esse resultado não é surpreendente uma vez que, observando-se a tabela 7 , pode-se dizer que as diferenças encontradas entre os níveis de dispêndio médio de um e outro grupo, para os diversos alimentos, foram tênues. Ainda assim, pode-se dizer que, observando-se os efeitos marginais totais e ampliados, existe uma ligeira tendência de as pessoas de famílias com mulheres 'que trabalham' adotarem um padrão 'moderno' de alimentação no domicílio, baseado na facilidade e economia de tempo.

A alimentação fora do domicílio, por sua vez, é feita com mais freqüência e em maior 'quantidade' pelas pessoas de famílias com mulheres 'que trabalham' - valendo notar que as pessoas dessas famílias comem com mais freqüência tanto as 'refeições' como os 'outros' alimentos fora do domicílio que as de famílias sem mulheres 'que trabalham', mas o nível de consumo dos 'outros' alimentos é relativamente maior, caracterizando um tipo de alimentação 'menos saudável' fora do domicílio. 
Tabela 19. Efeito marginal total sobre o consumo alimentar per capita da existência de mulheres 'que trabalham' nas famílias, e os sinais dos efeitos indiretos.

\begin{tabular}{l|cc|c}
\hline \multicolumn{1}{c}{ Tipo de despesa } & \multicolumn{2}{|c|}{ Mulheres 'que trabalham' } & $\begin{array}{c}\text { Sinal do Efeito } \\
\text { Marginal Indireto }\end{array}$ \\
\cline { 2 - 4 } & Efeito Direto & Efeito Total & Margec \\
\hline Alimentação em geral & $-0,047^{* *}$ & $-0,027$ & + \\
Alimentação no domicílio & $-0,084^{* * *}$ & $-0,064$ & + \\
Cereais, leguminosas e oleaginosas & $-0,037$ & $-0,009$ & + \\
Alimentos frescos & $-0,009$ & $-0,021$ & - \\
Alimentos proteicos & $-0,024$ & $-0,025$ & - \\
Leite e derivados & $-0,053^{* * *}$ & $-0,055$ & - \\
Refrigerantes & 0,014 & 0,016 & + \\
Enlatados e conservas & 0,124 & 0,028 & - \\
Alimentos preparados & 0,092 & 0,106 & + \\
Alimentação fora do domicílio & $0,100^{* * *}$ & 0,121 & + \\
Refeições (Almoço ou jantar) & $-0,001$ & 0,027 & + \\
Outros & $0,075^{* * *}$ & 0,105 & + \\
\hline Fonte: Microdados/IBGE. Nivel de significância: ${ }^{* * *} \alpha=1 \% ;{ }^{* *} \alpha=2 \% \mathrm{e}{ }^{*} \alpha=10 \%$. &
\end{tabular}

Tabela 20. O efeito marginal ampliado das famílias com mulheres 'que trabalham' e seus componentes

\begin{tabular}{l|cc|c}
\hline & Efeito A & Efeito B & $\begin{array}{c}\text { Efeito Mg } \\
\text { Ampliado }\end{array}$ \\
\hline Alimentação em geral & $-0,026$ & 0,013 & $-0,013$ \\
Alimentação no domicílio & $-0,062$ & 0,017 & $-0,044$ \\
Cereais, leguminosas e oleaginosas & $-0,003$ & 0,029 & 0,026 \\
Alimentos frescos & $-0,014$ & 0,008 & $-0,006$ \\
Alimentos proteicos & $-0,020$ & $-0,003$ & $-0,022$ \\
Leite ederivados & $-0,044$ & 0,004 & $-0,040$ \\
Refrigerantes & 0,006 & $-0,008$ & $-0,002$ \\
Enlatados e conservas & 0,003 & 0,008 & 0,011 \\
Alimentos preparados & 0,011 & $-0,006$ & 0,005 \\
Alimentação fora do domić́lio & 0,080 & 0,051 & 0,131 \\
Refeições (Almoço ou jantar) & 0,006 & 0,045 & 0,052 \\
Outros & 0,063 & 0,055 & 0,118 \\
\hline
\end{tabular}

Fonte: Microdados/1BGE.

\subsubsection{O efeito da organização familiar}

Para ser analisado o efeito dos diferentes 'tipos' familiares sobre o consumo, uma qualificação deve ser feita. Deve-se ter em mente que a análise do comportamento dessas variáveis estará isenta da influência do número de pessoas nas famílias, já captada pela variável 'tamanho' da família. Na tabela 21 pode ser observado o comportamento do 'tamanho' das 
famílias segundo o tipo familiar - onde apresenta-se clara relação entre as variáveis, sobretudo para o caso dos domicílios unitários.

Tabela 21. Número de famílias segundo o 'tipo' e número de componentes

\begin{tabular}{|c|c|c|c|c|c|}
\hline $\begin{array}{l}\text { Número de } \\
\text { Componentes }\end{array}$ & \begin{tabular}{|l} 
Famílias \\
Tradicionais
\end{tabular} & $\begin{array}{l}\text { Famílias } \\
\text { Complexas }\end{array}$ & $\begin{array}{l}\text { Novas } \\
\text { Famílias }\end{array}$ & $\begin{array}{l}\text { Domicílios } \\
\text { Unitários } \\
\end{array}$ & $\begin{array}{l}\text { Outros } \\
\text { Domicílios }\end{array}$ \\
\hline 1 & - & - & - & 1.057 .005 & \\
\hline 2 & 1.256 .837 & 304.569 & 599.955 & 11.138 & 66.840 \\
\hline 3 & 2.022 .046 & 151.804 & 565.843 & 950 & 17.289 \\
\hline 4 & 2.529 .064 & 96.428 & 414.707 & 113 & 1.585 \\
\hline 5 & 1.489 .802 & 55.870 & 265.187 & - & 319 \\
\hline 6 & 706.421 & 28.295 & 118.943 & - & - \\
\hline 7 & 310.248 & 20.647 & 67.378 & - & - \\
\hline 8 & 148.410 & 10.236 & 41.113 & - & - \\
\hline 9 & 49.982 & 4.462 & 25.939 & - & - \\
\hline 10 a 14 & 60.031 & 4.113 & 28.649 & - & - \\
\hline 15 a 30 & 2.212 & 437 & 857 & - & - \\
\hline Total & 8.575 .053 & 676.861 & 2.128 .571 & 1.069 .206 & 86.033 \\
\hline Tamanho Médio & 4.1 & 3.3 & 3.7 & 1.0 & 2.2 \\
\hline
\end{tabular}

A unidade de referência para essa variável binária é a categoria 'famílias tradicionais'. São objeto de análise os resultados das variáveis 'novas famílias', 'famílias complexas' e 'domicílios unitários', sendo desconsiderada a categoria residual.

Observando os resultados do modelo de próbites (tabela 10), pode-se dizer que as pessoas das 'famílias complexas' e das 'novas famílias' tendem a adquirir os alimentos 'tradicionais' com uma freqüência pouco maior que as das 'famílias tradicionais'. A freqüência de aquisição dos alimentos 'modernos' a serem consumidos no domicílio, por sua vez, não diverge muito entre as pessoas dos diferentes tipos familiares, dados os coeficientes não significativos e de valores absolutos muito baixos. A probabilidade de uma pessoa comer 'fora do domicílio', por sua vez, aumenta quando ela participa de 'novas famílias' ou 'mora sozinha' (em 'domicílios unitários')mas a primeira concentra suas aquisições em 'outros' alimentos fora do domicílio e a última, nas 'refeições'. O comportamento das 'famílias complexas' não divergiu estatisticamente do observado para a categoria básica quanto à freqüência em que se come fora de casa.

Os resultados mais gerais do modelo estimado para os diferentes 'tipos' familiares podem ser observados nas tabelas 22 e 23 .

Observando os resultados ampliados (tabela 23), pode-se dizer que as únicas pessoas que apresentam um nível de consumo alimentar per capita maior que das 'famílias tradicionais', 
abstraída a questão da renda e do tamanho das famílias, são as pessoas dos 'domicílios unitários', que influenciam positivamente o consumo tanto dentro como fora dos domicílios. Dentro dos domicílios, as pessoas que 'moram sozinhas' não discriminam entre os padrões alimentares 'tradicional' ou 'moderno', e fora deles, apesar de consumirem mais, em geral, dão primazia ao consumo dos 'outros alimentos' a serem consumidos fora do domicílio, que não as 'refeições' (lanches, sucos, cafezinho, etc). A elevação da frequiência de aquisição alimentar por parte das pessoas residentes em domicílios unitários, por outro lado, tende reduzir o consumo médio per capita de vários agregados alimentares - tanto dentro como fora dos domicílios.

O nível de consumo das pessoas das 'novas famílias' é menor que das 'famílias tradicionais' para praticamente todos os alimentos a serem consumidos no domicílio, e maior para os alimentos a serem consumidos fora deles - sobretudo para os 'outros' alimentos a serem consumidos fora do domicílio. A elevação da freqüência de aquisições de alimentos por esse grupo familiar, por sua vez, também tende a se refletir em um nível menor de consumo médio per capita dos agregados alimentares em geral.

As pessoas de 'famílias complexas' não apresentam um comportamento diferenciado das de 'famílias tradicionais' em relação à discriminação do consumo de alimentos 'tradicionais' ou 'modernos' a serem consumidos no domicílio. Como para os demais grupos, por outro lado, as pessoas desse tipo familiar também se destacam por apresentar um nível mais elevado de consumo de alimentos fora do domicílio, privilegiando, igualmente, os 'outros' alimentos. A elevação da frequiência de aquisição de alimentos por essas pessoas, em oposição às das demais, tende a influenciar positivamente o consumo per capita de diversos agregados alimentares.

Assim, é possível afirmar que as pessoas das 'famílias tradicionais' são aquelas que menos consomem alimentos fora do domicílio, e que não discriminam um padrão de alimentação no domicílio (entre 'moderno' e 'tradicional'). 
Tabela 22. Efeitos Marginais totais dos 'tipos' familiares e sinais dos efeitos marginais indiretos

\begin{tabular}{|c|c|c|c|}
\hline \multirow{2}{*}{ Tipo de despesa } & \multicolumn{3}{|c|}{ 'Tipos' Familiares } \\
\hline & $\begin{array}{c}\text { Famílias } \\
\text { Complexas } \\
\end{array}$ & $\begin{array}{c}\text { Novas } \\
\text { Famílias } \\
\end{array}$ & $\begin{array}{c}\text { Domicílios } \\
\text { Unitários }\end{array}$ \\
\hline \multicolumn{4}{|c|}{ EFEITO MARGINAL TOTAL } \\
\hline Alimentação em Geral & $-0,012$ & $-0,084$ & 0,241 \\
\hline Alimentação no domicílio & $-0,032$ & $-0,113$ & 0,070 \\
\hline Cereais, leguminosas e oleaginosas & $-0,090$ & 0,088 & 0,179 \\
\hline Alimentos frescos & $-0,130$ & $-0,123$ & $-0,289$ \\
\hline Alimentos protéicos & $-0,082$ & $-0,119$ & 0,021 \\
\hline Leite e derivados & $-0,032$ & $-0,137$ & $-0,050$ \\
\hline Refrigerantes & $-0,053$ & 0,011 & $-0,132$ \\
\hline Enlatados e conservas & 0,105 & 0,082 & $-0,005$ \\
\hline Alimentos preparados & $-0,062$ & $-0,042$ & 0,013 \\
\hline Alimentação fora do domicílio & 0,061 & 0,114 & 0,638 \\
\hline Refeições (Almoço ou jantar) & $-0,019$ & 0,092 & 0,258 \\
\hline Outros & 0,045 & 0,139 & 0,500 \\
\hline \multicolumn{4}{|c|}{ SINAL DO EFEITO MARGINAL INDIRETO } \\
\hline Alimentação em geral & - & + & - \\
\hline Alimentação no domicílio & - & + & - \\
\hline Cereais, leguminosas e oleaginosas & + & + & + \\
\hline Alimentos frescos & - & + & - \\
\hline Alimentos protéicos & - & - & - \\
\hline Leite e derivados & - & - & + \\
\hline Refrigerantes & + & + & + \\
\hline Enlatados e conservas & - & + & + \\
\hline Alimentos preparados & - & + & - \\
\hline Alimentação fora do domicílio & + & - & + \\
\hline Refeições (Almoço ou jantar) & + & - & + \\
\hline Outros & + & - & + \\
\hline
\end{tabular}

Fonte: Microdados/IBGE. 
Tabela 23. O efeito marginal ampliado dos diferentes 'tipos' familiares e seus componentes

\begin{tabular}{|c|c|c|c|c|c|c|}
\hline \multirow[b]{2}{*}{ Tipo de Despesa } & \multicolumn{3}{|c|}{ Novas Famílias } & \multicolumn{3}{|c|}{ Famílias Complexas } \\
\hline & Efeito $\mathrm{A}$ & Efeito B & $\begin{array}{c}\text { Efeito } \\
\text { Ampliado }\end{array}$ & Efeito $\mathrm{A}$ & Efeito B & $\begin{array}{c}\text { Efeito } \\
\text { Ampliado }\end{array}$ \\
\hline Alimentação em geral & $-0,012$ & $-0,002$ & $-0,014$ & $-0,083$ & $-0,004$ & $-0,087$ \\
\hline Alimentação no domicílio & $-0,031$ & $-0,004$ & $-0,035$ & $-0,110$ & $-0,010$ & $-0,119$ \\
\hline Cereais, leguminosas e oleaginosas & $-0,036$ & $-0,013$ & $-0,049$ & 0,035 & 0,034 & 0,069 \\
\hline Alimentos frescos & $-0,085$ & $-0,005$ & $-0,090$ & $-0,080$ & 0,055 & $-0,026$ \\
\hline Alimentos proteicos & $-0,065$ & $-0,018$ & $-0,083$ & $-0,094$ & $-0,048$ & $-0,142$ \\
\hline Leite e derivados & $-0,025$ & $-0,007$ & $-0,032$ & $-0,108$ & 0,023 & $-0,085$ \\
\hline Refrigerantes & $-0,019$ & 0,001 & $-0,019$ & 0,004 & $-0,004$ & 0,000 \\
\hline Enlatados e conservas & 0,012 & $-0,001$ & 0,011 & 0,009 & 0,002 & 0,012 \\
\hline Alimentos preparados & $-0,007$ & $-0,002$ & $-0,008$ & $-0,004$ & 0,002 & $-0,002$ \\
\hline Alimentação fora do domicílio & 0,040 & $-0,003$ & 0,037 & 0,076 & 0,078 & 0,154 \\
\hline Refeições (Almoço ou jantar) & $-0,005$ & 0,006 & 0,001 & 0,022 & 0,008 & 0,030 \\
\hline \multirow[t]{2}{*}{ Outros } & 0,027 & $-0,007$ & 0,020 & 0,083 & 0,071 & 0,155 \\
\hline & \multicolumn{3}{|c|}{ Domicílios Unitários } & & - & \\
\hline Alimentação em geral & 0,237 & 0,032 & 0,269 & & & \\
\hline Alimentação no domicílio & 0,068 & 0,045 & 0,113 & & & \\
\hline Cereais, leguminosas e oleaginosas & 0,072 & 0,039 & 0,111 & & & \\
\hline Alimentos frescos & $-0,188$ & $-0,020$ & $-0,208$ & & & \\
\hline Alimentos proteicos & 0,017 & $-0,126$ & $-0,110$ & & & \\
\hline Leite e derivados & $-0,040$ & 0,051 & 0,011 & & & \\
\hline Refrigerantes & $-0,048$ & $-0,059$ & $-0,107$ & & & \\
\hline Enlatados e conservas & $-0,001$ & $-0,004$ & $-0,005$ & & & \\
\hline Alimentos preparados & 0,001 & $-0,004$ & $-0,002$ & & & \\
\hline Alimentação fora do domicílio & 0,424 & $-0,032$ & 0,391 & & & \\
\hline Refeições (Almoço ou jantar) & 0,062 & $-0,050$ & 0,012 & & & \\
\hline Outros & 0,300 & $-0,006$ & 0,294 & & & \\
\hline
\end{tabular}

\subsubsection{A elasticidade-'renda' do dispêndio alimentar}

Uma das relações econômicas mais importantes estabelecidas por estudos da demanda é a elasticidade-renda. Sendo assim, julga-se relevante apresentar a diferença entre os resultados obtidos pela metodologia acima e pela estimação 'nas médias'.

As regressões poligonal log-log - estimadas 'nas médias' -, apresentadas na tabela 24 , se mostraram altamente significativas - todas apresentaram o teste ' $\mathrm{F}$ ' significativo ao nível de $1 \%$. Os coeficientes individuais também são, na grande maioria, estatisticamente significativos com exceção do segundo segmento da poligonal para a 'alimentação em geral', os 'enlatados' e a 'alimentação fora do domicílio', e do terceiro segmento para os 'refrigerantes' e os 'outros alimentos fora do domicílio'. 
Os limites de classes de 'renda' per capita adotados foram os decis da mesma variável, e o 'esquema de agrupamento' foi definido segundo o melhor ajuste da regressão. Assim, para o primeiro 'esquema' - 2-3-5 - tem-se que o primeiro estrato compreendeu os dois primeiros décimos; o segundo, os três seguintes; e o terceiro, os cinco últimos décimos da distribuição da 'renda' per capita.

Tabela 24. Regressão Poligonal $\log$ - $\log$

\begin{tabular}{|c|c|c|c|c|c|c|}
\hline \multirow{2}{*}{ Tipo de despesa } & \multirow{2}{*}{\multicolumn{2}{|c|}{ Ajustamento }} & \multicolumn{4}{|c|}{ Coeficientes } \\
\hline & & & $\alpha$ & $\beta$ & $\delta_{1}$ & $\delta_{2}$ \\
\hline \multirow[t]{2}{*}{ Alimentação em Geral } & $\mathbf{R}^{2}$ & 1,000 & $-0,483^{* * *}$ & $0,850^{* * *}$ & $-0,071$ & $-0,204^{* * *}$ \\
\hline & $\mathrm{F}$ & 4820 & $(0,135)$ & $(0,033)$ & $(0,055)$ & $(0,034)$ \\
\hline \multirow[t]{2}{*}{ Alimentação no domicílio } & $\mathbf{R}^{2}$ & 0,999 & $-0,379^{*}$ & $0,796^{* * *}$ & $-0,136^{*}$ & $-0,208^{* * *}$ \\
\hline & $\mathbf{F}$ & 1348 & $(0,213)$ & $(0,052)$ & $(0,075)$ & $(0,045)$ \\
\hline \multirow[t]{2}{*}{ Cereais, leguminosas e oleaginosas } & $\mathbf{R}^{2}$ & 0,963 & $-2,467^{* * *}$ & $0,719^{* * *}$ & $-0,521^{* * *}$ & $-0,156$ \\
\hline & F & 52 & $(0,409)$ & $(0,094)$ & $(0,138)$ & $(0,126)$ \\
\hline \multirow[t]{2}{*}{ Alimentos frescos } & $\mathbf{R}^{2}$ & 0,999 & $-3,953^{* * *}$ & $1,065^{* * *}$ & $-0,313^{* * *}$ & $-0,217^{* * *}$ \\
\hline & $\mathrm{F}$ & 1754 & $(0,179)$ & $(0,042)$ & $(0,077)$ & $(0,059)$ \\
\hline \multirow[t]{2}{*}{ Alimentos Proteicos } & $\mathrm{R}^{2}$ & 0,995 & $-1,539^{* * *}$ & $0,762^{* * *}$ & $-0,242^{* *}$ & $-0,160^{*}$ \\
\hline & $\mathrm{F}$ & 412 & $(0,255)$ & $(0,059)$ & $(0,110)$ & $(0,085)$ \\
\hline \multirow[t]{2}{*}{ Leite e derivados } & $\mathrm{R}^{2}$ & 0,997 & $-2,592^{* * *}$ & $0,867^{* * *}$ & $-0,257^{* * *}$ & $-0,145^{* *_{e}}$ \\
\hline & $\mathrm{F}$ & 720 & $(0,290)$ & $(0,071)$ & $(0,102)$ & $(0,061)$ \\
\hline \multirow[t]{2}{*}{ Refrigerantes } & $\mathrm{R}^{2}$ & 0,996 & $-5,362^{* * *}$ & $1,100^{* * *}$ & $-0,827^{* * *}$ & 0,271 \\
\hline & $\mathrm{F}$ & 504 & $(0,214)$ & $(0,044)$ & $(0,157)$ & $(0,187)$ \\
\hline \multirow[t]{2}{*}{ Enlatados e conservas } & $\mathbf{R}^{2}$ & 0,994 & $-5,822^{* * *}$ & $0,714^{*}$ & 0,644 & $-0,536^{* * *}$ \\
\hline & $\mathrm{F}$ & 348 & $(1,426)$ & $(0,380)$ & $(0,469)$ & $(0,156)$ \\
\hline \multirow[t]{2}{*}{ Alimentos preparados } & $\mathbf{R}^{2}$ & 0,994 & $-9,601^{* * *}$ & $1,748^{* * *}$ & $-0,461^{* *}$ & $-0,890^{6 *}$ \\
\hline & $\mathbf{F}$ & 315 & $(0,527)$ & $(0,112)$ & $(0,225)$ & $(0,394)$ \\
\hline \multirow[t]{2}{*}{ Alimentação fora do domicílio } & $\mathbf{R}^{2}$ & 0,997 & $-4,894^{* * *}$ & $1,393^{* * *}$ & $-0,592^{* * *}$ & 0,082 \\
\hline & $\mathrm{F}$ & 597 & $(0,365)$ & $(0,082)$ & $(0,221)$ & $(0,197)$ \\
\hline \multirow[t]{2}{*}{ Refeições (Almoço ou jantar) } & $\mathbf{R}^{2}$ & 0,995 & $-9,427^{* * * *}$ & $2,180^{* * *}$ & $-0,622$ & $-0,406^{* *}$ \\
\hline & $\mathrm{F}$ & 393 & $(1,818)$ & $(0,485)$ & $(0,598)$ & $(0,199)$ \\
\hline \multirow[t]{2}{*}{ Outros } & $\mathbf{R}^{2}$ & 0,996 & $-4,588^{* * *}$ & $1,254^{* * *}$ & $-0,585^{* * *}$ & $-0,171$ \\
\hline & $\mathrm{F}$ & 534 & $(0,289)$ & $(0,064)$ & $(0,114)$ & $(0,120)$ \\
\hline
\end{tabular}

Fonte: Microdados/IBGE. Desvio padrão entre parênteses. Nível de significância: ${ }^{* * *} \alpha=1 \%$; ${ }^{* *} \alpha=2 \%$ e $\alpha=10 \%$

Na tabela 25 são apresentadas as estimativas das elasticidades-' renda' do dispêndio alimentar geradas pelo modelo da poligonal $\log$-log. As elasticidades médias correspondem à média ponderada das elasticidades em cada estrato, sendo o fator de ponderação a participação de cada estrato no total das despesas com o produto analisado (Hoffmann, 2000).

O comportamento esperado para a elașticidade-renda do dispêndio alimentar é que decresça à medida que os níveis de renda se elevem. Pellos resultados obtidos para a poligonal (tabela 25), esse movimento não se confirmou apenas para os 'refrigerantes', 'enlatados e conservas' e 
'alimentação fora do domicílio', mas todos esses alimentos apresentam coeficientes não significativos para a inflexão dos segmentos relevantes (tabela 24).

Tabela 25. Elasticidade-despesa global do dispêndio alimentar - poligonal log-log

\begin{tabular}{|c|c|c|c|c|c|}
\hline \multirow{2}{*}{ Tipo de despesa } & \multirow{2}{*}{\begin{tabular}{c|} 
Esquema de \\
Agrupamento
\end{tabular}} & \multicolumn{3}{|c|}{ Elasticidade no Estrato } & \multirow{2}{*}{$\begin{array}{l}\text { Elasticidade } \\
\text { Média }\end{array}$} \\
\hline & & I & II & III & \\
\hline Alimentação em geral & $2-3-5$ & 0,850 & 0,780 & 0,576 & 0,627 \\
\hline Alimentação no domicílio & $2-4-4$ & 0,796 & 0,660 & 0,452 & 0,536 \\
\hline Cereais, leguminosas e oleaginosas & $3-5-2$ & 0,719 & 0,197 & 0,041 & 0,259 \\
\hline Alimentos frescos & $3-3-4$ & 1,065 & 0,753 & 0,536 & 0,634 \\
\hline Alimentos protéicos & $3-3-4$ & 0,762 & 0,520 & 0,359 & 0,457 \\
\hline Leite e derivados & $2-4-4$ & 0,867 & 0,611 & 0,465 & 0,535 \\
\hline Refrigerantes & $6-2-2$ & 1,100 & 0,274 & 0,545 & 0,643 \\
\hline Enlatados e conservas & $1-4-5$ & 0,714 & 1,359 & 0,822 & 0,893 \\
\hline Alimentos preparados & $5-4-1$ & 1,748 & 1,287 & 0,397 & 0,957 \\
\hline Alimentação fora do domicílio & $4-2-4$ & 1,393 & 0,801 & 0,883 & 0,917 \\
\hline Refeições (Almoço ou jantar) & $1-4-5$ & 2,180 & 1,558 & 1,152 & 1,190 \\
\hline Outros & $4-4-2$ & 1,254 & 0,669 & 0,498 & 0,668 \\
\hline
\end{tabular}

Fonte: Microdados/IBGE.

Na tabela 26 pode ser observada a composição do efeito marginal 'ampliado' da renda sobre o consumo dos diferentes alimentos para o modelo log-log, como apresentado nas seções 3.2.3. e 4.3.1.2., que correspondem às próprias elasticidades-'renda' do dispêndio alimentar obtidas pelo procedimento de Heckman.

Tabela 26. A elasticidade-renda do dispêndio alimentar 'ampliada' - modelo log-log

\begin{tabular}{|c|c|c|c|c|c|c|}
\hline & $\begin{array}{c}\text { Efeito } \mathrm{Mg} \\
\text { direto } \\
\text { (a) }\end{array}$ & $\begin{array}{l}\text { Efeito } \mathrm{Mg} \\
\text { indireto } \\
\text { (b) }\end{array}$ & $\begin{array}{c}\text { Probabilidade } \\
\text { de Aquisição } \\
\text { (c) }\end{array}$ & $\begin{array}{l}\text { Efeito A } \\
{\left[(a+b)^{*} c\right]}\end{array}$ & $\begin{array}{c}\text { Efeito } \\
\mathrm{B}\end{array}$ & $\begin{array}{c}\text { Elasticidade-'renda' } \\
\text { do dispêndio } \\
\text { alimentar }(\mathrm{A}+\mathrm{B})\end{array}$ \\
\hline Alimentação em geral & 0,566 & 0,084 & 0,984 & 0,639 & 0,056 & 0,695 \\
\hline Alimentação no domicílio & 0,482 & 0,070 & 0,970 & 0,535 & 0,062 & 0,596 \\
\hline $\begin{array}{r}\text { Cereais, leguminosas e } \\
\text { oleaginosas }\end{array}$ & 0,147 & 0,067 & 0,401 & 0,086 & 0,068 & 0,154 \\
\hline Alimentos frescos & 0,717 & $-0,231$ & 0,652 & 0,317 & 0,145 & 0,462 \\
\hline Alimentos proteicos & 0,372 & 0,049 & 0,791 & 0,333 & 0,131 & 0,464 \\
\hline Leite e derivados & 0,559 & $-0,082$ & 0,791 & 0,378 & 0,118 & 0,495 \\
\hline Refrigerantes & 0,419 & $-0,035$ & 0,366 & 0,141 & 0,137 & 0,278 \\
\hline Enlatados e conservas & 0,978 & $-0,619$ & 0,114 & 0,041 & 0,049 & 0,090 \\
\hline Alimentos preparados & 0,748 & $-0,290$ & 0,106 & 0,049 & 0,135 & 0,183 \\
\hline $\begin{array}{l}\text { Álimentação fora do } \\
\text { domicílio }\end{array}$ & 0,664 & 0,167 & 0,664 & 0,552 & 0,397 & 0,949 \\
\hline $\begin{array}{l}\text { Refeições (Almoço ou } \\
\text { Jantar) }\end{array}$ & 0,310 & 0,301 & 0,241 & 0,147 & 0,487 & 0,634 \\
\hline Outros & 0,449 & 0,150 & 0,600 & 0,359 & 0,278 & 0,637 \\
\hline
\end{tabular}

Fonte: Microdados/IBGE. 
Na tabela 27 é possível contrastar diretamente as elasticidades obtidas pelo procedimento de Heckman (diretas, totais e 'ampliadas') e 'na médias'. As primeiras, as chamadas elasticidades totais, refletem o comportamento das pessoas que adquirem os alimentos, considerada a probabilidade de aquisição e, as 'ampliadas', as elasticidades-'renda' dos consumidores em geral. Para a maioria dos alimentos o efeito ampliado foi maior que o total - com exceção dos 'cereais, leguminosas e oleaginosas' e dos 'alimentos frescos', além dos agregados que tiverahn a hipótese de seleção amostral rejeitada ('refrigerantes', 'enlatados' e 'alimentos preparados'), que inclusive apresentaram um nível de 'elasticidade-renda ampliada' muito abaixo do esperado. É aceitável que a elasticidade-'renda' de quem já adquire os alimentos seja inferior à da população em geral - dependendo do agregado, algumas pessoas não adquirem os alimentos simplesmente porque não têm um nível de renda que o permita.

Ao comparar os resultados do modelo estimado segundo o procedimento de Heckman e 'nas médias' é possível observar que várias das elasticidades geradas pelo primeiro método são menores que as obtidas através do segundo. Um dos fatores que deve contribuir para essa diferença é o não tratamento dos erros de medida no modelo de seleção amostral - problema típico de dados individuais. Sabe-se que quando existem erros de medida tanto para a variável dependente como para a independente - que é tradicionalmente o caso para as variáveis de valor como despesas e renda - o estimador de mínimos quadrados tende a subestimar o valor absoluto do parâmetro [Hoffmann \& Vieira, 1987]. Ao trabalhar com dados médios não só as idiossincrasias individuais são 'suavizadas' ('smooth'), mas também são eliminados, ou bastante reduzidos, os efeitos dos erros de medida (Deaton, 1992).

É interessante notar, ainda, que quanto menor a 'amostra selecionada' (em relação à amostra global da POF) maior a diferença encontrada entre as elasticidades estimadas pelos distintos métodos - caso dos 'alimentos preparados', 'enlatados e conservas', 'refeições fora do domicílio' e 'refrigerantes'. 
Tabela 27. Elasticidade-despesa global do dispêndio alimentar, segundo os modelos $\log$-log e poligonal $\log$ - $\log$.

\begin{tabular}{l|cccc|c}
\multicolumn{1}{c|}{ Tipo de despesa } & \multicolumn{3}{|c|}{ log-log } & Poligonal \\
\cline { 2 - 6 } & E. Direta & E. Total & E.'Ampliada' & log-log \\
\hline Alimentação em geral & $\mathbf{0 , 5 6 6}$ & $\mathbf{0 , 6 5 0}$ & $\mathbf{0 , 6 9 5}$ & $\mathbf{0 , 6 2 7}$ \\
Alimentação no Domicílio & $\mathbf{0 , 4 8 2}$ & 0,551 & $\mathbf{0 , 5 9 6}$ & 0,536 \\
Cereais, leguminosas e oleaginosas & $\mathbf{0 , 1 4 7}$ & $\mathbf{0 , 2 1 4}$ & $\mathbf{0 , 1 5 4}$ & 0,259 \\
Alimentos frescos & $\mathbf{0 , 7 1 7}$ & 0,486 & 0,462 & 0,634 \\
Alimentos proteicos & $\mathbf{0 , 3 7 2}$ & 0,421 & $\mathbf{0 , 4 6 4}$ & 0,457 \\
Leite e derivados & $\mathbf{0 , 5 5 9}$ & 0,477 & 0,495 & 0,535 \\
Refrigerantes & $\mathbf{0 , 4 1 9}$ & 0,384 & 0,278 & 0,643 \\
Enlatados e conservas & $\mathbf{0 , 9 7 8}$ & $\mathbf{0 , 3 5 8}$ & $\mathbf{0 , 0 9 0}$ & 0,893 \\
Alimentos preparados & $\mathbf{0 , 7 4 8}$ & 0,458 & 0,183 & 0,957 \\
Alimentação fora do domicílio & $\mathbf{0 , 6 6 4}$ & 0,831 & 0,949 & 0,917 \\
Refeições (Almoço ou jantar) & $\mathbf{0 , 3 1 0}$ & 0,610 & 0,634 & 1,190 \\
Outros & $\mathbf{0 , 4 4 9}$ & 0,598 & 0,637 & 0,668 \\
\hline
\end{tabular}

Fonte: Microdados/IBGE. 


\section{CONCLUSÕES}

A proposta deste estudo foi a avaliação dos efeitos de algumas variáveis socioeconômicas sobre o consumo alimentar do brasileiro metropolitano. Muitas evidências foram encontradas e várias questões surgiram, abrindo portas para novas investigações pertinentes.

Julga-se que saber quais são os grupos socioeconômicos que privilegiam um ou outro padrão alimentar é suficiente para dar os primeiros passos na direção de solucionar a questão inicialmente colocada - como os brasileiros estão se alimentando? Assim, seguem os principais resultados obtidos pelo estudo e sua conexão com a dinâmica da sociedade brasileira.

A renda, ainda é um forte condicionante do consumo alimentar de grande parte dos brasileiros. A freqüência de compra de alimentos é diretamente proporcional à renda e as elasticidades-renda médias do dispêndio alimentar ainda são altas para a maioria dos alimentos - indicando que incrementos na renda ainda serão convertidos, num percentual razoável, em consumo alimentar.

Classificando certos agregados alimentares como 'tradicionais ${ }^{28}$, e 'modernos ${ }^{29}$, é possível afirmar que a renda condiciona mais a alimentação 'moderna' que a 'tradicional', com especial apelo para a alimentação fora dos domicílios.

Pode-se afirmar, igualmente, que as economias de escala no consumo alimentar já não são significativas entre os brasileiros metropolitanos. Assim sendo, a tendência observada de diminuição do tamanho das famílias brasileiras pode elevar o 'desperdício' de alimentos, o que

${ }^{28}$ Os alimentos 'tradicionais' são aqueles associados à alimentação tipicamente brasileira, feita nos domicílios, que exigem uma certa elaboração antes do consumo, como os 'cereais, leguminosas e oleaginosas', 'alimentos frescos', 'proteicos' e 'leite e derivados'.

${ }^{29}$ Os alimentos 'modernos' se dividem entre os alimentos 'modernos' a serem consumidos nos domicílios, representados pelos 'refrigerantes', 'enlatados e conservas' e 'alimentos preparados', e os alimentos consumidos fora do domicílio, que compreendem as 'refeições' e os 'outros' tipos de alimentos, que agregam os lanches, salgadinhos, sucos, etc. 
deve ser alvo de atenção do poder público.

O comportamento dos consumidores, por faixas etárias ${ }^{30}$, é relativamente homogêneo para três grandes grupos: pessoas de famílias com crianças e adolescentes (de até 20 anos), com jovens de 21 a 30 anos e com pessoas de 51 anos ou mais. Pessoas do primeiro e do último grupo comem com menos freqüência fora do domicílio do que as demais, mas, o nível de consumo per capita de alimentos fora do domicílio é maior para as famílias com pessoas de 51 anos ou mais do que para as com crianças e adolescentes. Na alimentação no domicílio, as pessoas de famílias com pessoas de 51 anos ou mais privilegiam o consumo de alimentos 'tradicionais' enquanto, as com crianças e adolescentes não discriminam entre esses e os alimentos 'modernos'.

As pessoas de famílias com grande proporção de jovens de 21 a 30 anos consomem mais alimentos fora do domicílio que todas as demais, mas seja por restrição de tempo, seja por despreocupação com a questão nutricional, consomem mais dos 'outros' tipos de alimentos (lanches, salgadinhos, sucos, etc.) do que as 'refeições'. No domicílio, pessoas dessa faixa etária também não discriminam o padrão alimentar.

Com base nessas observações, pode-se inferir que o envelhecimento esperado da população acabe por 'mesclar' mais os padrões 'tradicionais' e 'modernos' de alimentação entre as famílias brasileiras, mas não que venha ocorrer a substituição do primeiro. Isso evidencia-se na não discriminação entre o consumo de alimentos 'tradicionais' ou 'modernos' no domicílio por pessoas de famílias com crianças e adolescentes e na certa 'focalização' do hábito de comer fora do domicílio entre os jovens de 21 a 30 anos. Sendo os hábitos formados principalmente na infância, pode-se dizer que o costume de se fazer as refeições no domicílio não se perderá e, se nesse período aprendeu-se a valorizar os alimentos 'tradicionais', esses devem continuar tendo seu espaço às mesas dos brasileiros, ainda que em proporção menor.

A existência de mulheres que chefiam os domicílios ou são cônjuges e trabalham fora de casa, auferindo alguma renda, nas famílias, por sua vez, propicia um tipo de alimentação 'moderno' para os seus integrantes. As evidências são mais consistentes para o privilégio ao consumo de alimentos fora do domicílio do que para a alimentação 'moderna' no domicílio mais uma vez dando destaque aos ‘outros' alimentos que não as 'refeições'.

\footnotetext{
${ }^{30} \mathrm{O}$ comportamento da faixa etária mais frequiente nas famílias - pessoas de 31 a 50 anos - não foi analisado por questões técnicas.
} 
A constatação de que tanto os jovens como as pessoas de famílias que têm mulheres 'que trabalham' privilegiam a alimentação 'ligeira' fora do domicílio gera alguma preocupação principalmente para o último grupo, uma vez que cada vez mais as mulheres estão se inserindo no mercado de trabalho e, o seu exemplo à prole é fundamental para a formação dos hábitos das gerações futuras.

As diferentes organizações familiares ${ }^{31}$ também apresentam impactos relativamente diferenciados sobre o consumo alimentar das pessoas. Mais uma vez essa diferenciação recai na alimentação a ser feita fora dos domicílios, uma vez que dentro deles não existem evidências de discriminação de padrão alimentar. As pessoas dos diferentes 'tipos' familiares consomem mais alimentos fora do domicílio que as 'famílias tradicionais'. Em geral essas pessoas consomem menos as 'refeições' e mais os 'outros' alimentos a serem consumidos fora do domicílio. Assim, ao procurar promover qualquer campanha na tentativa de estimular as pessoas a terem um padrão de alimentação mais saudável, fora do domicílio, esse tipos familiares deveriam ser focados, sobretudo as 'novas famílias' - que são uma categoria em ascensão e que necessariamente têm crianças aos seus cuidados.

Acredita-se que o prolongamento desse estudo, numa análise temporal das mesmas variáveis, seria de grande proveito para a compreensão mais profunda do tema.

\footnotetext{
${ }^{31}$ Os diferentes tipos familiares explorados são: Familias Tradicionais: domicílios compostos pela pessoa de referência e seu cônjuge; com ou sem filhos, outros parentes e empregados e sem não-parentes); Novas familias (domicílios compostos pela pessoa de referência e filhos, sem cônjuge; com ou sem outros parentes e empregados: e sem não-parentes); Famílias Complexas (domicílios habitados pelos tipos familiares acima citados, incluindo obrigatoriamente a presença de não-parentes; ou a simples coabitação de parentes que não cônjuges ou filhos, com ou sem não-parentes ou empregados); Domicílios Unitários (domicílios habitados somente pela pessoa de referência, com ou sem empregados).
} 


\title{
APÊNDICE
}

\section{Saída do modelo $\log$-log , do software LIMDEP, para o item 'alimentação em geral'}

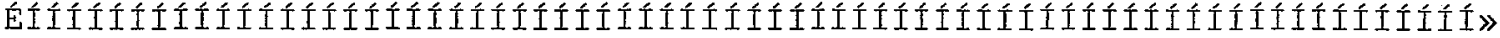 \\ - LIMDEP Estimation Results \\ - Current sample contains 16042 observations. \\ Run log line 7 Page $2{ }^{\circ}$
}

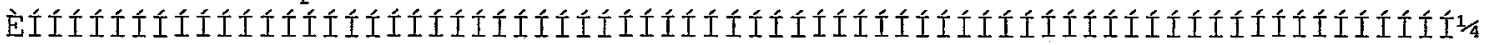

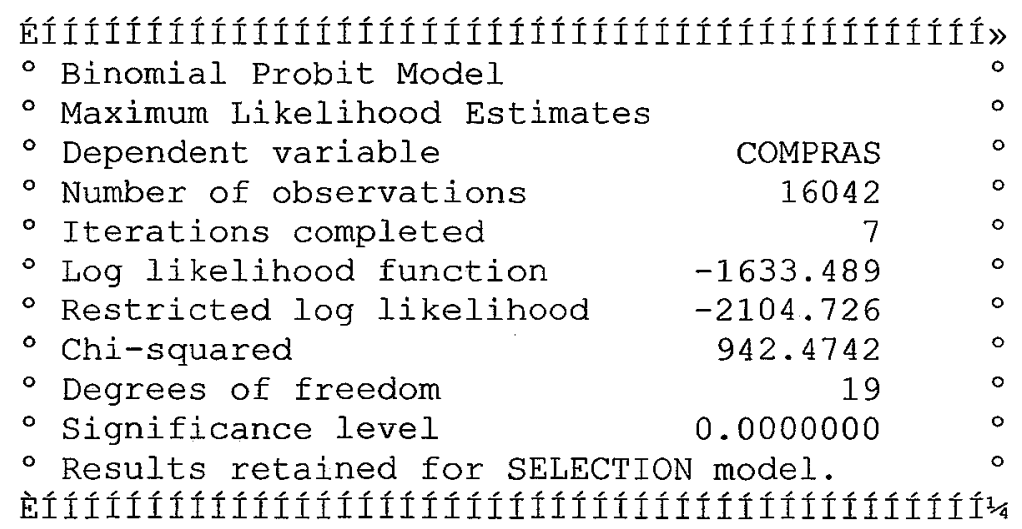

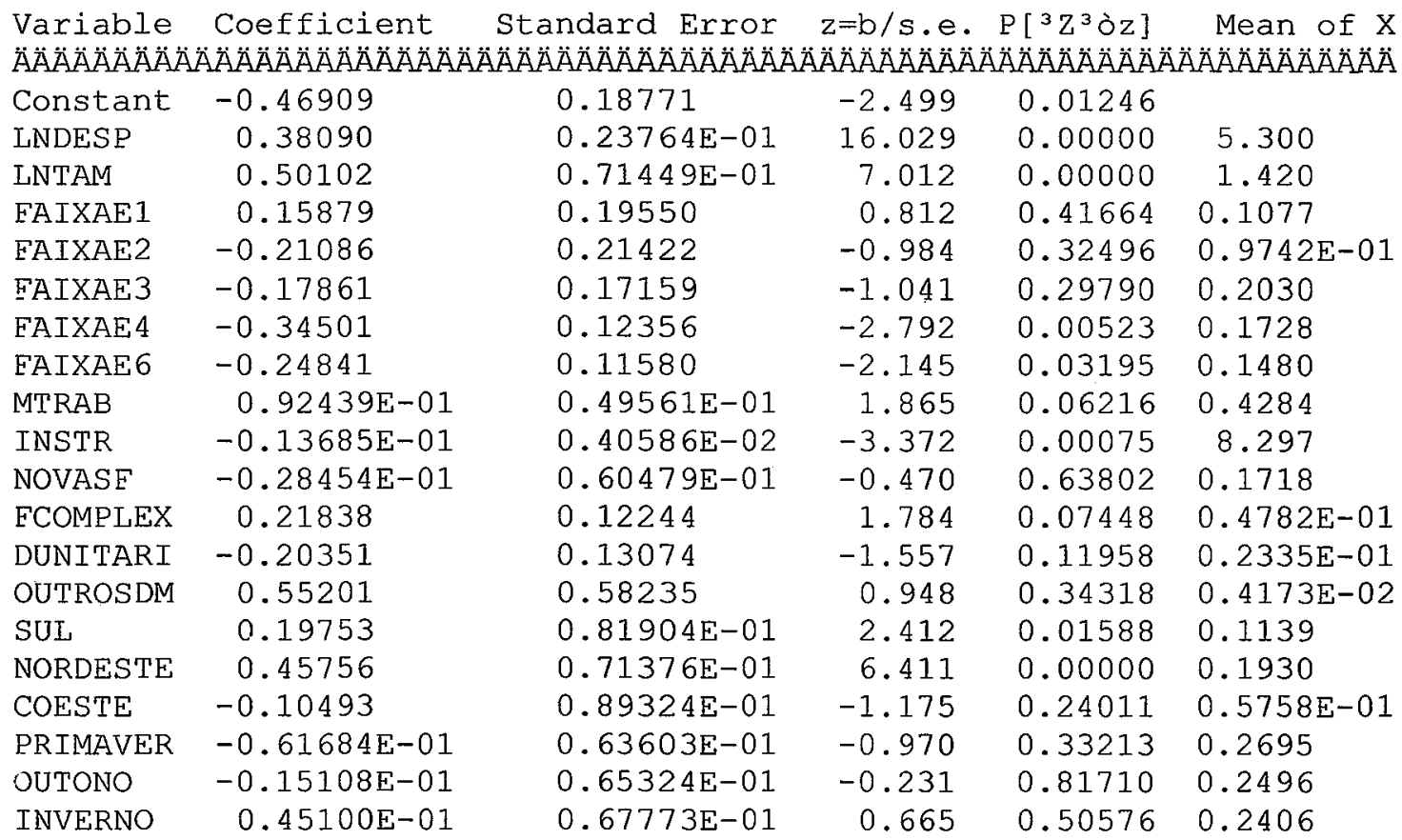




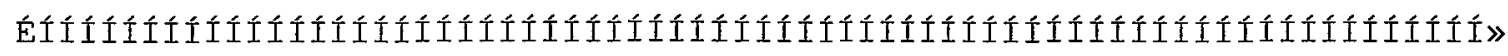

- LIMDEP Estimation Results

'Current sample contains 16042 observations. Run log line 7 Page $3 \%$

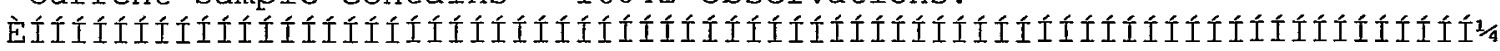

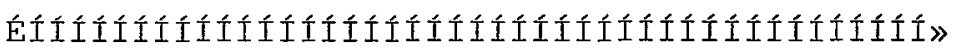

- Partial derivatives of $E[y]=$ è [*] with ${ }^{\circ}$

- respect to the vector of characteristics. ०

- They are computed at the means of the Xs.

- Observations used for means are All Obs. 0

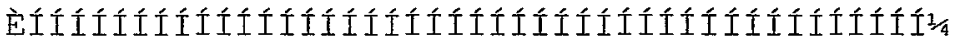

\begin{tabular}{|c|c|c|c|c|c|}
\hline $\begin{array}{l}\text { Variable } \\
\ddot{A} \ddot{A ̈} \ddot{A ̈} \ddot{A} \ddot{A} \ddot{A} \ddot{A} \ddot{A}\end{array}$ & $\begin{array}{l}\text { Coefficient } \\
\ddot{A} \ddot{A} \ddot{A} \ddot{A} \ddot{A} \ddot{A} \ddot{A} \ddot{A} \ddot{A} \ddot{A} \ddot{A} \ddot{A} \dot{A}\end{array}$ & 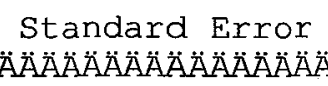 & $\begin{array}{l}z=b / s . e \\
\ddot{A} \ddot{A} \ddot{A} \ddot{A} \ddot{A} \ddot{A} \ddot{A}\end{array}$ & 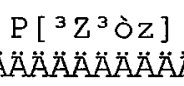 & $\begin{array}{r}\text { Mean of } X \\
\ddot{A} \ddot{A} \ddot{A} \ddot{A} \ddot{A} \ddot{A} \ddot{A} \ddot{A} \ddot{A} \ddot{A} \ddot{A}\end{array}$ \\
\hline Constant & $-0.18575 E-01$ & $0.72323 \mathrm{E}-02$ & -2.568 & 0.01022 & \\
\hline LNDESP & $0.15082 \mathrm{E}-01$ & $0.97930 \mathrm{E}-03$ & 15.401 & 0.00000 & 5.300 \\
\hline LNTAM & $0.19839 \mathrm{E}-01$ & $0.28006 \mathrm{E}-02$ & 7.084 & 0.00000 & 1.420 \\
\hline EAIXAE1 & $0.62878 E-02$ & $0.77446 \mathrm{E}-02$ & 0.812 & 0.41685 & 0.1077 \\
\hline EAIXAE2 & $-0.83493 \mathrm{E}-02$ & $0.84696 \mathrm{E}-02$ & -0.986 & 0.32423 & $0.9742 E-01$ \\
\hline EAIXAE3 & $-0.70726 \mathrm{E}-02$ & $0.67866 \mathrm{E}-02$ & -1.042 & 0.29735 & 0.2030 \\
\hline FAIXAE4 & $-0.13661 \mathrm{E}-01$ & $0.48737 \mathrm{E}-02$ & -2.803 & 0.00506 & 0.1728 \\
\hline FAIXAE 6 & $-0.98363 E-02$ & $0.45914 \mathrm{E}-02$ & -2.142 & 0.03217 & 0.1480 \\
\hline MTRAB & $0.36603 \mathrm{E}-02$ & $0.19595 \mathrm{E}-02$ & 1.868 & 0.06176 & 0.4284 \\
\hline INSTR & $-0.54186 E-03$ & $0.16201 \mathrm{E}-03$ & -3.345 & 0.00082 & 8.297 \\
\hline NOVASF & $-0.11267 \mathrm{E}-02$ & $0.23946 \mathrm{E}-02$ & -0.471 & 0.63799 & 0.1718 \\
\hline FCOMPLEX & $0.86473 \mathrm{E}-02$ & $0.48395 \mathrm{E}-02$ & 1.787 & 0.07397 & $0.4782 \mathrm{E}-01$ \\
\hline DUNITARI & $-0.80583 E-02$ & $0.52116 \mathrm{E}-02$ & -1.546 & 0.12205 & $0.2335 E-01$ \\
\hline OUTROSDM & $0.21858 \mathrm{E}-01$ & $0.23021 \mathrm{E}-01$ & 0.949 & 0.34237 & $0.4173 E-02$ \\
\hline SUL & $0.78214 E-02$ & $0.32335 E-02$ & 2.419 & 0.01 & 0.1139 \\
\hline NORDESTE & $0.18118 E-01$ & $0.27687 E-02$ & 6.544 & 0.00000 & 0.1930 \\
\hline COESTE & $-0.41550 \mathrm{E}-02$ & $0.35397 E-02$ & -1.174 & 0.24046 & $0.5758 \mathrm{E}-01$ \\
\hline PRIMAVER & $-0.24425 E-02$ & $0.25183 \mathrm{E}-02$ & -0.970 & 0.33210 & 0.2695 \\
\hline OUTONO & $-0.59824 \mathrm{E}-03$ & $0.25862 \mathrm{E}-02$ & -0.231 & 0.81707 & 0.2496 \\
\hline INVERNO & $0.17858 \mathrm{E}-02$ & $0.26844 \mathrm{E}-02$ & 0.665 & 0.50588 & 0.2406 \\
\hline
\end{tabular}

Frequencies of actual \& predicted outcomes Predicted outcome has maximum probability.

Eredicted

\begin{tabular}{|c|c|c|}
\hline Actual & 0 & 1 \\
\hline 0 & 5 & 460 \\
\hline 1 & 0 & 15577 \\
\hline TOTAL & 5 & 16037 \\
\hline
\end{tabular}




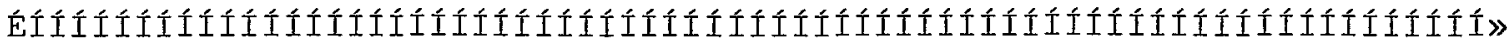
${ }^{\circ}$ LIMDEP Estimation Results ${ }^{\circ}$ Current sample contains 16042 observations. $n$ log line 9 Page 4 잉

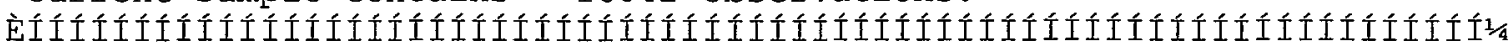

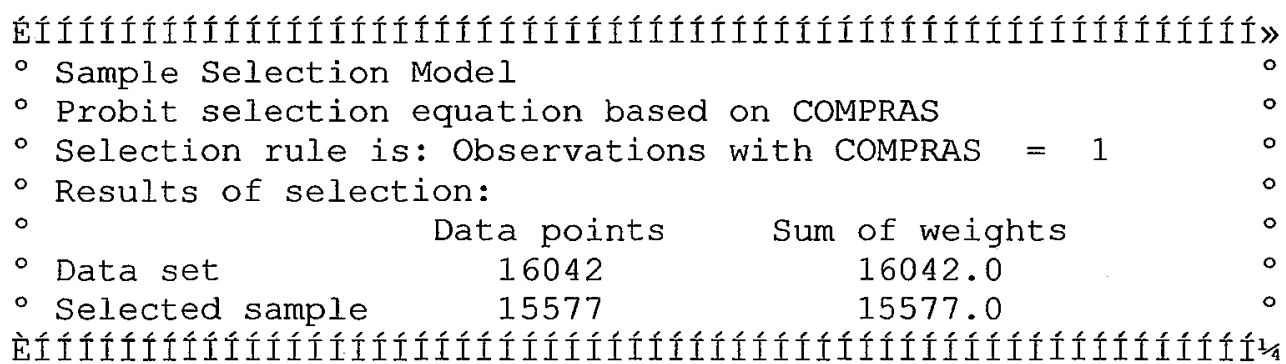

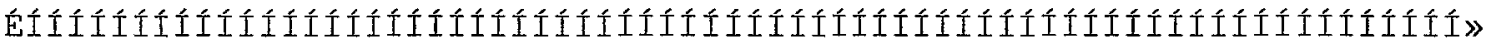
- Sample Selection Model

-Two stage least squares regression Weighting variable $=$ EXPANSAO ${ }^{\circ}$ ${ }^{\circ}$ Dependent variable is LNALIM Mean $=3.68469, \quad$ S.D. $=1.0284^{\circ}$ ${ }^{\circ}$ Model size: Observations $=15577$, Parameters $=20$, Deg.Fr. $=15557^{\circ}$ ${ }^{\circ}$ Residuals: Sum of squares $=8594.62 \quad$ Std.Dev. $=\quad 0.74328^{\circ}$ ${ }^{\circ}$ Fit:

$\circ$ $\mathrm{R}$-squared $=0.47755$, Adjusted R-squared $=0.47691^{\circ}$ Note: Not using OLS. R-squared is not bounded in $[0,1]^{\circ}$ ${ }^{\circ}$ Model test: $\mathrm{F}[19,15557]=748.42, \quad$ Prob value $=0.00000^{\circ}$ ${ }^{\circ}$ Diagnostic: Log-L $=-17471.2997$, Restricted(á=0) Log-I $=-22537.8026^{\circ}$ - Amemiya Pr. Crt.= 0.553, Akaike Info. Crt. $=2.246^{\circ}$ - Standard error corrected for selection.... 1.0817

- Correlation of disturbance in regression

- and Selection Criterion (Rho).......... -1.0000

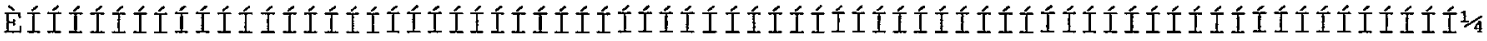

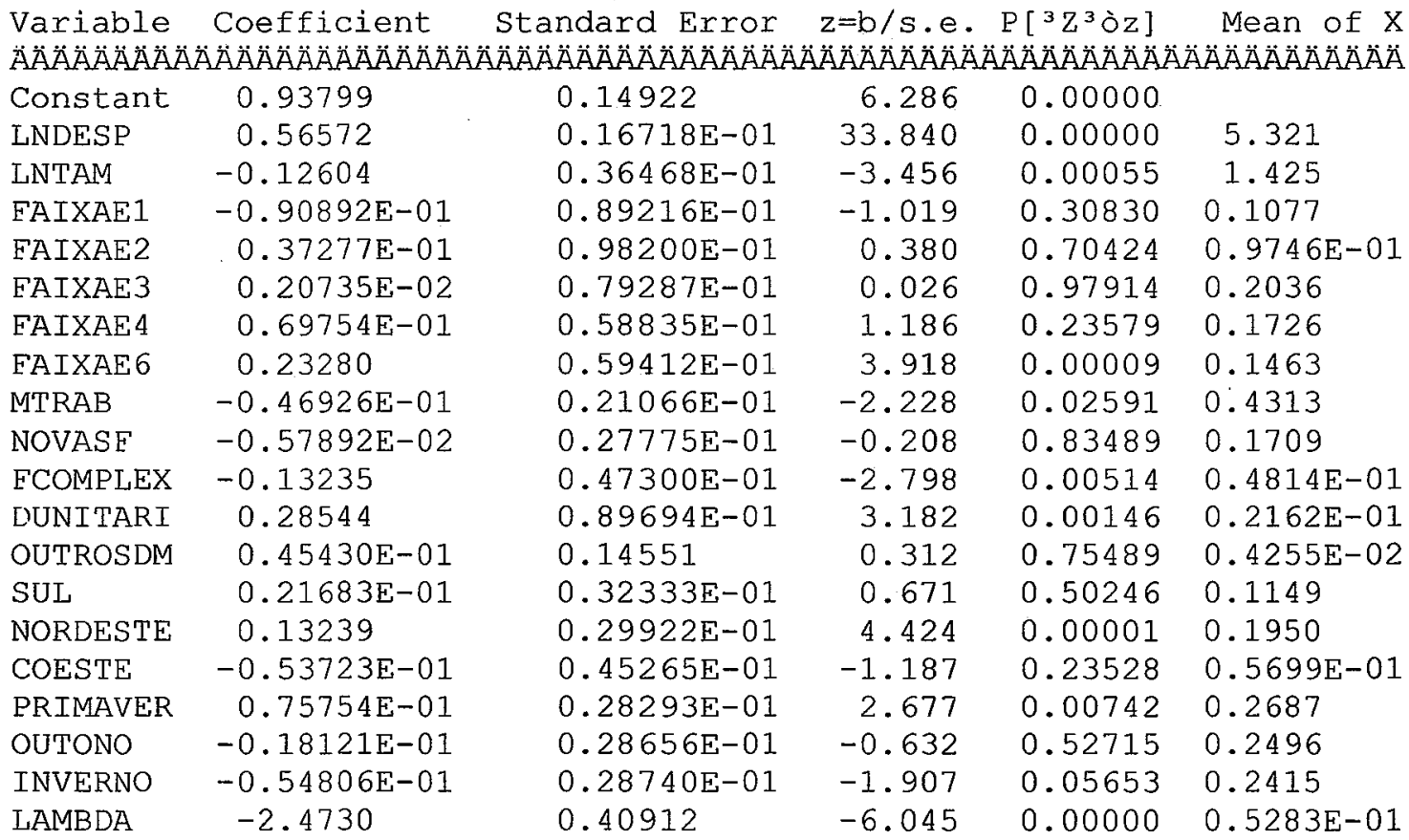




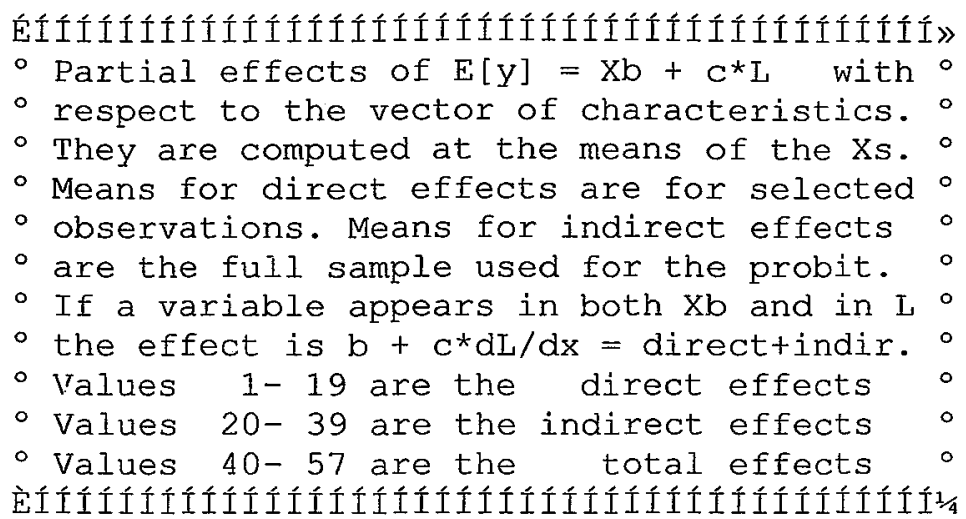

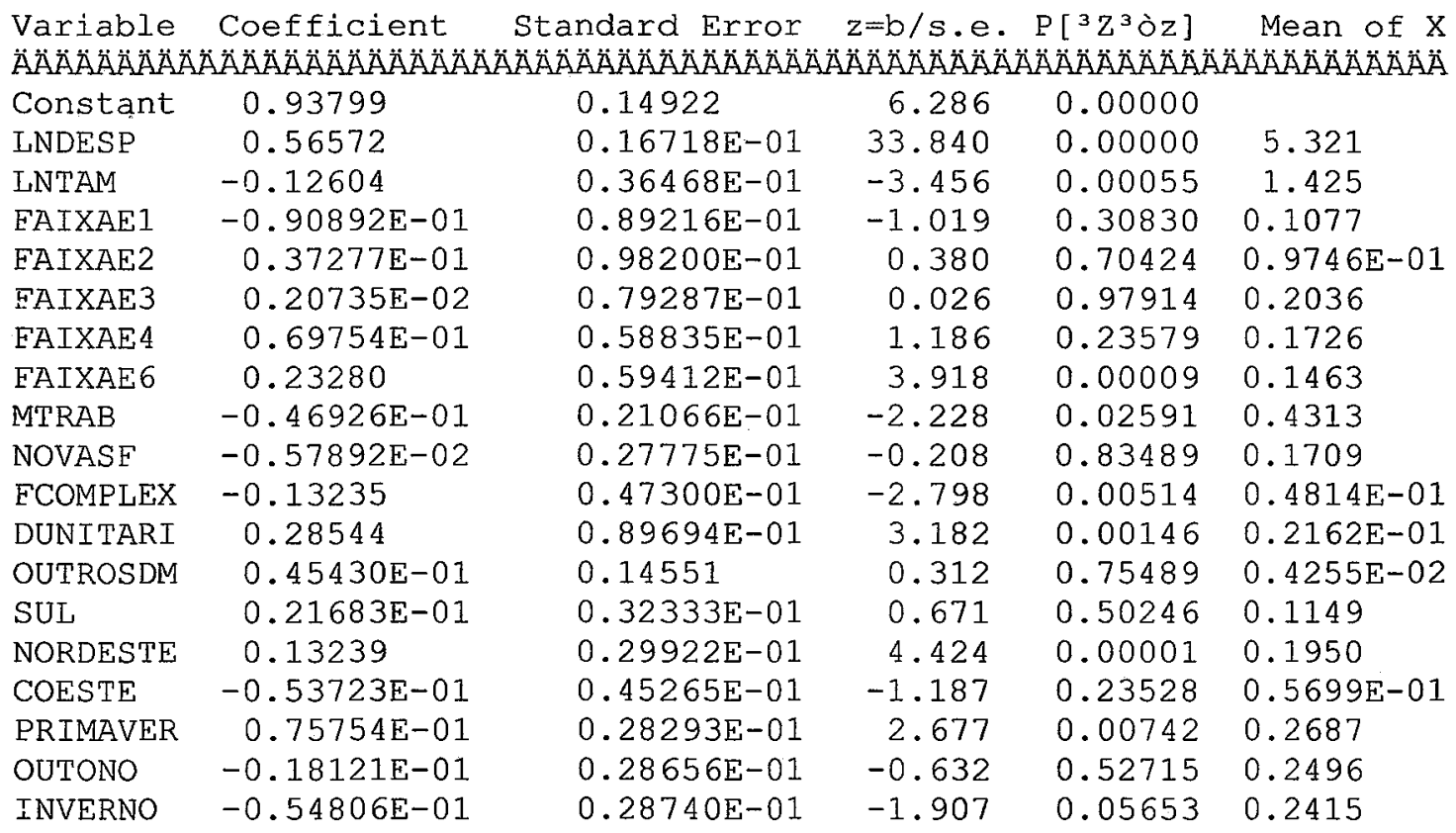




\begin{tabular}{|c|c|c|c|c|c|}
\hline 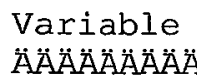 & 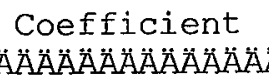 & 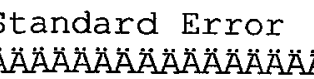 & 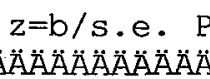 & 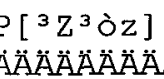 & 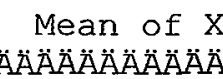 \\
\hline Constant & -0.10332 & $0.19320 \mathrm{E}-01$ & -5.348 & 0.00000 & \\
\hline LNDESP & $0.83896 \mathrm{E}-01$ & $0.65272 E-02$ & 12.853 & 0.00000 & 5.312 \\
\hline LNTAM & 0.11035 & $0.94961 \mathrm{E}-02$ & 11.621 & 0.00000 & 1.233 \\
\hline FAIXAE 1 & $0.34976 \mathrm{E}-01$ & $0.17637 \mathrm{E}-01$ & 1.983 & 0.04736 & $0.9590 \mathrm{E}-01$ \\
\hline EAIXAE2 & $-0.46443 E-01$ & $0.19491 \mathrm{E}-01$ & -2.383 & 0.01718 & $0.8274 \mathrm{E}-01$ \\
\hline EAIXAE3 & $-0.39341 \mathrm{E}-01$ & $0.15624 \mathrm{E}-01$ & -2.518 & 0.01180 & 0.1797 \\
\hline FAIXAE4 & $-0.75991 \mathrm{E}-01$ & $0.12379 \mathrm{E}-01$ & -6.139 & 0.00000 & 0.1855 \\
\hline EAIXAE 6 & $-0.54714 E-01$ & $0.11215 E-01$ & -4.878 & 0.00000 & 0.1831 \\
\hline MTRAB & $0.20360 \mathrm{E}-01$ & $0.46717 \mathrm{E}-02$ & 4.358 & 0.00001 & 0.4234 \\
\hline INSTR & $-0.30141 E-02$ & $0.41225 \mathrm{E}-03$ & -7.311 & 0.00000 & 8.524 \\
\hline NOVASE & $-0.62672 \mathrm{E}-02$ & $0.53932 E-02$ & -1.162 & 0.24521 & 0.1788 \\
\hline ECOMPLEX & $0.48101 \mathrm{E}-01$ & $0.11498 \mathrm{E}-01$ & 4.183 & 0.00003 & $0.5822 E-01$ \\
\hline DUNITARI & $-0.44824 E-01$ & $0.11975 \mathrm{E}-01$ & -3.743 & 0.00018 & $0.7942 E-01$ \\
\hline OUTROSDM & 0.12158 & $0.52891 E-01$ & 2.299 & 0.02152 & $0.5797 \mathrm{E}-02$ \\
\hline SUL & $0.43506 \mathrm{E}-01$ & $0.83444 \mathrm{E}-02$ & 5.214 & 0.00000 & 0.1445 \\
\hline NORDESTE & 0.10078 & $0.11752 \mathrm{E}-01$ & 8.576 & 0.00000 & 0.4238 \\
\hline COESTE & $-0.23112 \mathrm{E}-01$ & $0.76749 \mathrm{E}-02$ & -3.011 & 0.00260 & 0.149 \\
\hline PRIMAVER & $-0.13586 E-01$ & $0.57444 \mathrm{E}-02$ & -2.365 & 0.01802 & 0.2627 \\
\hline OUTONO & $-0.33277 E-02$ & $0.58334 \mathrm{E}-02$ & -0.570 & 0.56837 & 0.2467 \\
\hline INVERNO & $0.99336 \mathrm{E}-02$ & $0.60772 \mathrm{E}-02$ & 1.635 & 0.10214 & 0.2475 \\
\hline LNDESP & 0.64962 & $\ldots \ldots \ldots$ (Fixed & Parameter) & & 5.321 \\
\hline LNTAM & $-0.15688 \mathrm{E}-01$ & $\ldots \ldots$. (Fixed & Parameter) & $\ldots$ & 1.425 \\
\hline F'AIXAEI & $-0.55917 \mathrm{E}-01$ & $\ldots \ldots \ldots$ (Fixed & Parameter) & & 0.1077 \\
\hline FAIXAE2 & $-0.91664 \mathrm{E}-02$ & $\ldots \ldots \ldots$ (Fixed & Parameter) & & $0.9746 E-01$ \\
\hline FAIXAE3 & $-0.37268 E-01$ & $\ldots \ldots \ldots$ (Fixed & Parameter) & & 0.2036 \\
\hline EATXAE 4 & $-0.62375 E-02$ & $\ldots \ldots \ldots$ (Fixed & Parameter) & & 0.1726 \\
\hline EAIXAE 6 & 0.17809 & $\ldots \ldots \ldots$ (Eixed & Parameter) & & 0.1463 \\
\hline MTRAB & $-0.26565 \mathrm{E}-01$ & $\ldots \ldots \ldots$ (Fixed & Parameter) & & 0.4313 \\
\hline NOVASE & $-0.12056 \mathrm{E}-01$ & $\ldots \ldots \ldots$ (Eixed & Parameter) & & 0.1709 \\
\hline ECOMPLEX & $-0.84245 E-01$ & $\ldots \ldots \ldots$ (Fixed & Parameter) & & $0.4814 \mathrm{E}-0$ \\
\hline DUNITARI & 0.24061 & $\ldots \ldots \ldots$ (Fixed & Parameter) & & $0.2162 \mathrm{E}-01$ \\
\hline OUTROSDM & 0.16701 & $\ldots \ldots \ldots$ (Fixed & Parameter) & & $0.4255 \mathrm{E}-02$ \\
\hline SUL & $0.65189 \mathrm{E}-01$ & $\ldots \ldots \ldots$ (Fixed & Parameter) & & 0.1149 \\
\hline NORDESTE & 0.23317 & $\ldots \ldots \ldots$ (Fixed & Parameter) & & 0.1950 \\
\hline COESTE & $-0.76835 E-01$ & ....... (Fixed & Parameter) & & $0.5699 \mathrm{E}-01$ \\
\hline PRIMAVER & $0.62168 \mathrm{E}-01$ & $\ldots \ldots \ldots$ (Fixed & Parameter) & & 0.2687 \\
\hline OUTONO & $-0.21449 \mathrm{E}-01$ & $\ldots \ldots$. (Fixed & Parameter) & & 0.2496 \\
\hline INVERNO & $-0.44873 E-01$ & $\ldots \ldots \ldots$ (Fixed & Parameter) & & 0.2415 \\
\hline
\end{tabular}




\section{Saída do modelo log-quadrático, do software LIMDEP, para o item 'alimentação em geral'}

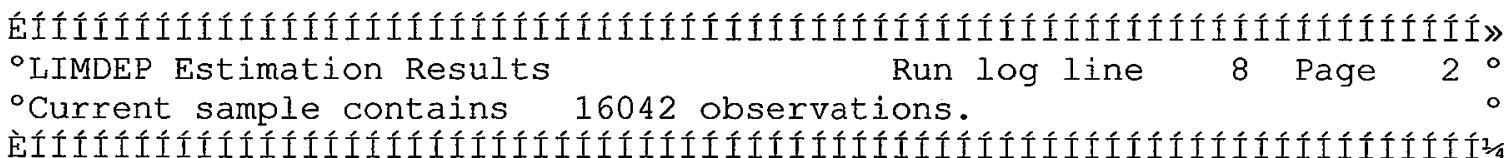

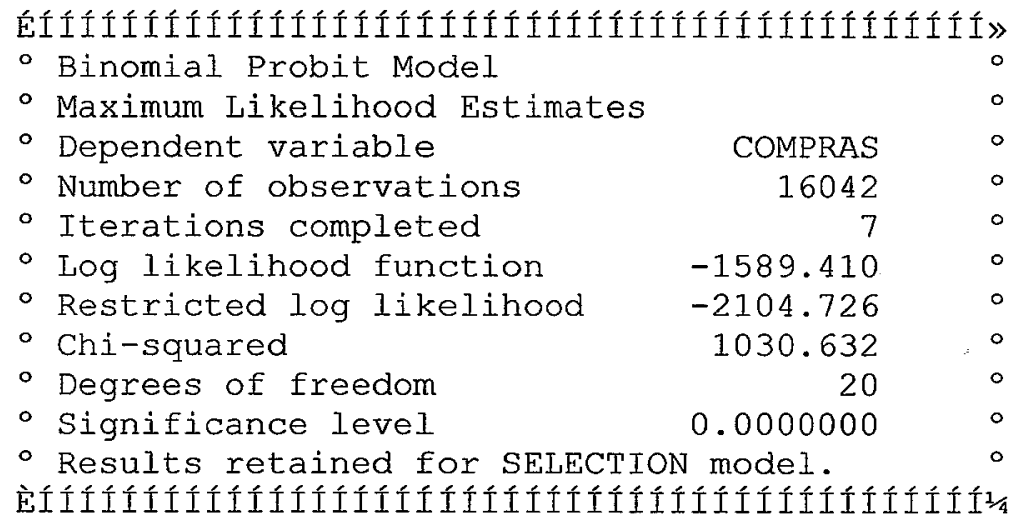

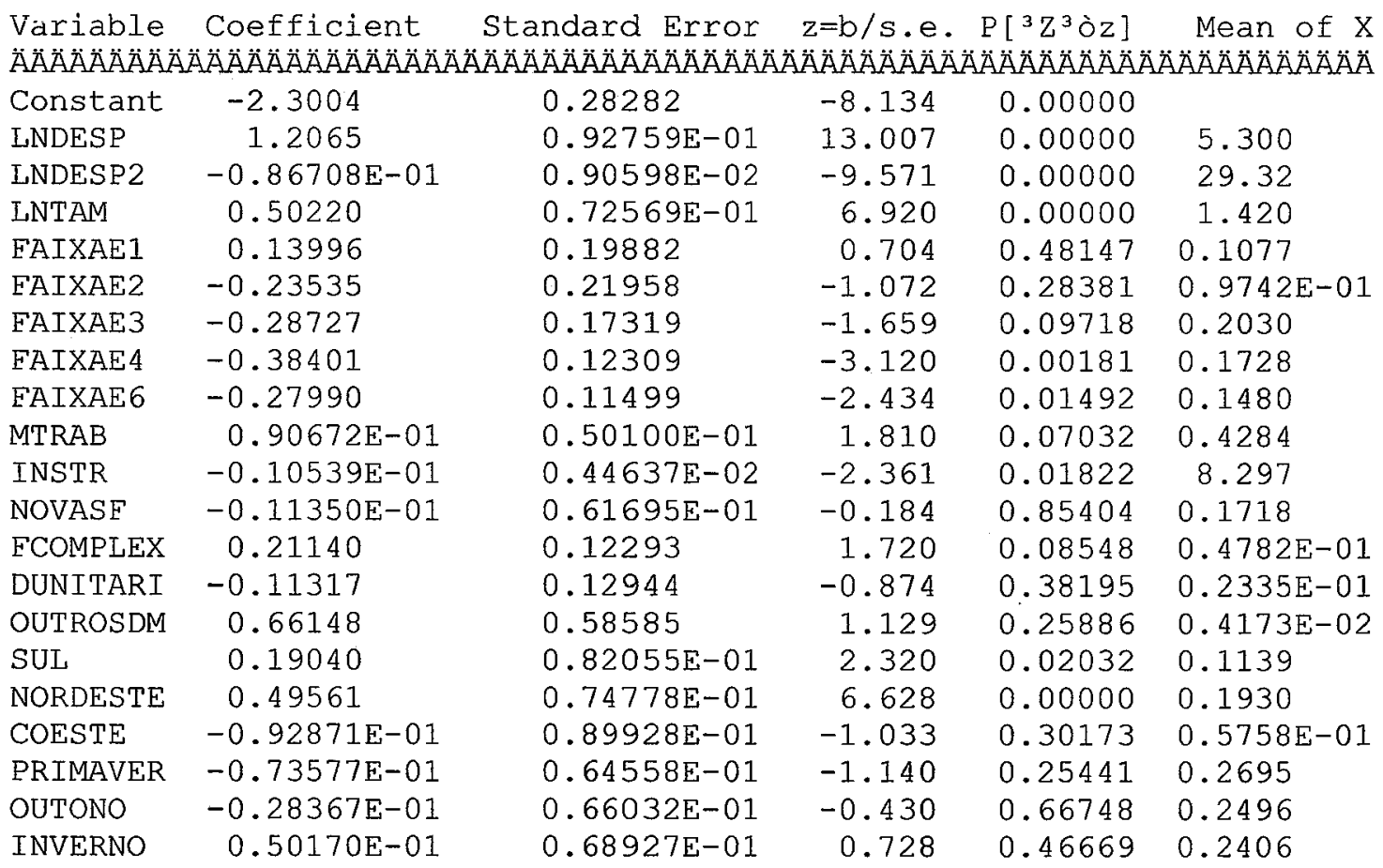




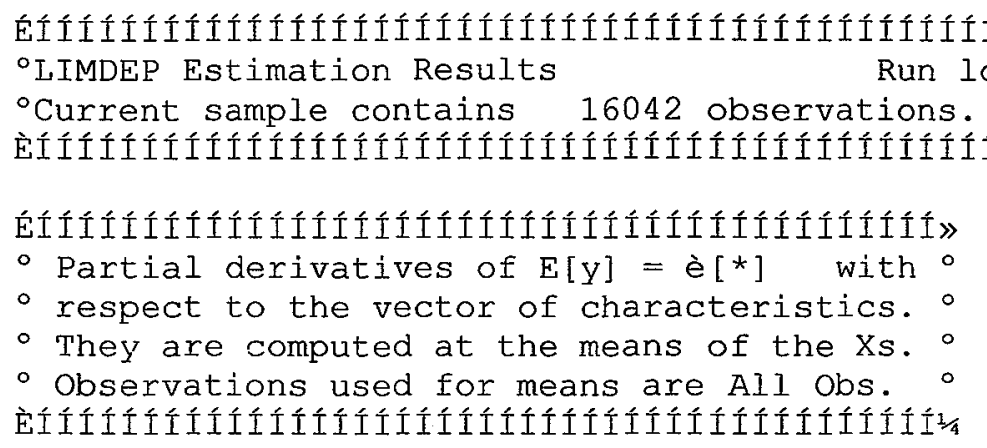

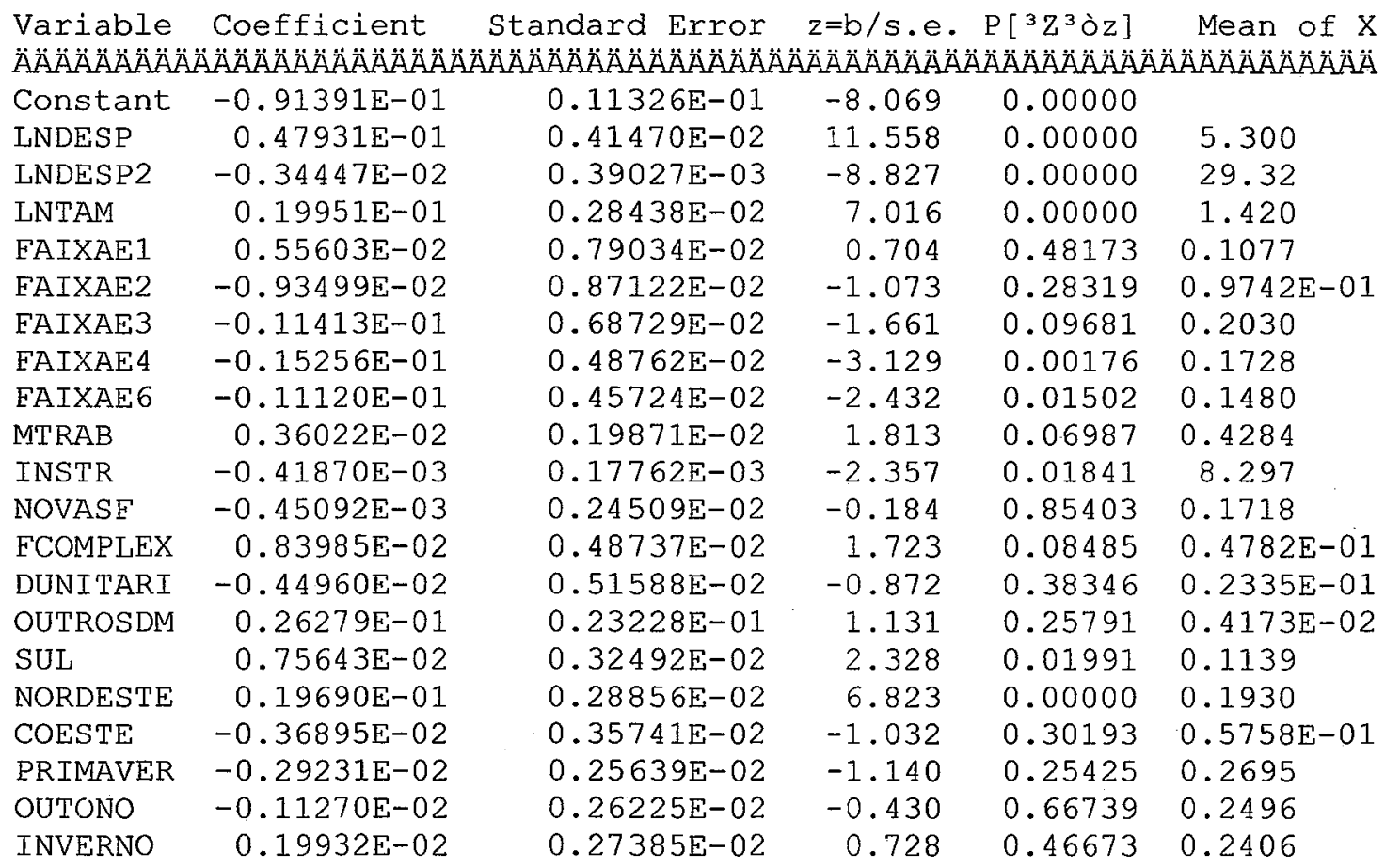

Frequencies of actual \& predicted outcomes Predicted outcome has maximum probability.

Predicted

$\begin{array}{crrr}\text { Actual } & 0 & 1 & \text { TOTAL } \\ & & & \\ 0 & 18 & 447 & 465 \\ 1 & 9 & 15568 & 15577 \\ \text { TOTAL } & 27 & 16015 & 16042\end{array}$




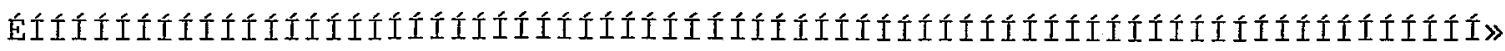
$\begin{array}{llll}{ }^{\circ} \text { IIMDEP Estimation Results } & \text { Run log line } 10 \text { Page } 4{ }^{\circ} \\ { }^{\circ} \text { Current sample contains } & 16042 \text { observations. }\end{array}$

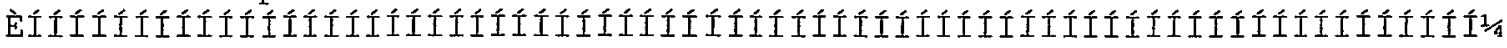

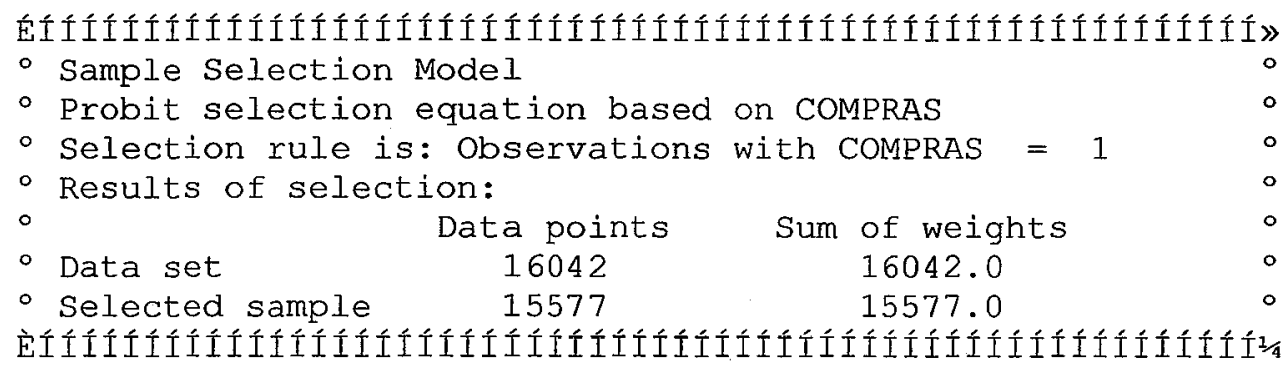

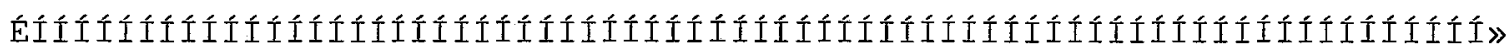
-Sample Selection Model

${ }^{\circ}$ Two stage least squares regression Weighting variable $=$ EXPANSAO ${ }^{\circ}$ ${ }^{\circ}$ Dependent variable is WAIIM Mean $=0.25637, \mathrm{~S} . \mathrm{D} .=0.1685^{\circ}$ ${ }^{\circ}$ Model size: Observations $=15577$, Parameters $=4$, Deg.Fr. $=15573^{\circ}$ -Residuals: Sum of squares= $344.826 \quad$ Std.Dev. $=0.14880^{\circ}$

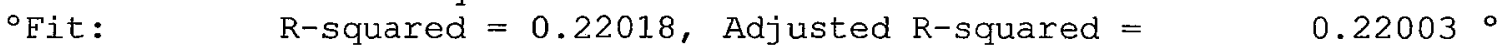
Note: Not using OLS. R-squared is not bounded in $[0,1]^{\circ}$ oModel test: $E[3,15573]=1465.65$, Prob value $=0.00000^{\circ}$ ${ }^{\circ}$ Diagnostic: $\log -\mathrm{I}=7575.3511$, Restricted(á=0) Log-L $=5636.4331^{\circ}$ - Amemiya Pr. Crt. $=0.022$, Akaike Info. Crt. $=-0.972^{\circ}$ - Standard error corrected for selection.... 0.15531

- Correlation of disturbance in regression

- and Selection Criterion (Rho).......... -0.91281

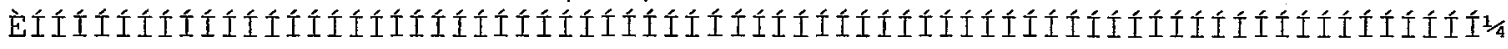

Variable Coefficient standard Error $z=b / s . e . ~ P\left[{ }^{3} \mathrm{Z}^{3} \mathrm{o} z\right]$ Mean of $\mathrm{X}$

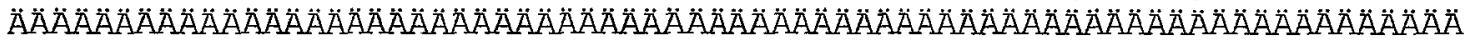
Constant
0.72675
$0.25825 \mathrm{E}-01$
28.141
$0.90942 E-02$
$-10.910$
0.00000
LNDESP
$-0.99217 \mathrm{E}-01$
LNDESP 2
$0.21976 \mathrm{E}-02$
$0.81037 \mathrm{E}-03$
2. 712
0.00000
5.321
LAMBDA
$-0.14177$
$0.27668 \mathrm{E}-01$
$-5.124$
0.00669
29.48
0.00000
$0.5134 \mathrm{E}-01$ 


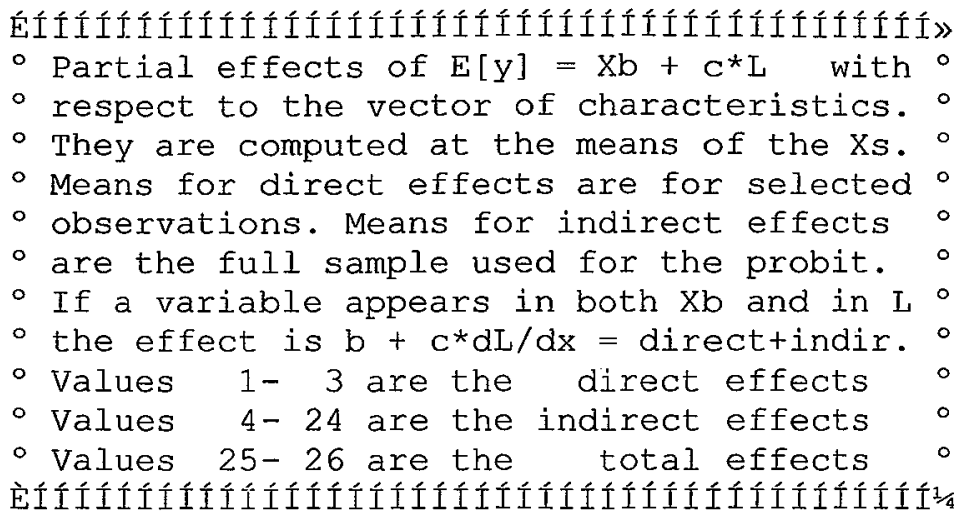

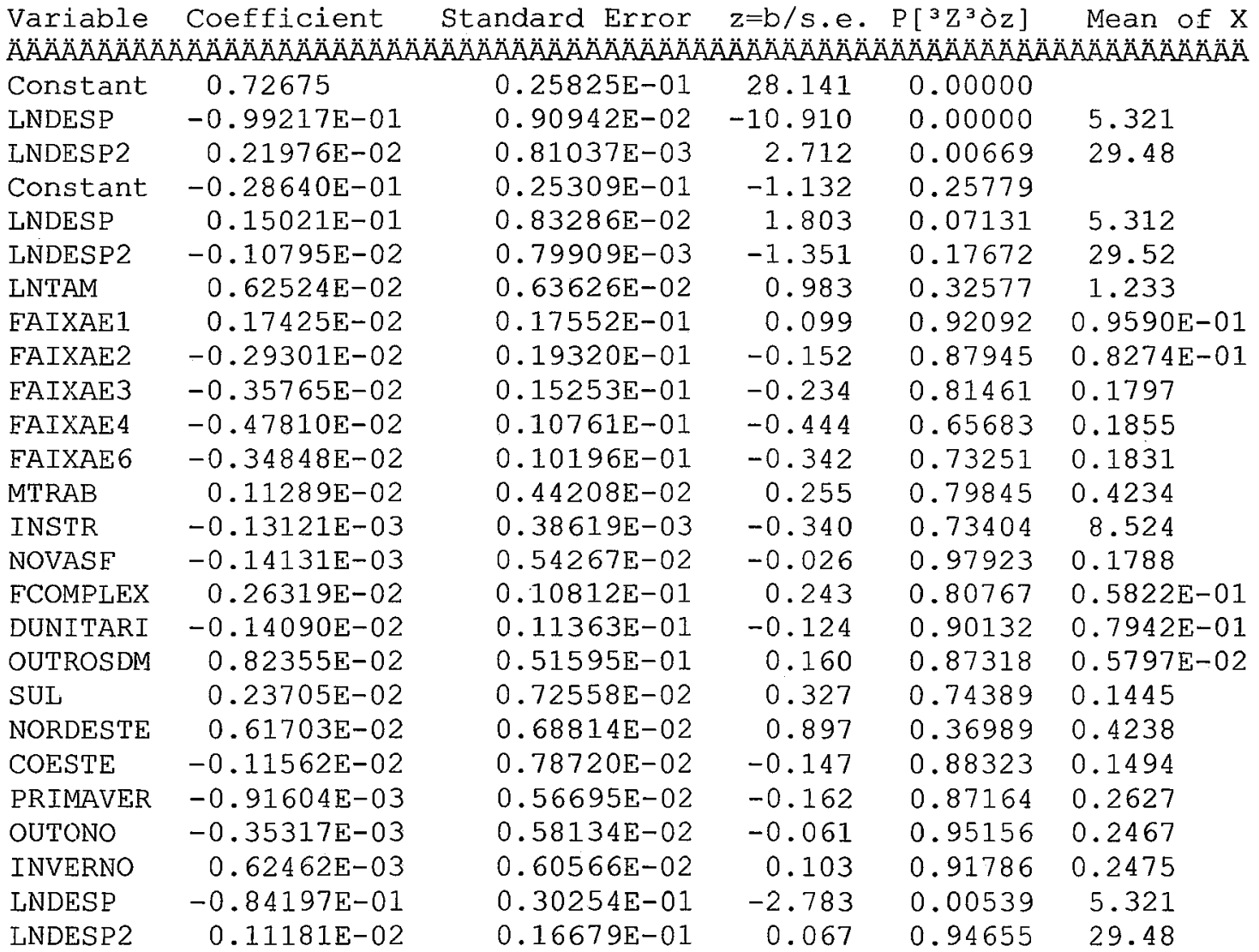




\section{Saída do modelo poligonal $\log$-log, do software cedido pelo Professor Rodolfo}

\section{Hoffmann, para o item 'alimentação em geral'}

ANALISE DE DADOS INDIVIDUAIS da POF 95-96 - DETERM. DA ELASTIC. da DESPESA (CONSUMO) PER CAP. EM RELACAO À DESPESA GLOBAI MENSAL PER CAP. AJUSTE DE UMA POLIGONAL LOG-LOG - PROGRAMA POLPCYD5

REGRESSAO MULTIPLA PONDERADA DE Y CONTRA $X(1), X(2) \mathrm{E} X(3)$ ESTIMATIVA DO PARAMETRO E DO SEU DESVIO PADRAO E TESTE T

\begin{tabular}{|c|c|c|c|}
\hline A & B1 & $\mathrm{B} 2$ & B3 \\
\hline \multicolumn{4}{|c|}{ 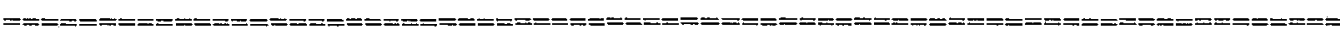 } \\
\hline $\begin{array}{r}-0.482961 \\
0.134801 \\
-3.582760\end{array}$ & $\begin{array}{r}0.850436 \\
0.033219 \\
25.601270\end{array}$ & $\begin{array}{r}-0.070663 \\
0.054791 \\
-1.289678\end{array}$ & $\begin{array}{r}-0.204240 \\
0.034008 \\
-6.005708\end{array}$ \\
\hline
\end{tabular}

$\begin{array}{ccrrrr}\text { COEF.DETER. } & \text { COEF.CORR. } & \text { TESTE F } & \text { S.Q.RES. } & \text { DESV.PADR.RES. } & \text { C.V. } \\ 0.999585 & 0.999793 & 4819.7569 & 0.002222 & 0.019243 & 0.004819\end{array}$

\begin{tabular}{|c|c|c|c|c|}
\hline OBSERVACAO & $Y$ & Y ESTIMADO & DESVIO & DESVIO REDUZ. \\
\hline & & & & \\
\hline 1 & 2.506094 & 2.504758 & 0.001337 & 0.069469 \\
\hline 2 & 3.093342 & 3.098888 & -0.005546 & -0.288207 \\
\hline 3 & 3.414077 & 3.396581 & 0.017496 & 0.909217 \\
\hline 4 & 3.603144 & 3.616099 & -0.012955 & -0.673230 \\
\hline 5 & 3.809876 & 3.828987 & -0.019111 & -0.993141 \\
\hline 6 & 4.046463 & 4.017344 & 0.029119 & 1.513238 \\
\hline 7 & 4.168283 & 4.180509 & -0.012227 & -0.635394 \\
\hline 8 & 4.379491 & 4.366847 & 0.012643 & 0.657043 \\
\hline 9 & 4.603100 & 4.616914 & -0.013813 & -0.717848 \\
\hline 10 & 5.189886 & 5.186717 & 0.003169 & 0.164661 \\
\hline
\end{tabular}
S.Q.RES. PONDERADOS
DURBIN-WATSON NAO-POND.
MEDIA POND. QUADR. DESV.DESP. 0.002221734

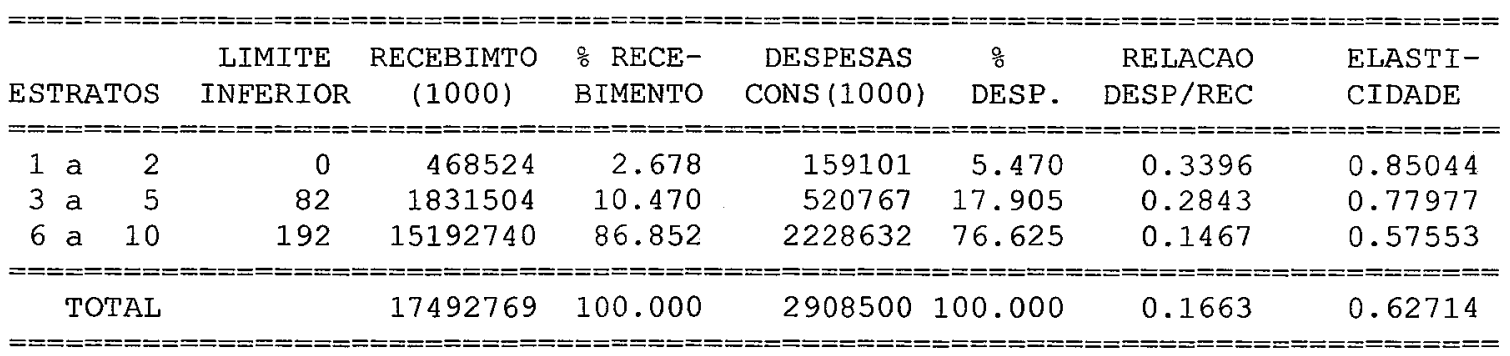

ELASTICIDADE DESV.PADR. $t$ 0.627140

\subsection{3}

INTERV.de $90 \%$ de CONEIANCA
$\begin{array}{ll}0.614958 & 0.639322\end{array}$

TESTE $t$ PARA ELASTICIDADE $=0$

100.026871 


\section{Referências Bibliográficas}

BANKS, J.; BLUNDELL, R.; LEWBEL, A. Quadratic Engel Curves and Consumer Demand. The Review of Economics and Statistics. Vol XXIX, Number 4, 527-539, November, 1997.

BARROS, R.P., MENDONÇA, R. A evolução do bem-estar, pobreza e desigualdade no Brasil ao longo das últimas três décadas - 1960/90. Pesquisa e Planejamento Econômico. Rio de Janeiro, v.25, $\mathrm{n}^{\circ} 1, \mathrm{p}$ 115-164, abr-1995.

BLEIL, S. I. O Padrão Alimentar Ocidental: Considerações sobre a mudança de hábitos no Brasil. Cadernos de Debate, Vol. VI, 1998.

BLISARD, N. AND BLAYLOCK, J.R. U.S. Demand for Food: Household Expenditures, Demographics, and Projections for 1990-2010. Commodity Economics Division, Economic Research Service, USDA. Technical Bulletin No. 1818. Washington, DC. December, 1993.

BLUNDELL, R. Consumer Behaviour: Theory and Empirical Evidence - A Survey. The Economic Journal. Vol 98, Number 389, 16-65, March, 1988.

BOLETIM DO BANCO CENTRAL DO BRASIL. Volume 35, n²12, Brasília, dezembro, 1999.

COX, T.L, AND M.K. WOHLGENANT. Prices and Quality Effects in Cross-Sectional Demand Analysis. Amer. J. Agr. Econ., Volume 68, November 1986: 908-19. 
DEATON, A. Demand Analysis. In: GRILICHES AND M.D. INTRILIGATOR (Edited by). Handbook of Econometrics, Vol III. Amsterdam: North-Holland, 1986. cap.30, p.1767-1839.

DEATON, A. Understanding Consumption. New York: Oxford University Press Inc., 1992. 242p.

DEATON, A. The Analysis of Household Surveys - A Microeconometric Approach to Development Policy. Washington, D.C.: The International Bank for Reconstroction and Development/The World Bank, 1997.479p.

DEATON, A, MUEllbaUER, J. Economics and Consumer Behaviour. Cambridge: Cambridge University Press, 1980.450p.

GALLO, A.E. Food Advertising in the United States. In America's Eating Habits: Changes and Consequences. U.S. Departement of Agriculture, Economic Research Service, Food and Rural Economics Division. Information bulletin $\mathrm{N}^{\circ} 484$ pp. May 1999

GOLDANI, AM. Changing Brasilian families and the consequent need for policy. Social Science Journal: Changing Family Patterns. November. 1990. p.523-537

GREENE, W.H. Econometric Analisys. Third edition. USA: Macmillan, 1993.791p.

GREENE, W.H. Econometric Analisys. Fourth edition. USA: Macmillan, 2000.1004p.

GREENE, W.H. LIMDEP Version 7.0 - User's Guide. USA: Econometric Software, Inc., 1995,850 p.

HECKMAN, J.J. Sample Selection Bias as a Specification Error. Econometrica, Volume 47, January 1979: p.153-161.

HEIN, D.; DURHAM, C. A Test of the Habit Formation Hypothesis using Household data. The Review of Economics and Statistics, Vol. 73, May 1991: p.189-199. 
HOFFMANN, R.; FURTUOSO, M. C. O. Determinação da Elasticidade-Renda da Demanda de Alimentos no Estado de São Paulo Através do Ajustamento de uma Poligonal. In: III Encontro Brasileiro de Econometria, Olinda-PE, 1981. Anais. p.455-471.

HOFFMANN, R.; VIEIRA, S. Análise de Regressão - Uma Introdução à econometria. São Paulo: Editora HUCITEC, 1987, 379 p.

HOFFMANN, R. Elasticidades-renda das despesas e do consumo físico de alimentos no Brasil metropolitano em 1995-96. 2000. A ser publicado.

HOFFMANN, R. Desigualdade e Pobreza no Brasil no Periodo 1979-99. IE-UNICAMP, texto não publicado, Set/2000a, 24p.

IBGE. Anuário Estatístico do Brasil - 1971. Rio de Janeiro: Instituto Brasileiro de Geografia e Estatística, 1972.

IBGE. Pesquisa de Orçamentos Familiares 1995-1996. Primeiros Resultados. Rio de Janeiro: Instituto Brasileiro de Geografia e Estatística, 1997.

IBGE. Anuário Estatístico do Brasil - 1997. Rio de Janeiro: Instituto Brasileiro de Geografia e Estatística, 1998.

KASSOUF, A.L. Saneamento e Educação, Bens Substitutos ou Complementares?. Anais do XXII Encontro Nacional de Economia. Florianópolis. Dezembro. 1994.

KINSEY, J. D.. Food and Families' Socioeconomic Status. The Journal of Nutrition. 124: 1878S-1885S, September, 1994.

Mc DOWELL, D. R.; ALLEN-SMITH, J. E.; McLEAN-MEYINSSE, P. E. Food Expenditures and Socioeconomic Characteristics: Focus on Income Class. American Journal of Agricultural Economics. Vol. 78, number 5, 1997, p.1444-1451. 
MADDALA, G.S. Limited-Dependent Qualitative Variables in Econometrics. Cambridge: Cambridge University Press, 1983. p.

MARTINS, E. Variações no consumo de Alimentos no Brasil de 1974/75 a 1987/88. Dissertação de Mestrado. Piracicaba, 1998, 117p.

PARK, J. L.; RODNEY, B. H.; KELLIE, C. R.; ORAL, C.J. A Demand Systems Analysis of Food Commodities by U.S. Households Segmented by Income. American Journal of Agricultural Economics. Vol. 78, number 2, may-1996, p.290-300.

PEREZ, M. C. R. C. Contribuição ao Estudo da Elasticidade-renda do Consumo de Alimentos. Dissertação de Mestrado. Piracicaba, 1973.

PHLIPS, L. Applied Consumption Analysis. Revised Edition. Amsterdam: North-Holland, 1983. $331 \mathrm{p}$.

SAHA, A.; CAPPS, O. J.; BYRNE, P.J. Calculating Marginal Effects in Models for Zero Expenditures in Household Budgets Using a Heckman-type Correction. Applied Economics. 29, 1997. p.1311-1316. 